Tercer Encuentro Nacional de Semilleros de Investigación de Ingeniería Industrial

$$
\text { (ENSIII) - } 2019
$$
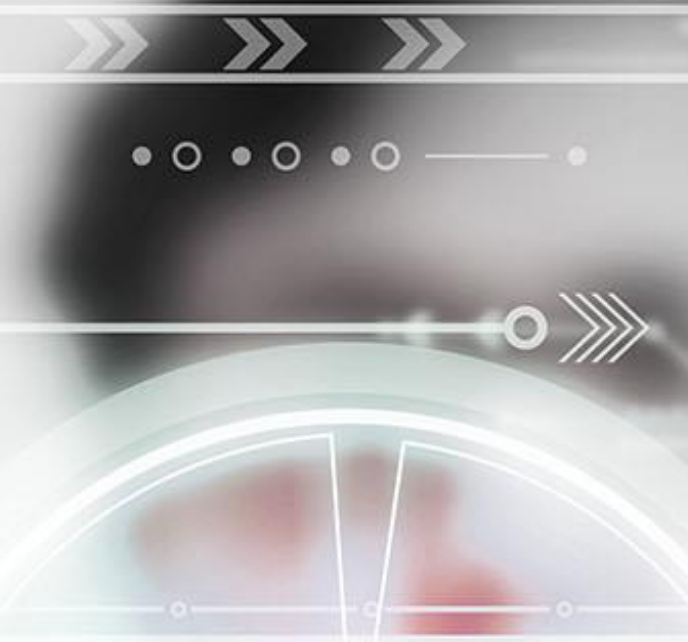


\title{
Tercer Encuentro Nacional de Semilleros de Investigación de Ingeniería Industrial (ENSIII) - 2019
}

\author{
Libro de Memorias
}

Tercera Edición: 2019

ISSN: 2619-4201 


\section{Tabla de Contenido}

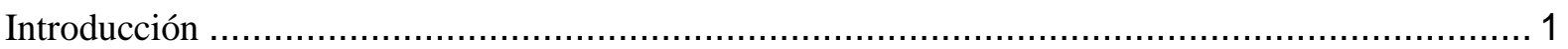

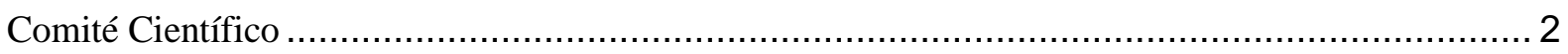

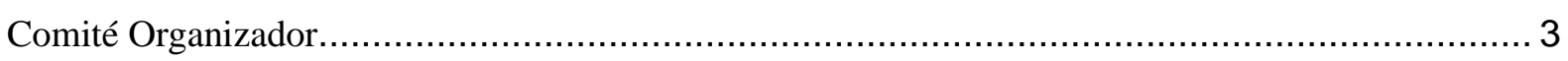

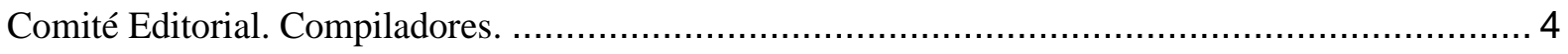

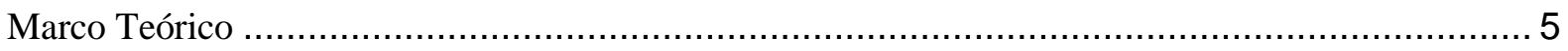

El mejoramiento de procesos como factor de competitividad ........................................................ 5

Innovación y sustentabilidad un mundo de diversidad ............................................................... 6

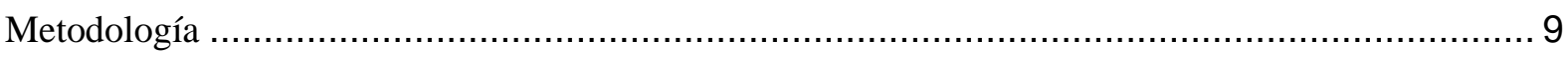

PONENCIAS EN PRESENTACIÓN ORAL TRACK : INNOVACIÓN Y SUSTENTABILIDAD. .. 0

Diseño de un plan de marketing ecológico para el manejo sostenible de los residuos de aparatos eléctricos y electrónicos - RAEE en el sector doméstico para la población de estrato 3 en la ciudad de Barranquilla.

Diseñar un plan de marketing ambiental como estrategia que permita apoyar la reducción del impacto producido por los residuos sólidos provenientes de los establecimientos dedicados a la actividad turística en las playas de Puerto Colombia (Atlántico). .................................................... 11

Análisis de las tecnologías en sistemas de abastecimientos de agua potable.....................................21

Emitier: Una propuesta de un aplicativo en Visual Basic for Applications para la estimación de emisiones de gases contaminantes generados por fuentes móviles ..................................................28

PONENCIAS EN PRESENTACIÓN ORAL TRACK :GESTIÓN ORGANIZACIONAL .............. 35

Estudio de casos de emprendimientos locales apoyados por el centro de emprendimiento y

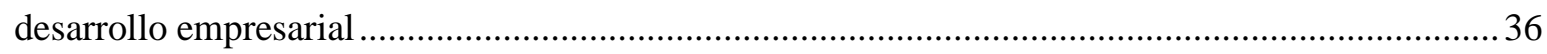

PONENCIAS EN PRESENTACIÓN ORAL TRACK :MEJORAMIENTO DE PROCESOS .......... 43

Aplicación del método ERIN y rediseño de puesto de trabajo "porcionado" de carne

Análisis estadístico de la producción y exportación de la Cadena hortofrutícola en Colombia y

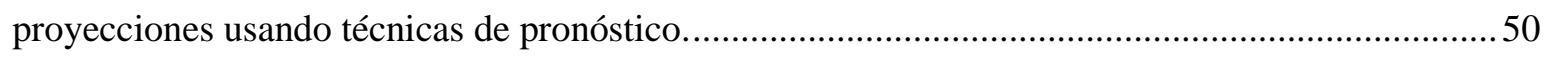

Optimización del proceso de tindalización para Residuos Orgánicos ...............................................57

Perspectivas del uso y producción de biopolímeros en Colombia ................................................... 72

Diseño, puesta a punto y validación del proceso de curvado rápido (Hyperbending) para vidrio

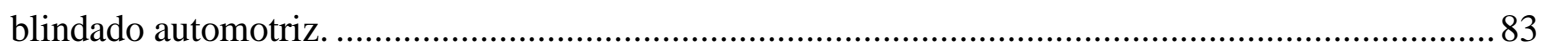

Elaboración de un jabón de tocador con extracto de cúrcuma utilizando aceite reciclado ................90

Modelo de Gestión Estratégico de Inventarios IQR para Pymes .....................................................96

Fuerza de agarre según edad y género en un grupo de trabajadores de la ciudad de Bogotá. ......... 105

Antropometría y biomecánica aplicada al rediseño del puesto de trabajo soldadura de compresor111

Conclusiones 


\section{Introducción}

La Universidad Santo Tomás desde 1580 como Primer Claustro de Colombia, tiene por objetivo promover la educación científica de la nación desde una perspectiva humanista e integradora donde la promoción del saber producto de la interacción social es una de sus prioridades. Desde el año 2017 la Facultad de Ingeniería Industrial de la Sede Principal desarrolla un Encuentro Nacional de Semilleros de programas de Ingeniería Industrial que tiene como propósito generar dinámicas colaborativas entre diversas escuelas de pensamiento con el fin de promover la evaluación de las principales tendencias de la disciplina en el país.

En el marco del Sistema Nacional de Ciencia, Tecnología e Innovación, este encuentro de carácter científico promueve el pensamiento científico de los estudiantes apoyados por sus profesores y mentores, la exposición abierta de ideas, la integración regional y nacional y sobre todo, promover el uso de herramientas científicas en la ingeniería con visión práctica y de impacto social.

En este tercer encuentro, se promovió el Desarrollo Empresarial Sostenible en Colombia como tema central desde tres perspectivas: la innovación y sostenibilidad, la gestión organizacional y el mejoramiento de procesos recibiendo noventa contribuciones de todo el país que permitieron el primero de noviembre de 2019 un amplio punto de vista de las percepciones y visiones sobre la profesión y los principales retos en Colombia.

III Encuentro Nacional de Semilleros de Investigación de Ingeniería Industrial 


\section{Comité Científico}

Doctor en Ingeniería Gustavo Gatica.

Docente Investigador

Facultad de Ingeniería

Universidad Andrés Bello. Chile

Doctora en Ingeniería Diana Yomali Ospina Lopez

Docente Investigadora

Facultad de Ingeniería

Universidad Autónoma de Manizales. Colombia

Magister Beatriz Rodríguez Montenegro.

Decana de Facultad

Facultad de Ingeniería Industrial

Universidad Santo Tomás Colombia.

Magister Magda Viviana Monroy Silva.

Líder de Investigación

Facultad de Ingeniería Industrial

Universidad Santo Tomás

Magister Helien Parra Riveros

Líder de Semillero de Mejoramiento de procesos - SIMEP

Facultad de Ingeniería

Universidad Santo Tomás Colombia.

III Encuentro Nacional de Semilleros de Investigación de Ingeniería Industrial

Universidad Santo Tomás. Facultad de Ingeniería Industrial. 1 de noviembre de 2019 


\section{Comité Organizador}

Helien Parra Riveros

Líder de Semillero de Mejoramiento de procesos - SIMEP

Facultad de Ingeniería

Universidad Santo Tomás Colombia.

José Luis Sandoval Sandoval

Líder de Semillero de Gestión Organizacional - SIGEO

Facultad de Ingeniería Industrial

Universidad Santo Tomás

Luis Felipe Chaparro Parada

Líder de Semillero de Lúdicas en Procesos Organizacionales - SELPRO

Facultad de Ingeniería Industrial

Universidad Santo Tomás

Oscar Emannuel Granados Delgado

Líder de Semillero Innovación y Sustentabilidad SIIS

Facultad de Ingeniería Industrial

Universidad Santo Tomás

III Encuentro Nacional de Semilleros de Investigación de Ingeniería Industrial

Universidad Santo Tomás. Facultad de Ingeniería Industrial. 1 de noviembre de 2019 


\section{Comité Editorial. Compiladores.}

Magda Viviana Monroy Silva.

Líder de Investigación

Facultad de Ingeniería Industrial

Universidad Santo Tomás

Helien Parra Riveros

Líder de Semillero de Mejoramiento de procesos - SIMEP

Facultad de Ingeniería

Universidad Santo Tomás Colombia. 


\section{Marco Teórico}

\section{El mejoramiento de procesos como factor de competitividad}

El Mejoramiento de Procesos puede definirse una "actividad proactiva empresarial consistente en identificar, analizar y mejorar los procesos comerciales existentes dentro de una organización para su optimización y para cumplir con nuevas cuotas o estándares de calidad por medio de un enfoque sistemático que sigue una metodología específica siguiendo un progreso " incremental " evaluado con el tiempo o una mejora "revolucionaria" de transformación radical [1]. Tradicionalmente el mejoramiento de procesos puede ser abordado por dos vías; la primera por la Gestión de Operaciones que incluye Métodos cuantitativos que contiene las ciencias administrativas (Management Science MS y la Investigación Operativa OR). La segunda ha sido abordado por modelos de Gestión Organizacional la que surge para facilitar y simplificar el primer enfoque orientado hacia la generación de un comportamiento organizacional eficaz basado en la creación de una filosofía de empresa orientada a criterios de carácter superlativo como la competitividad, eficiencia y globalización [2]. Actualmente se han venido generando una línea enfocada en la digitalización de las operaciones y la cultura del uso consciente y eficiente de la información y la toma de decisiones resultado en una suerte de mezcla de los dos enfoques orientado a la transformación digital empresarial [3]

En estos tres énfasis se consideran los principales exponentes para la Gestión de Operaciones a los clásicos F.W. Taylor [4], F.B y L. Gilbreth [5] C.W. S. Beer [6], Churchman, R.L. Ackoff [7] entre otros centrando actualmente sus estudios en Sistemas Productivos, Métricas de productividad, Organización Empresarial, Operaciones de Servicio, Modelamiento Matemático y Seguridad, Gestión del riesgo y mantenibilidad.[8] En la Gestion Organizacional desde los clasicos Deming [9], Juran [10], Ishikawa [11], Shingo [12], Ohno [13] entre otros centrando actualmente sus estudios en técnicas como Lean, Six Sigma, 
modelos de excelencia y certificación. Finalmente en la transformación digital de operaciones siendo un enfoque tan reciente, se están consolidando referentes como Österle [14] y Barros [15].

La tendencia actual es la profundización y extensión de la Gestión Organizacional en enfoques como son los modelos Lean[16] y la Ingeniería de Negocios enfocado en la transformación digital empresarial combinado con la Optimización Computacional [17].

\section{Innovación y sustentabilidad un mundo de diversidad}

Las investigaciones en temas de Innovación y Sustentabilidad en el programa de Ingeniería Industrial apoyan y enriquecen los énfasis de Mejoramiento de Procesos y Gestión Organizacional. En la actualidad, se trabajan proyectos que aportan valor al compromiso institucional y nacional con los Objetivos de Desarrollo Sostenible de la Organización de las Naciones Unidas [18] declarados el 25 de septiembre de 2015 y adoptado en Colombia en Mayo de 2019, en la presentación del Plan Nacional de Desarrollo 2018-2022 "Pacto por Colombia. Pacto por la Equidad" y fundamento principal de la política de Gobierno [19].

De acuerdo con la Organización Mundial de la Propiedad Intelectual (OMPI) [20] los países más innovadores son: China, Suiza, los Países Bajos, el Reino Unido, Singapur y los Estados Unidos. Actualmente se considera que las principales tendencias en innovación empresarial son: el Internet de las cosas (IoT), Industria 4.0, Inteligencia Artificial, Blockchain, Big Data, e-commerce, sustentabilidad, Machine Learning, entre otros.

Hacia el futuro se prevén grandes cambios producto de la innovación en el procesamiento de grandes volúmenes de datos, computación cuántica entre otros que llegarán a la Ingeniería Industrial como retos de aprendizaje y nuevas tendencias en la formación disciplinar.

\section{Referencias.}

[1] Y. Tiamaz, F. Lahboube, and N. Souissi, "A business process improvement method," in Proceedings of the International Conference on Industrial Engineering and

III Encuentro Nacional de Semilleros de Investigación de Ingeniería Industrial 
Operations Management, 2018, vol. 2018, no. SEP, pp. 823-836.

[2] M. F. van Assen, "The moderating effect of management behavior for Lean and process improvement," Oper. Manag. Res., vol. 11, no. 1-2, 2018.

[3] M. Szelągowski, "Evolution of the BPM Lifecycle," in Communication Papers of the 2018 Federated Conference on Computer Science and Information Systems, 2018, vol. 17, pp. 205-211.

[4] E. V. O'Daniel, F. W. Taylor, and W. D. Ennis, "The Principles of Scientific Management.Works Management.," Polit. Sci. Q., vol. 27, no. 3, p. 534, 1912.

[5] F. B. Gilbreth and L. M. Gilbreth, "What scientific management means to America's industrial position,” Ann. Am. Acad. Pol. Soc. Sci., vol. 61, no. 1, pp. 208-216, 1915.

[6] S. Beer, "What Has Cybernetics to Do with Operational Research?," OR, vol. 10, no. 1, p. 1, 1959.

[7] C. W. Churchman, "Operations Research as a Profession," Manage. Sci., vol. 17, no. 2, p. B-37-B-53, 1970.

[8] APICS The Association for Operations Management, APICS Operations Manamgent Body Of Knowledge Framework. 2009.

[9] E. Deming, "Calidad, productividad y competitividad: la salida de la crisis," Ediciones Díaz Santos, vol. 53, p. 160, 1989.

[10] J. M. Juran, Juran's quality handbook, vol. 1, no. 2. 1993.

[11] K. Ishikawa and K. Ishikawa, "What is Quality Control?," in Introduction to Quality Control, 1989, pp. 1-96.

[12] S. Shingo, A Revolution in Manufacturing: The SMED System. 2019.

[13] T. Ohno and N. Bodek, Toyota Production System, vol. 4. 1988.

[14] H. Österle and H. Österle, "Foundations of a Business Engineering Method," in Business in the Information Age, 1995, pp. 353-363.

[15] O. Barros, "Business process patterns and frameworks: Reusing knowledge in process innovation,” Bus. Process Manag. J., vol. 13, no. 1, pp. 47-69, 2007.

[16] T. F. Chay, Y. C. Xu, A. Tiwari, and F. S. Chay, "Towards lean transformation: The analysis of lean implementation frameworks," Journal of Manufacturing Technology Management, vol. 26, no. 7. pp. 1031-1052, 2015.

III Encuentro Nacional de Semilleros de Investigación de Ingeniería Industrial 
[17] M. Krämer and Z. Besenyoi, "Towards Digitalization of Building Operations with BIM," in IOP Conference Series: Materials Science and Engineering, 2018, vol. 365, no. 2 .

[18] Organización de las Naciones Unidas ONU, "Objetivos de Desarrollo Sostenible ODS, 2015.

[19] Gobierno de Colombia, "Bases del Plan Nacional de Desarrollo 2018-2022," 2019.

[20] Organización Mundial de la Propiedad Intelectual, "Índice Mundial de Innovación 2018: ¿Cuáles son las economías que innovan con eficiencia?,” 2018, 2018. [Online]. Available: http://www.wipo.int/pressroom/es/stories/gii_2018.html. 


\section{Metodología}

El Tercer Encuentro Nacional de Semilleros de Investigación de Ingeniería Industrial (ENSIII) convocó a los programas de Ingeniería Industrial de todo el país en tres (3) modalidades de participación:

- Proyectos de investigación terminados: En esta modalidad se reciben artículos de resultados de proyectos de investigación culminados (sustentados o evaluados en las instituciones de origen)

- Proyecto de investigación en curso: En esta modalidad se reciben resúmenes extendidos de avances en proyectos de investigación avalados por las instituciones de origen

- Propuesta de Investigación: En esta modalidad se reciben resúmenes de ideas de investigación que desean someterse a una comunidad para su validación

Los proyectos de investigación terminados se recibieron como artículos completos para ser publicados en las memorias del evento y presentaron Ponencia Oral. Los proyectos en curso y propuestas se recibieron como poster que fueron expuestos y evaluados. Cada uno de los proyectos fue clasificado en uno de los tres (3) Tracks del evento asi:

- Mejoramiento de procesos: En esta línea se recibieron contribuciones de proyectos que hayan identificado una problemática empresarial en producción y /o servicios y hayan establecido el uso de técnicas, métodos, conocimientos, habilidades y destrezas propias de la ingeniería industrial o disciplinas afines para fijar un objetivo y resolverla. Semillero Anfitrión: Mejoramiento de Procesos SiMeP.

- Gestión Organizacional: En esta línea se recibieron contribuciones de proyectos que hayan identificado problemáticas empresariales en producción y / o servicios que hayan desarrollado de habilidades y competencias de carácter gerencial y de liderazgo para una adecuada administración de los recursos, la generación de planes estratégicos dentro del marco de la normatividad y la responsabilidad social empresarial. Semillero Anfitrión: Gestión Organizacional SIGEO

III Encuentro Nacional de Semilleros de Investigación de Ingeniería Industria 
- Innovación y Sostenibilidad: En esta línea se recibieron contribuciones de proyectos que hayan definido la creación de un producto o servicio basado en el entendimiento de las necesidades de clientes potenciales ó hayan definido soluciones novedosas a problemáticas sociales y ambientales de comunidades identificables. Semillero Anfitrión: Innovación y Sustentabilidad SII2

La convocatoria nacional se gestionó por la plataforma Easy Chair desde el 30 de mayo hasta el 18 de octubre de 2019 siendo evaluador por el Comité Científico conforme a rúbrica de la plataforma recibiéndose 90 contribuciones lo que en comparación con el ENSIII 2018

\begin{tabular}{|c|l|l|}
\hline & ENSIII 2018 & ENSIII 2019 \\
\hline TOTAL CONTRIBUCIONES & 52 & 90 \\
\hline$\bullet \quad$ Ponencias & 31 & 32 \\
\hline$\bullet \quad$ Póster & 16 & 58 \\
\hline$\bullet \quad$ Otro & 5 & - \\
\hline CONTRIBUCIONES ACEPTADAS & 44 & 50 \\
\hline$\bullet \quad$ Ponencias & 28 & 16 \\
\hline$\bullet \quad$ Póster & 13 & 34 \\
\hline$\bullet \quad$ Otro & 3 & - \\
\hline$\%$ DE ACEPTACIÓN & $84.61 \%$ & $55.55 \%$ \\
\hline
\end{tabular}

Tabla 1.Detallado de las contribuciones al II y III ENSIII. Fuente: Compiladores.

La participación creció un $173 \%$ respecto al año anterior y se caracterizó por aumentar el rigor evaluativo para las dos etapas; selección y evaluación de contribuciones lo que se ve reflejado en el porcentaje de aceptación el cual se redujo cerca del 30\%. Para este evento finalmente se presentaron efectivamente la relación de las siguientes ponencias y póster por cada track donde 2 póster y 2 presentaciones orales finalmente cancelaron su asistencia.

\begin{tabular}{|l|r|r|r|}
\hline TRACK & PONENCIA & POSTER & Total general \\
\hline GESTIÓN ORGANIZACIONAL & 1 & 3 & 4 \\
\hline INNOVACIÓN Y SUSTENTABILIDAD & 5 & 10 & 15 \\
\hline MEJORAMIENTO DE PROCESOS & 9 & 18 & 27 \\
\hline Total general & 15 & 31 & 46 \\
\hline
\end{tabular}

Tabla 2. Detallado de las contribuciones por track. Fuente: Compiladores.

III Encuentro Nacional de Semilleros de Investigación de Ingeniería Industrial

Universidad Santo Tomás. Facultad de Ingeniería Industrial. 1 de noviembre de 2019 
Todas las contribuciones fueron evaluadas con un sistema de rúbricas donde se estableció una escala de valoración hasta diez puntos por factor por el comité científico en un sistema doble ciego usando la herramienta Easy Chair ${ }^{\circledR}$ (disponible en https://easychair.org/). Las rúbricas se detallan a continuación:

\begin{tabular}{|c|c|c|c|}
\hline \multirow[t]{2}{*}{ ITEM } & \multicolumn{3}{|c|}{ PUNTOS } \\
\hline & $10-8$ & $7-5$ & $4-2$ \\
\hline $\begin{array}{l}\text { 1. PROBLEMA DE } \\
\text { INVESTIGACIÓN }\end{array}$ & $\begin{array}{l}\text { El problema se presenta } \\
\text { de forma clara y simple } \\
\text { comprensible para el } \\
\text { auditorio sustentado por } \\
\text { pertinencia situacional y } \\
\text { tratado con } \\
\text { herramientas de } \\
\text { ingeniería industrial }\end{array}$ & $\begin{array}{l}\text { El problema es } \\
\text { presentado de forma } \\
\text { general con sustento } \\
\text { situacional genérico no } \\
\text { tratado con } \\
\text { herramientas de } \\
\text { ingeniería industrial }\end{array}$ & $\begin{array}{l}\text { El problema es una } \\
\text { conjetura del } \\
\text { investigador sin } \\
\text { sustento situacional }\end{array}$ \\
\hline $\begin{array}{l}\text { 2. ANTECEDENTES } \\
\text { TEÓRICOS }\end{array}$ & $\begin{array}{l}\text { La bibliografía que } \\
\text { sustenta el argumento } \\
\text { es de buena calidad } \\
\text { (bibliométrica) y de } \\
\text { dominio del expositor } \\
\text { con referencias de los } \\
\text { últimos } 5 \text { años }\end{array}$ & $\begin{array}{l}\text { La bibliografía que } \\
\text { sustenta el argumento } \\
\text { es de buena calidad } \\
\text { (bibliométrica) pero no } \\
\text { de dominio del } \\
\text { expositor con } \\
\text { referencias de los } \\
\text { últimos } 10 \text { años }\end{array}$ & $\begin{array}{l}\text { La bibliografía que } \\
\text { sustenta el argumento es } \\
\text { informativa no } \\
\text { científica } \\
\text { (bibliométrica) }\end{array}$ \\
\hline $\begin{array}{l}\text { 3. OBJETIVOS DE LA } \\
\text { INVESTIGACIÓN }\end{array}$ & $\begin{array}{l}\text { Los objetivos } \\
\text { presentados indican el } \\
\text { uso de metodología } \\
\text { SMART o similar, su } \\
\text { magnitud indica un } \\
\text { proceso de calidad de } \\
\text { investigación científica }\end{array}$ & $\begin{array}{l}\text { Los objetivos son } \\
\text { presentados sin indicar } \\
\text { un uso de metodología } \\
\text { en su formulación pero } \\
\text { muestran un proceso de } \\
\text { calidad de investigación } \\
\text { científica }\end{array}$ & $\begin{array}{l}\text { Los objetivos son } \\
\text { presentados de forma } \\
\text { general pero su } \\
\text { magnitud no indica un } \\
\text { proceso de calidad de } \\
\text { investigación científica }\end{array}$ \\
\hline 4. MÉTODOS & $\begin{array}{l}\text { Los métodos empleados } \\
\text { son de avanzada en la } \\
\text { Ingeniería Industrial y } \\
\text { muestran el dominio de } \\
\text { técnicas superiores al } \\
\text { promedio de la } \\
\text { enseñanza en pregrado }\end{array}$ & $\begin{array}{l}\text { Los métodos empleados } \\
\text { son propios de la } \\
\text { Ingeniería Industrial a } \\
\text { nivel de trabajo de } \\
\text { grado }\end{array}$ & $\begin{array}{l}\text { Los métodos empleados } \\
\text { son de corto alcance y } \\
\text { muestran el uso de } \\
\text { técnicas de clase }\end{array}$ \\
\hline 5. RESULTADOS & $\begin{array}{l}\text { Los resultados son } \\
\text { propios de una } \\
\text { publicación científica } \\
\text { internacional }\end{array}$ & $\begin{array}{l}\text { Los resultados son } \\
\text { propios de una } \\
\text { publicación científica } \\
\text { nacional }\end{array}$ & $\begin{array}{l}\text { Los resultados son } \\
\text { propios de una } \\
\text { publicación no indexada }\end{array}$ \\
\hline 6. CONCLUSIONES & $\begin{array}{l}\text { Las conclusiones se } \\
\text { relacionan con los } \\
\text { objetivos y evidencian } \\
\text { el tratamiento de } \\
\text { Hipótesis de } \\
\text { investigación }\end{array}$ & $\begin{array}{l}\text { Las conclusiones se } \\
\text { relacionan con los } \\
\text { objetivos }\end{array}$ & $\begin{array}{l}\text { Las conclusiones se } \\
\text { relacionan difusamente } \\
\text { con los objetivos }\end{array}$ \\
\hline
\end{tabular}

Tabla 3. Rubrica para presentación oral. Fuente: Compiladores. 


\begin{tabular}{|c|c|c|c|}
\hline \multirow[t]{2}{*}{ ITEM } & \multicolumn{3}{|c|}{ PUNTOS } \\
\hline & 10-8 & $7-5$ & 4-2 \\
\hline $\begin{array}{l}\text { 1. PROBLEMA DE } \\
\text { INVESTIGACIÓN }\end{array}$ & $\begin{array}{l}\text { El problema se } \\
\text { presenta de forma clara } \\
\text { y simple comprensible } \\
\text { para el auditorio } \\
\text { sustentado por } \\
\text { pertinencia situacional } \\
\text { y tratado con } \\
\text { herramientas de } \\
\text { ingeniería industrial }\end{array}$ & $\begin{array}{l}\text { El problema es } \\
\text { presentado de forma } \\
\text { general con sustento } \\
\text { situacional genérico no } \\
\text { tratado con herramientas } \\
\text { de ingeniería industrial }\end{array}$ & $\begin{array}{l}\text { El problema es una } \\
\text { conjetura del } \\
\text { investigador sin sustento } \\
\text { situacional }\end{array}$ \\
\hline 2. JUSTIFICACIÓN & $\begin{array}{l}\text { La justificación d la } \\
\text { investigación es acorde } \\
\text { a las dinámicas de la } \\
\text { ingeniería industrial y } \\
\text { las necesidades del } \\
\text { ámbito de la } \\
\text { investigación y es } \\
\text { expuesta de forma } \\
\text { clara y precisa }\end{array}$ & $\begin{array}{l}\text { La justificación d la } \\
\text { investigación es acorde } \\
\text { a las dinámicas de la } \\
\text { ingeniería industrial } \\
\text { pero no es clara su } \\
\text { pertinencia con el } \\
\text { entorno y es expuesta de } \\
\text { forma general }\end{array}$ & $\begin{array}{l}\text { La justificación d la } \\
\text { investigación no es clara } \\
\text { o precisa y no obedece a } \\
\text { un contexto definido o } \\
\text { claro }\end{array}$ \\
\hline $\begin{array}{l}\text { 3. OBJETIVOS DE LA } \\
\text { INVESTIGACIÓN }\end{array}$ & $\begin{array}{l}\text { Los objetivos } \\
\text { presentados indican el } \\
\text { uso de metodología } \\
\text { SMART o similar, su } \\
\text { magnitud indica un } \\
\text { proceso de calidad de } \\
\text { investigación científica }\end{array}$ & $\begin{array}{l}\text { Los objetivos son } \\
\text { presentados sin indicar } \\
\text { un uso de metodología } \\
\text { en su formulación pero } \\
\text { muestran un proceso de } \\
\text { calidad de investigación } \\
\text { científica }\end{array}$ & $\begin{array}{l}\text { Los objetivos son } \\
\text { presentados de forma } \\
\text { general pero su } \\
\text { magnitud no indica un } \\
\text { proceso de calidad de } \\
\text { investigación científica }\end{array}$ \\
\hline 4. MÉTODOS & $\begin{array}{l}\text { Los métodos } \\
\text { empleados o } \\
\text { propuestos son de } \\
\text { avanzada en la } \\
\text { Ingeniería Industrial y } \\
\text { muestran el dominio de } \\
\text { técnicas superiores al } \\
\text { promedio de la } \\
\text { enseñanza en pregrado }\end{array}$ & $\begin{array}{l}\text { Los métodos empleados } \\
\text { o propuestos son } \\
\text { propios de la Ingeniería } \\
\text { Industrial a nivel de } \\
\text { trabajo de grado }\end{array}$ & $\begin{array}{l}\text { Los métodos empleados } \\
\text { o propuestos son de } \\
\text { corto alcance y } \\
\text { muestran el uso de } \\
\text { técnicas de clase }\end{array}$ \\
\hline 5. RESULTADOS & $\begin{array}{l}\text { El proyecto tiene } \\
\text { resultados adelantados } \\
\text { y publicados o en } \\
\text { proceso de publicación } \\
\text { o apropiación social } \\
\end{array}$ & $\begin{array}{l}\text { El proyecto tiene } \\
\text { resultados potenciales } \\
\text { para publicación o } \\
\text { apropiación social }\end{array}$ & $\begin{array}{l}\text { El proyecto tiene } \\
\text { resultados difusos y no } \\
\text { claros para ser } \\
\text { publicados }\end{array}$ \\
\hline 6. CAPACIDAD ORAL & $\begin{array}{l}\text { Los expositores } \\
\text { dominan el tema, son } \\
\text { concisos y ajustados al } \\
\text { tiempo de exposición } \\
(5 \text { minutos }) \\
\end{array}$ & $\begin{array}{l}\text { Los expositores } \\
\text { dominan el tema } \\
\text { parcialmente ó se } \\
\text { extienden más del } \\
\text { tiempo reglamentario }\end{array}$ & $\begin{array}{l}\text { Los expositores no } \\
\text { dominan el tema y no } \\
\text { manejan el tiempo } \\
\text { reglamentario }\end{array}$ \\
\hline
\end{tabular}

Tabla 4. Rubrica para poster. Fuente: Compiladores.

Al finalizar el evento, se hizo reconocimiento público (premiación) a las ponencias y posters que obtuvieron las puntuaciones más altas en la segunda fase de evaluación. Las

III Encuentro Nacional de Semilleros de Investigación de Ingeniería Industrial

Universidad Santo Tomás. Facultad de Ingeniería Industrial. 1 de noviembre de 2019 
contribuciones incluidas en el presente libro de memorias corresponden a aquellas que cumplieron con los lineamientos editoriales y cuyos autores firmaron el formato de cesión de derechos 


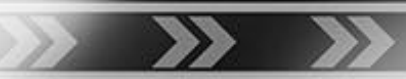

- 0.0 .0

\section{PONENCIAS EN PRESENTACIÓN ORAL TRACK : INNOVACIÓN Y SUSTENTABILIDAD.}




\title{
Diseño de un plan de marketing ecológico para el manejo sostenible de los residuos de aparatos eléctricos y electrónicos - RAEE en el sector doméstico para la población de estrato 3 en la ciudad de Barranquilla
}

\author{
Cabrales Vásquez Alfonso Luis ${ }^{1}$ \\ Fonseca Pineda Jorge Armando ${ }^{2}$ \\ Orozco Mosquera Leidy ${ }^{3}$ \\ Celin Castro Manuel Guillermo ${ }^{2}$
}

\section{Resumen}

En la presente investigación se diseñó un plan de marketing ambiental para el manejo de RAEE en el sector de estrato 3 en la ciudad de Barranquilla. La propuesta busca educar a las personas y recicladores que habitan en el sector sobre la buena gestión y manipulación de los residuos tecnológicos en los hogares. Para el estudio se utilizo un cuestionario de percepción que permitió caracterizar los comportamientos que posee la población con sus RAEE. Los resultados fueron evaluados mediante un diagnostico, definiendo estrategias para luego generar el plan correspondiente para cada una de estas.

\section{Palabras Claves}

Residuos tecnológicos, Marketing ambiental, RAEE.

\footnotetext{
${ }^{1}$ Universidad del Atlántico, Sede Barranquilla. Semillero Green Engineers Marketing. Contacto: acabrales@est.uniatlantico.edu.co

${ }^{2}$ Universidad del Atlántico, Sede Barranquilla. Docente de planta de Gestión de Mercadeo y Green Marketing. Contacto: manuelcelin@mail.uniatlantico.edu.co
}

III Encuentro Nacional de Semilleros de Investigación de Ingeniería Industrial

Universidad Santo Tomás. Facultad de Ingeniería Industrial. 1 de noviembre de 2019 


\section{Problema de Investigación}

Actualmente según el Ministerio del Ambiente $^{2}$ en Colombia se genera anualmente un promedio de 130.000 toneladas de RAEE. Para mitigar este problema, el gobierno ha establecido leyes que regulen la producción de estos residuos, como también han promovido campañas para su recolección y aun así no han sido suficiente para llegar a personas y a empresas productoras de RAEE. En Barranquilla existen organizaciones que realizan la gestión integral de los RAEE como lo es la empresa LITO S.A.S. ${ }^{3}$, No obstante, no han podido cambiar esos comportamientos respecto a la disposición final de los RAEE en los barranquilleros. Debido a esto, se propone diseñar un plan de marketing ecológico que promueva la gestión de RAEE en el sector doméstico, además de generar conciencia a las personas barranquilleras. Se espera fomentar buenas prácticas en la recolección y tratamiento de estos desechos tecnológicos. así mismo se busca implementar un programa de concientización de reciclaje RAEE que genere conciencia ambiental.

¿Cómo promover la disposición adecuada de los desechos tecnológicos del sector doméstico estrato 3 en la ciudad de Barranquilla?

\section{Antecedentes teóricos}

Entre los estudios que se sustenta está investigación se encuentra el artículo publicado por MinAmbiente en el año 2010 titulado “Lineamientos técnicos para el manejo de residuos de aparatos eléctricos y electrónicos", el trabajo de Daniel Alfonso Fuentes Lopez (2015) "Sistema de información para el apoyo de la gestión integral de los residuos de aparatos eléctricos y electrónicos (RAEE) en la universidad de Cartagena” cuyos objetivos es la reducción del impacto ambiental de los RAEE y la creación de políticas que ayuden al correcto manejo de estos desechos.

III Encuentro Nacional de Semilleros de Investigación de Ingeniería Industrial

Universidad Santo Tomás. Facultad de Ingeniería Industrial. 1 de noviembre de 2019 


\section{Objetivo General}

Diseñar un plan de marketing ecológico para el manejo sostenible de los residuos de aparatos eléctricos y electrónicos - RAEE en el sector doméstico para la población de estrato 3 en la ciudad de Barranquilla.

2. EL TIEMPO. Colombia produce al año aproximadamente 130.000 toneladas de la considerada basura electrónica [En línea]. En: El Tiempo, Colombia. 06, junio, 2017. [consultado 3 de octubre de 2017]. Disponible en Internet: http://www.eltiempo.com/vida/medio-ambiente/basura-electronica-en-colombia-96280.

3. Lito SAS. [En línea] 2018. Disponible en Internet: http://www.litoltda.com/

\section{Objetivos Específicos}

- Caracterizar el comportamiento actual de la comunidad Barranquillera para identificar los Insights más adecuados para influenciar y mejorar las prácticas con respecto a la disposición final de la basura electrónica de los barranquilleros.

- Formular un plan de mercadeo ambiental para promover el cierre de brechas en materia de disposición final de basura electrónica por parte de la comunidad Barranquillera.

\section{Metodología}

El presente proyecto se desarrolló bajo el método lógico inductivo incompleto de la investigación y un modelo de estudio descriptivo. Para estimar la cantidad habitantes que viven en el estrato 3, se calculó primero el incremento anual entre los periodos 2008 - 2011, 2009 2011 y 2010 - $2011^{4}$ : utilizando la fórmula del interés compuesto.

Tabla 1: Incremento anual para la población de estrato 3 según el periodo

\begin{tabular}{|c|c|c|}
\hline \multicolumn{3}{|c|}{ INCREMENTO ANUAL } \\
\hline $\mathbf{r}(\mathbf{2 0 0 8} \mathbf{- 2 0 1 1})$ & $\mathbf{r}(\mathbf{2 0 0 9}-\mathbf{2 0 1 1})$ & $\mathbf{r ( 2 0 1 0}-\mathbf{2 0 1 1})$ \\
\hline $0.64 \%$ & $0.63 \%$ & $0.61 \%$ \\
\hline
\end{tabular}

III Encuentro Nacional de Semilleros de Investigación de Ingeniería Industrial

Universidad Santo Tomás. Facultad de Ingeniería Industrial. 1 de noviembre de 2019 


\begin{tabular}{|c|c|c|}
\hline \multicolumn{3}{|c|}{ ESTIMACIÓN POBLACIÓN (P) PARA UN TIEMPO (T) FUTURO (2018) SEGÚN } \\
LOS INCREMENTOS CALCULADOS \\
\hline 262167.92 & 261888.13 & 261594.90 \\
\hline
\end{tabular}

Fuente: Elaboración propia de los autores

Se usó la ecuación de población finita para calcular el número de encuestas a realizar, donde $\mathrm{N}$ tuvo un valor de 384.59 muestras.

4 MINSALUD. Análisis de la situación de salud [En línea]. En: Ministerio de Salud y Protección Social. 2012 [consultado 17 de octubre de 2018], Disponible en Internet:

https://www.minsalud.gov.co/plandecenal/Paginas/mapa/Analisis-de-Situacion-Salud-Barranquilla-20122015.pdf

\section{Análisis de resultados}

FASE 1: DISEÑO DE ENCUESTA PARA LEVANTAMIENTO DE INFORMACIÓN

Tabla 2: Análisis e interpretación de resultados

\begin{tabular}{|l|l|c|c|}
\hline Pregunta 1 & \multicolumn{2}{l|}{$\begin{array}{l}\text { ¿Conoce usted las consecuencias que conlleva el desecho inadecuado de } \\
\text { aparatos electrónicos? }\end{array}$} \\
\cline { 2 - 4 } & Opción & Cantidad & Porcentaje \\
& A- Si & A- 266 & A- $69.1 \%$ \\
B- No & B- 119 & B- $30.9 \%$ \\
\hline Análisis e interpretación: Más de la mitad de personas encuestadas (69.1\%) tienen conocimientos \\
acerca de los inconvenientes causados por la RAEE & Cantidad & Porcentaje \\
\hline Pregunta 2 & ¿Desecha usted aparatos eléctricos y electrónicos? \\
\cline { 2 - 4 } & Opción & A- 234 & A- $60.8 \%$ \\
& A- Si & B- 151 & $39.2 \%$ \\
\hline
\end{tabular}

III Encuentro Nacional de Semilleros de Investigación de Ingeniería Industrial

Universidad Santo Tomás. Facultad de Ingeniería Industrial. 1 de noviembre de 2019 


\begin{tabular}{|c|c|c|c|}
\hline \multicolumn{4}{|c|}{ Análisis e interpretación: El 60.8\% de los encuestados afirmaron que desechan las RAEE } \\
\hline \multirow[t]{2}{*}{ Pregunta 3} & \multicolumn{3}{|c|}{ ¿Con qué frecuencia desecha usted aparatos eléctricos y electrónicos? } \\
\hline & $\begin{array}{l}\text { Opción } \\
\qquad \begin{array}{l}\text { A- Mensualmente } \\
\text { B- Trimestralmente } \\
\text { C- Anualmente } \\
\text { D- Rara vez } \\
\text { E- Nunca }\end{array}\end{array}$ & $\begin{array}{l}\text { Cantidad } \\
\begin{aligned} \text { A- } 5 \\
\text { B- } 18 \\
\text { C- } 81 \\
\text { D- } 214 \\
\text { E- } 67\end{aligned}\end{array}$ & $\begin{array}{l}\text { Porcentaje } \\
\qquad \begin{array}{l}\text { A- } 1.3 \% \\
\text { B- } 4.7 \% \\
\text { C- } 21 \% \\
\text { D- } 55.6 \% \\
\text { E- } 17.4 \%\end{array}\end{array}$ \\
\hline \multicolumn{4}{|c|}{$\begin{array}{l}\text { Análisis e interpretación: Las cinco opciones logran caracterizar el comportamiento de la población } \\
\text { frente a este tipo de actividad, siendo predominante rara vez con un porcentaje de } \\
55.6 \%\end{array}$} \\
\hline \multirow[t]{2}{*}{ Pregunta 4} & $\begin{array}{l}\text { ¿Cuál es la disposición final q } \\
\text { eléctricos y electrónicos? }\end{array}$ & le da usted a & siduos de aparatos \\
\hline & $\begin{array}{l}\text { Opción } \\
\qquad \begin{aligned} & \text { A- } \text { Se reparan y se } \\
& \text { reutilizan } \\
& \text { B- } \text { Desecha con basura } \\
& \text { común } \\
& \text { C- } \text { Entrega a empresa de } \\
& \text { servicios públicos } \\
& \text { AAA } \\
& \text { D- } \text { Entrega } \\
& \text { recicladores } \\
& \text { informales } \\
& \text { E- Entrega a empresa } \\
& \text { especializada }\end{aligned}\end{array}$ & $\begin{array}{l}\text { Cantidad } \\
\qquad \begin{array}{r}\text { A- } 76 \\
\text { B- } 80 \\
\text { C- } 20 \\
\text { D- } 105 \\
\text { E- } 26 \\
\text { F- } 78\end{array}\end{array}$ & $\begin{array}{l}\text { Porcentaje } \\
\begin{array}{l}\text { A- } 19.70 \% \\
\text { B- } 20.80 \% \\
\text { C- } 5.19 \% \\
\text { D- } 27.30 \% \\
\text { E- } \quad 6,75 \% \\
\text { F- } 20.30 \%\end{array}\end{array}$ \\
\hline
\end{tabular}

Fuente: Elaboración propia de los autores

III Encuentro Nacional de Semilleros de Investigación de Ingeniería Industrial

Universidad Santo Tomás. Facultad de Ingeniería Industrial. 1 de noviembre de 2019 
FASE 2: IDENTIFICACIÓN DE PRÁCTICAS EXITOSAS DE RECICLAJE Proyecto educativo de reciclaje doméstico Madrid Recicla: A principios del 2016, se inició un proyecto educativo de reciclaje doméstico en Madrid, ciudad capital de España, cuyo objetivo era ejecutar estrategias de comunicación y marketing a través de los medios digitales como Twitter con fin de sensibilizar, concientizar y divulgar la labor realizada por los 11 promotores y 63 educadores ambientales a pie de calle en pro a la estimulación del reciclaje en la ciudad. La clasificación de cada uno de sus post en Twitter se referenciaba bajo el hashtag \#MadridRecicla, con el fin de generar tendencia en esta red social sobre las labores ambientales realizadas por el grupo de trabajo.

FASE 3: DISEÑO DEL PLAN DE MARKETING ECOLÓGICO: El plan adopta medidas educativas y correctivas de alto impacto que incentivan a los habitantes del sector en crear una cultura ecológica en su entorno, articulando una serie de pasos y estrategias aplicables posteriormente a toda la comunidad barranquillera.

\section{Objetivos estratégicos}

1. Minimizar la producción de RAEE.

2. Promover una gestión integral de RAEE para reducir los riesgos sobre la salud humana y el ambiente.

3. Promover la plena integración y participación de los productores, comercializadores y usuarios de los aparatos eléctricos y electrónicos en la elaboración de estrategias, planes y proyectos para una gestión integral de RAEE.

\section{Estrategias}

Las siguientes estrategias se articulan con la misión, visión y objetivos estratégicos establecidos en el plan estratégico del proyecto:

III Encuentro Nacional de Semilleros de Investigación de Ingeniería Industrial

Universidad Santo Tomás. Facultad de Ingeniería Industrial. 1 de noviembre de 2019 
Tabla 6: Estrategias

\begin{tabular}{|c|c|c|}
\hline Estrategias & Estrategia específica & Actividades \\
\hline Educativas & $\begin{array}{l}\text {-Concientizar a estudiantes } \\
\text { del sector mediante modelos } \\
\text { pedagógicos sobre el } \\
\text { manejo integral que se le } \\
\text { deben dar a los RAEE. }\end{array}$ & $\begin{array}{l}\text {-Promover el desarrollo de } 4 \text { módulos ecológicos en } \\
\text { los colegios del sector durante todo el periodo } \\
\text { escolar, trabajando } 1 \text { módulo ecológico } \\
\text { respectivamente por cada periodo. } \\
\text {-Desarrollar actividades lúdicas en colegios del } \\
\text { sector con ayuda de un educador ambiental junto con } \\
\text { dos personas de apoyo recreativo, para inculcar e } \\
\text { instruir mediante actividades y talleres pedagógicos a } \\
\text { jóvenes estudiantes sobre el impacto que genera el } \\
\text { gestionar de forma inadecuada residuos tecnológicos. } \\
\text {-Ejecutar dos campañas de recolección de RAEE } \\
\text { durante el año en colaboración con la empresa LITO } \\
\text { S.A.S. }\end{array}$ \\
\hline $\begin{array}{l}\text { Digitales } \\
\text { mediante } \\
\qquad \text { el uso } \\
\text { de Redes } \\
\text { sociales }\end{array}$ & $\begin{array}{l}\text {-Gestionar la promoción } \\
\text { de eventos en Facebook, } \\
\text { Twitter e Instagram, con } \\
\text { imágenes y videos } \\
\text { multimedia alusivos a la } \\
\text { misión promoviendo un } \\
\text { mensaje ecológico a todos } \\
\text { los followers o seguidores de } \\
\text { estas páginas. El fin de esta } \\
\text { estrategia se enfoca en } \\
\text { generar tendencia en cada } \\
\text { publicación realizada en } \\
\text { estas redes sociales. }\end{array}$ & $\begin{array}{l}\text {-Promocionar eventos y campañas de reelección } \\
\text { de RAEE con ayuda de Influenciadores } \\
\text { Barranquilleros en las redes sociales como } \\
\text { Facebook, Twitter e Instagram, para impulsar } \\
\text { programas de recolección de desechos tecnológicos. } \\
\text {-Crear y administrar perfiles de Facebook, Twitter e } \\
\text { Instagram con el fin de publicar contenidos virales } \\
\text { relacionados a la gestión adecuada de RAEE. } \\
\text {-Generar tendencia en cada publicación posteada } \\
\text { para llamar la atención de más seguidores y } \\
\text { suscriptores de estas redes sociales. }\end{array}$ \\
\hline
\end{tabular}

III Encuentro Nacional de Semilleros de Investigación de Ingeniería Industrial

Universidad Santo Tomás. Facultad de Ingeniería Industrial. 1 de noviembre de 2019 


\begin{tabular}{|c|c|c|}
\hline Recolección & $\begin{array}{l}\text {-Capacitar a recicladores de } \\
\text { oficio sobre las buenas } \\
\text { prácticas de reciclaje a tener } \\
\text { en cuenta a la hora de } \\
\text { gestionar RAEE. } \\
\text {-Pegar poster en las tiendas } \\
\text { de barrio del sector para } \\
\text { informar fecha de } \\
\text { recolección de RAEE en la } \\
\text { zona. } \\
\text {-Comunicar por medio de la } \\
\text { radio jornadas de } \\
\text { recolección de RAEE. }\end{array}$ & $\begin{array}{l}\text {-Plan de capacitación a recicladores de oficio. - } \\
\text { Realizar tres sesiones anuales a recicladores } \\
\text { informales o de oficio con empresas autorizadas } \\
\text { para la gestión de RAEE, sobre la importancia que } \\
\text { genera al medio ambiente las buenas prácticas de } \\
\text { gestión de estos residuos. } \\
\text {-Formalizar la gestión realizada por los recicladores } \\
\text { de oficio, vinculándolos a programas pos consumo de } \\
\text { RAEE, ampliando la cobertura del proceso de } \\
\text { recolección de estos residuos tecnológicos } \\
\text { promoviendo la formalización de este trabajo. }\end{array}$ \\
\hline
\end{tabular}

\section{Conclusiones}

Mediante las encuestas, se identificaron aspectos que determinaban las actitudes de las personas del sector en cuanto al manejo de sus RAEE. La mayoría de las personas, no tenían conocimiento acerca de un ente que trataba de forma especial sus residuos tecnológicos. Se evidencia claramente que estas empresas se limitan a campañas de recolección, que, aunque sea una buena medida a corto plazo para los RAEE, no dejan un mensaje claro a esas personas que hacían parte de la de gestión de RAEE, debido a que las jornadas escasamente se realizaban una vez al año. Según el estudio, las personas si están dispuestas a colaborar reciclando sus RAEE y entregarlos a una empresa para su tratamiento. Se deben implementar estrategias que marquen un antes y un después del proceso de gestión de RAEE como las presentadas anteriormente en el plan.

III Encuentro Nacional de Semilleros de Investigación de Ingeniería Industrial

Universidad Santo Tomás. Facultad de Ingeniería Industrial. 1 de noviembre de 2019 


\section{Referencias Bibliográficas}

[1] AMERICAN MARKETING ASSOCIATION, «ama,» Julio 2013. [En línea]. Available: https://www.ama.org/AboutAMA/Pages/Definition-of-Marketing.aspx. [Último acceso: 23 Septiembre 2018].

[2] A. BALMACEDA, «Zicla,» 16 Octubre 2017. [En línea]. Available: https://www.zicla.com/blog/transicion-economia-circular-en-la-union-europea/. [Último acceso: 6 agosto 2018].

[3] The Global E-waste Monitor, «International Telecommunication Union,» 2017. [En línea]. Available: https://www.itu.int/en/ITU-D/Climate-

Change/Documents/GEM\%202017/Global-E-waste\%20Monitor\%202017\%20.pdf. [Último acceso: 6 agosto 2018].

[4] CANCILLERÍA DE LA REPÚBLICA DE COLOMBIA, «Misíon Permanente de Colombia ante las Naciones Unidad en Ginebra,» 19 enero 2013. [En línea]. Available: http://ginebra-onu.mision.gov.co/convenio-minamata. [Último acceso: 28 septiembre 2018].

[5] CATORCE6, «Colombia, ejemplo para Latinoamérica en el manejo de residuos eléctricos y electrónicos RAEE,» Revista ambiental Catorce6, 2018.

[6] EL ESPECTADOR, «Puntos Verdes Lito: vida para todos,» El Espectador, 28 junio 2017.

[7] EL TIEMPO, «Colombia produce al año aproximadamente 130.000 toneladas de la considerada basura electronica,» El Tiempo, Colombia, 2017.

[8] MINAMBIENTE, «Ministerio de ambiente y Desarrollo Sostenible,» 2017. [En línea]. Available: http://www.minambiente.gov.co/images/AsuntosambientalesySectorialyUrbana/pdf/ebook_rae_/Poli tica_RAEE.pdf. [Último acceso: 29 septiembre 2018].

[9] A. Farbiarz Mas, «Informe sobre tendencia de los RAEE a nivel mundial. Residuos profesionales,» Residuos Profesional, 9 enero 2018. [En línea]. Available: https://www.residuosprofesional.com/informe-tendencias-raee-nivel-mundial/. [Último acceso: 6 agosto 2018].

[10] MINAMBIENTE, «Ministerio de Ambiente y Desarrollo Sostenible,» julio 2017. [En línea]. Available:

III Encuentro Nacional de Semilleros de Investigación de Ingeniería Industrial 
http://www.residuoselectronicos.net/wpcontent/uploads/2012/03/Guia_RAEE_MADS_2011reducida.pdf. [Último acceso: 6 agosto 2018].

[11] Stockholm Convention, «Protecting human health and the enviroment from persistent organic pollutants,» de Stockholm Convention, Srockholm, 2008.

[12] R. Ignacio, «GSMA,» febrero 2015. [En línea]. Available: https://www.gsma.com/latinamerica/wp-content/uploads/2015/02/ewaste-colombia.pdf. [Último acceso: 29 julio 2018].

[13] SRI, «Innovación ambiental - INNOVA 12,» mayo 2017. [En línea]. Available: http://www.innovaambiental.com.co/wp-content/uploads/2017/05/5.Gestion-RAEEenColombia.pdf. [Último acceso: 29 julio 2018].

[14] M. ZULETA BANDERA, «Residuos electrónicos, ¿qué hacer con ellos?,» EL HERALDO, 3 junio 2013.

III Encuentro Nacional de Semilleros de Investigación de Ingeniería Industrial 


\title{
Diseñar un plan de marketing ambiental como estrategia que permita apoyar la reducción del impacto producido por los residuos sólidos provenientes de los establecimientos dedicados a la actividad turística en las playas de Puerto Colombia (Atlántico).
}

\author{
García Llanos Sammy Alexander ${ }^{3}$ \\ Restrepo Pizarro Carlos Emiro ${ }^{2}$ \\ Suarez Giraldo Elizabeth ${ }^{3}$ \\ Celín Castro Manuel Guillermo ${ }^{4}$
}

\section{Resumen}

En este documento se diseña un plan de mercadeo ambiental basado en entrevistas y encuestas realizadas a establecimientos dedicados al turismo, trabajadores, clientes y/o turistas que frecuentan las playas de Puerto Colombia (Atlántico), se pretende analizar el impacto de la disposición final inadecuada de residuos sólidos a fin de generar estrategias y medidas de supervisión, evaluación y control que permitan mejorar la situación a corto y mediano plazo. Los resultados muestran que es necesaria una inversión del gobierno municipal que permita la creación de una conciencia ambiental.

\footnotetext{
${ }^{3}$ Universidad del Atlántico, Semillero Green Engineers Marketing. Contacto: esuarezg @est.uniatlantico.edu.co

${ }^{4}$ Universidad del Atlántico. Docente de planta de Gestión de Mercadeo y Green Marketing. Contacto: manuelcelin@mail.uniatlantico.edu.co
}

III Encuentro Nacional de Semilleros de Investigación de Ingeniería Industrial

Universidad Santo Tomás. Facultad de Ingeniería Industrial. 1 de noviembre de 2019 


\section{Palabras Claves}

Comercialización ambiental, desechos sólidos, mercadeo ambiental, conciencia ambiental.

\section{Problema de Investigación}

Las playas de Puerto Colombia se han caracterizado por ser uno de los lugares más representativos de la costa debido a sus atractivos turísticos como lo es el muelle de Puerto Colombia; sin embargo, el mal manejo de los residuos sólidos provenientes de los establecimientos y la falta de conciencia por parte de los clientes, turistas y trabajadores, ha creado un impacto ambiental negativo para este sector y el ecosistema en general; así mismo, existe la creencia de que la mayoría de las enfermedades que se dan en este sector son causadas por la mala gestión de los residuos sólidos. Esto ha causado que se cree una mala imagen del lugar para los que visitan el lugar y lo encuentran en malas condiciones.

Con este proyecto se buscar informar de qué manera un plan de marketing ambiental como estrategia permite apoyar la reducción del impacto producido por el mal manejo de los residuos sólidos en las playas de Puerto Colombia por parte de los establecimientos dedicados a la actividad turística como de los visitantes. Esto con el fin de explotar al máximo el sector turístico de las playas de Puerto Colombia, sin afectar el ecosistema, creando conciencia en los diferentes involucrados.

A continuación, se presentan unas imágenes de la situación de las playas:

III Encuentro Nacional de Semilleros de Investigación de Ingeniería Industrial

Universidad Santo Tomás. Facultad de Ingeniería Industrial. 1 de noviembre de 2019 


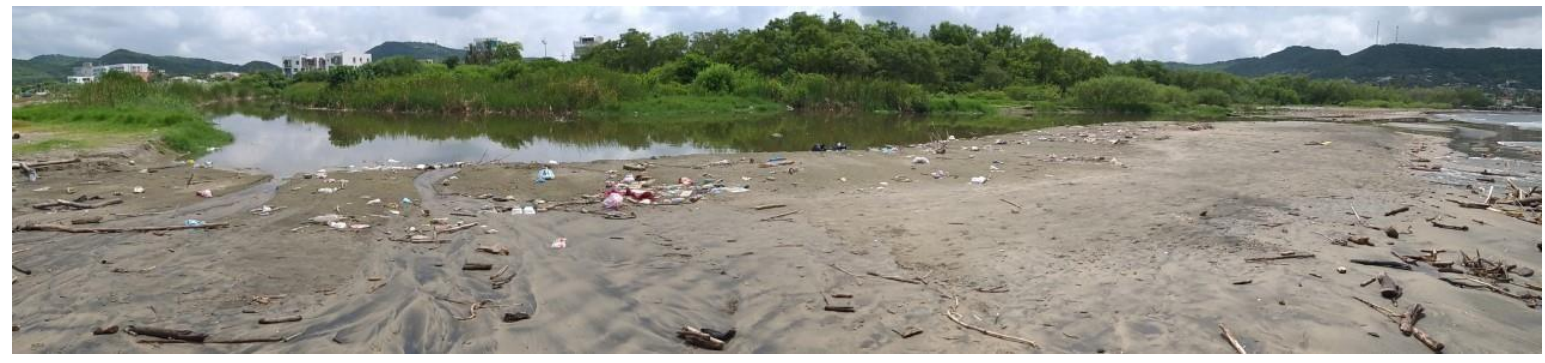

Fig. 1. Vista panorámica del estado de las playas de Puerto Colombia (Atlántico). Fuente: Autores del proyecto.

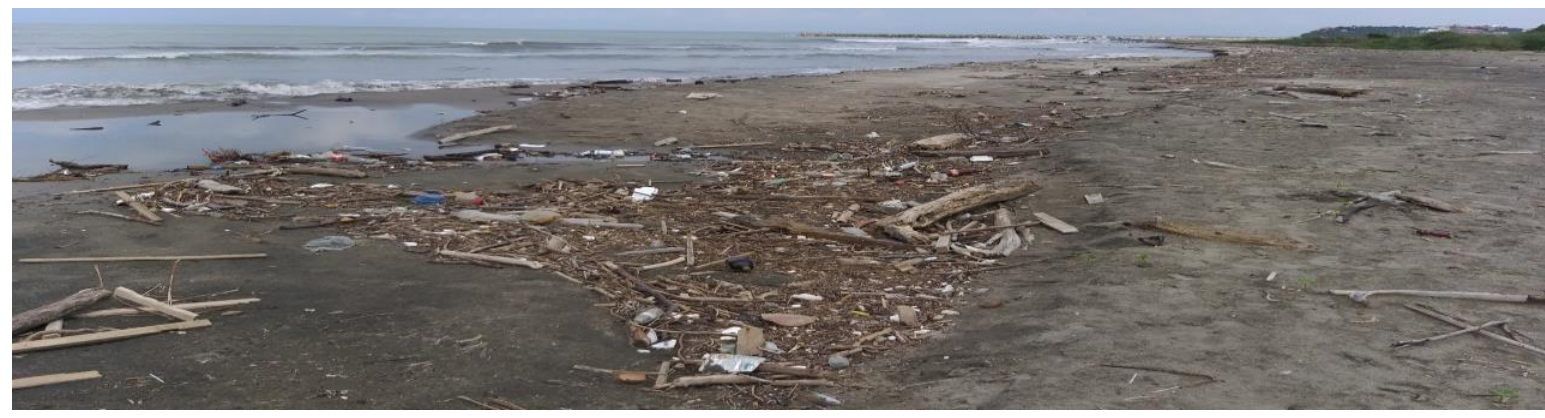

Fig. 2. Estado de las playas de Puerto Colombia (Atlántico). Fuente: Autores del proyecto.

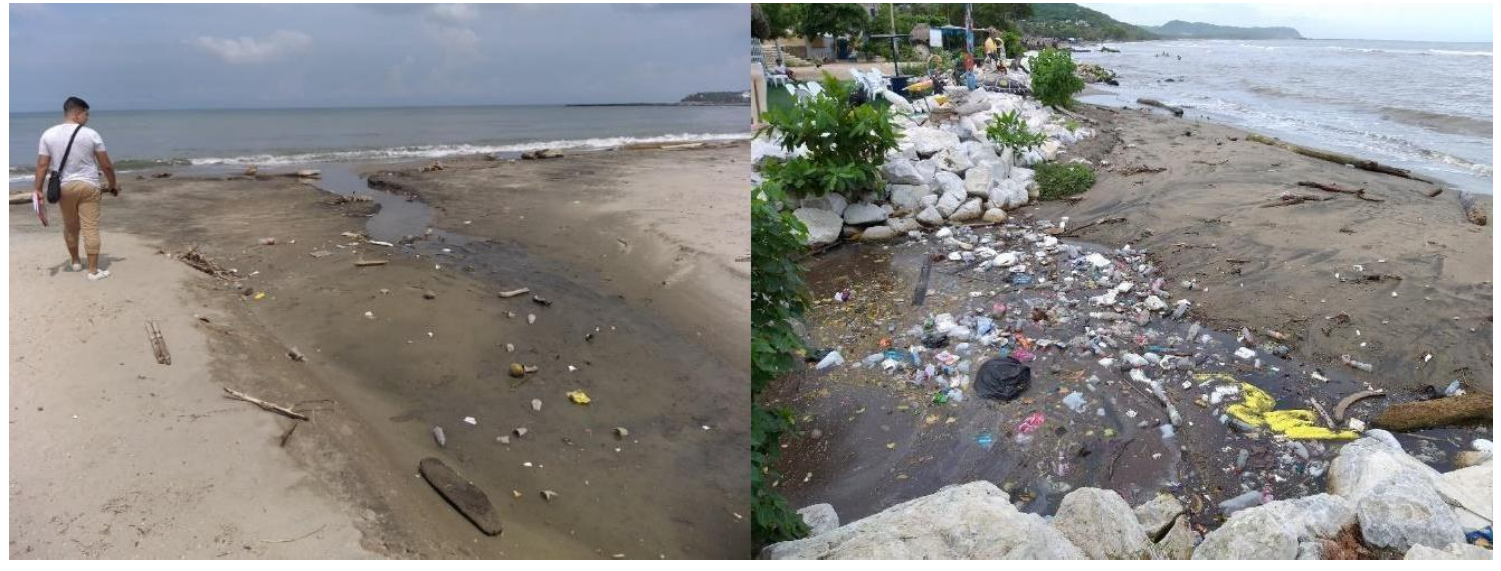

Fig. 3. Estado de las playas de Puerto Colombia

Fuente: Autores del proyecto.

Fig. 4. Estado de las playas de Puerto Colombia

Fuente: Autores del proyecto.

\section{Antecedentes teóricos}

III Encuentro Nacional de Semilleros de Investigación de Ingeniería Industrial

Universidad Santo Tomás. Facultad de Ingeniería Industrial. 1 de noviembre de 2019 
El Marketing Ambiental se ha convertido en una prioridad para las grandes organizaciones. Uno de los pocos indicadores en los que Colombia ha destacado positivamente en el ámbito internacional es en el Índice de Desempeño Ambiental que elabora anualmente la Universidad de Yale. En el ranking correspondiente al año 2010, el país se encontraba entre los 10 primeros, por encima de Gran Bretaña, Chile, Nueva Zelanda, Japón y muchos otros de alto nivel de desarrollo [1]; sin embargo, para el año 2018 se encontraba en el puesto 42, caracterizándose por su conservación ecológica [2]; por estas razones se hace necesario que en Colombia se tomen medidas que permitan lograr mejorar en materia ambiental.

La constante problemática de la contaminación del medio ambiente en la parte marina y costera de Colombia, está llevando a que poco a poco la naturaleza sufra una muerte lenta; uno de los factores que más genera impacto ambiental sobre los ecosistemas marinos y costeros es la presencia de residuos sólidos como el plástico y el vidrio; el plástico es uno de los principales contaminantes de los mares y se puede encontrar en cualquier playa del mundo, ya que las fuentes de generación son diversas; es por esta razón que en las playas como las de Santa Marta se realizan jornadas de limpieza donde se involucran alrededor de 300 voluntarios, recogiendo aproximadamente cuarenta toneladas de residuos; en playas de Cartagena, especialmente el caso de tierra bomba, se sensibilizan a los turistas y se reúnen muchos voluntarios para limpiar las playas y aprovechar la riqueza natural de las mismas; un caso a resaltar es el de las playas de Riohacha/La Guajira/Colombia, las cuales están cerca de obtener la certificación internacional "bandera azul", el cual es un galardón anual que se entrega a una playa que cumpla con los requisitos establecidos en un sistema de certificación de la calidad ambiental desarrollado por la FEE, esta se otorga por su dedicación a mantener las playas limpias, ordenadas y con más servicios y actividades de educación ambiental para los turistas y habitantes. El programa promueve y premia la participación en iniciativas ambientales voluntarias de las autoridades municipales, la población local y visitante y los agentes del sector del turismo. Los criterios para obtener la Bandera Azul se agrupan en cuatro áreas: Calidad de las aguas de baño, Información y educación ambiental, Gestión ambiental y Seguridad, servicios e Instalaciones.

III Encuentro Nacional de Semilleros de Investigación de Ingeniería Industrial 


\section{Objetivo General}

Diseñar un plan de Marketing Ambiental como estrategia que permita apoyar la reducción del impacto producido por los residuos sólidos provenientes de los establecimientos dedicados a la actividad turística en las playas de Puerto Colombia (Atlántico).

\section{Objetivos Específicos}

- Identificar el comportamiento en materia medioambiental enfocado a los residuos sólidos producidos por parte de los clientes o turistas, los operadores turísticos, los vendedores informales y los habitantes de Puerto Colombia que permita la correcta visualización de la situación que se presenta y el impacto que esto trae consigo.

- Diseñar estrategias de marketing ambiental como herramienta para la apropiación y concientización de los diferentes interesados, referente a la óptima disposición o aprovechamiento de los residuos sólidos provenientes de la actividad turística en las playas de Puerto Colombia (Atlántico).

- Proponer medidas de supervisión, evaluación y control de los índices de contaminación en materia de residuos sólidos en las playas de Puerto Colombia (Atlántico) fundamentadas en el plan de marketing ambiental estructurado en conformidad con las medidas de gestión que la alcaldía de Puerto Colombia tiene plasmadas en este tema.

\section{Metodología}

Se llevó a cabo una investigación de tipo descriptivo longitudinal prospectivo. Se hizo la recolección de datos a través de encuestas realizadas a diferentes actores implicados, como lo son: Clientes - Turistas, Operadores turísticos, Vendedores Informales y Habitantes de Puerto Colombia. Luego se realizó un análisis estadístico de los datos obtenidos. El método descriptivo permitió analizar, describir y evaluar la información adquirida mediante encuestas y observación de campo. La técnica utilizada tiene un ámbito de aplicación geográfico, temporal: Playas de

III Encuentro Nacional de Semilleros de Investigación de Ingeniería Industrial 
Puerto Colombia en el sector del muelle. Los instrumentos de investigación que se utilizaron para la aplicación de la técnica fueron: encuestas, planes de muestreo, trabajos de campo, capacitación del personal, proceso de levantamiento de la información, procesamiento, codificación y análisis de datos de la información.

\section{Análisis de resultados}

Se realizaron 160 encuestas a los establecimientos: 93 encuestas a los trabajadores y 67 encuestas a los dueños. Los resultados obtenidos fueron los siguientes:

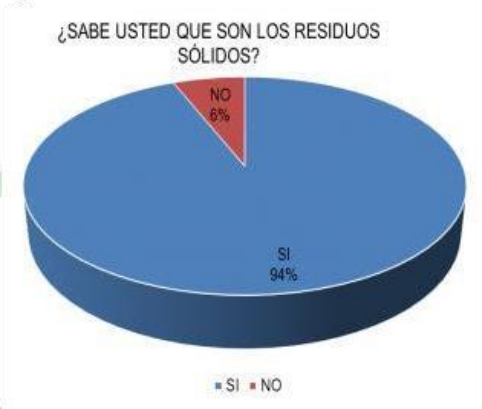

¿SABE USTED ACERCA DEL CORRECTO MANEJO DE LOS RESIDUOS SÓLIDOS?

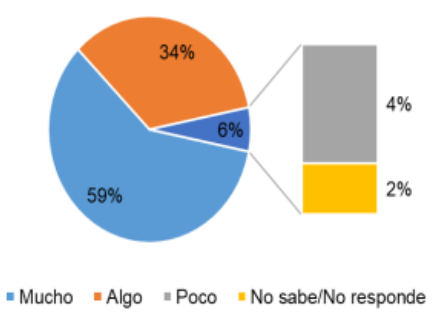
¿COMO ES EL MANEJO DE SUS RESIDUOS SOLIDOS
PRODUCIDOS DIARIAMENTE DESDE SU NEGOCIO?

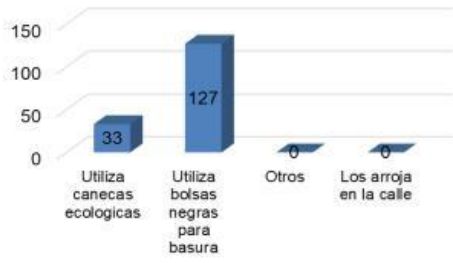

¿HA RECIBIDO CAPACITACIONES SOBRE EL CUIDADO DEL MEDIO AMBIENTE Y/O MANEJO DE RESIDUOS SÓLIDOS DE ALGUNA ENTIDAD?

$=$ Alcaldia $=$ Sena $=$ Otros (C.R.A)

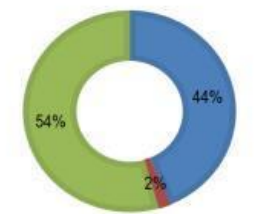

Fig. 5. Gráficas más importantes de resultados para dueños de establecimientos y trabajadores de los mismos. Fuente:

Autores del proyecto

Una de las conclusiones que se pudieron hacer con este estudio es que más de la mitad de los trabajadores encuestados optan por capacitarse con la C.R.A debido a la falta de herramientas suministradas por parte de la alcaldía del municipio de Puerto Colombia (Atlántico); otra información relevante es el hecho de que a pesar de que el SENA es una entidad del estado

III Encuentro Nacional de Semilleros de Investigación de Ingeniería Industrial

Universidad Santo Tomás. Facultad de Ingeniería Industrial. 1 de noviembre de 2019 
que dispone herramientas pedagógicas en cualquier área, estos cursos o carreras que se ofrecen para potenciar el turismo, no son aprovechados por los operadores turísticos. El número de encuestas realizadas a los clientes y/o turistas fue de 96; los resultados de las encuestas realizadas en cada pregunta fueron los siguientes:

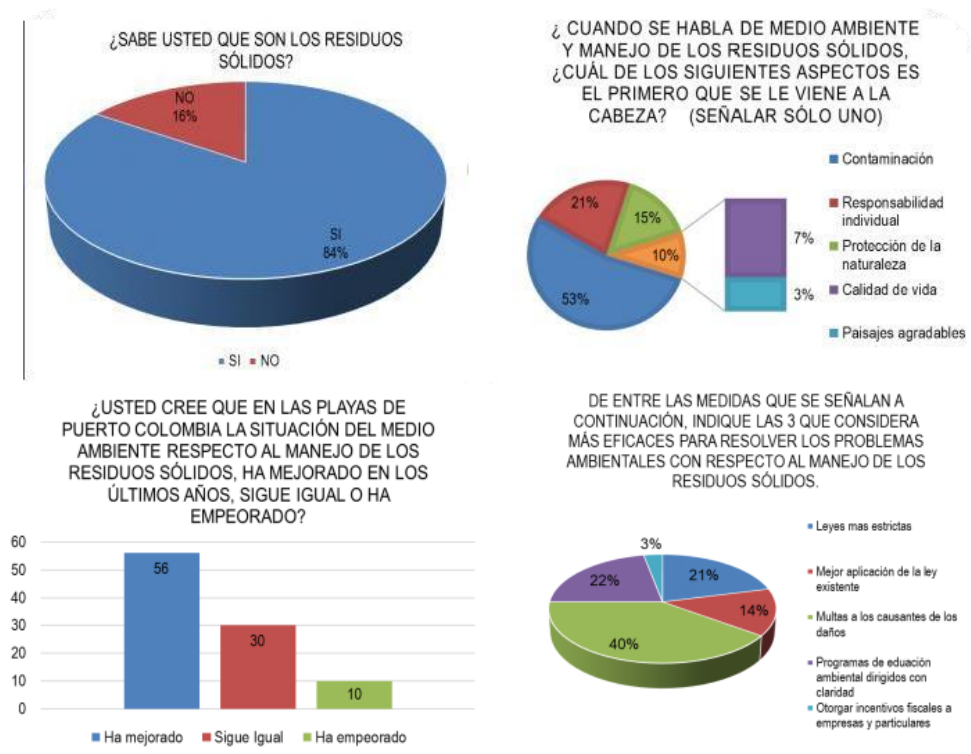

Fig. 5. Gráficas más importantes de resultados para para clientes y/o turistas que frecuentan las playas. Fuente: Autores del proyecto

Es posible afirmar, por medio de los resultados arrojados, que la problemática nace o parte de la desinformación y la falta de capacitación en temas medio ambientales de acuerdo a la normativa vigente; el problema no radica en la falta de leyes, sino en la falta de aplicación de las mismas y la adecuada sensibilización de todos los involucrados.

\section{PLAN DE MARKETING AMBIENTAL ENFOCADO AL MANEJO DE LOS RESIDUOS SÓLIDOS.}

El plan de marketing ambiental propone las siguientes estrategias:

Estrategias educativas:

III Encuentro Nacional de Semilleros de Investigación de Ingeniería Industrial

Universidad Santo Tomás. Facultad de Ingeniería Industrial. 1 de noviembre de 2019 
- Brindar programas y talleres educativos enfocados al correcto manejo de los residuos sólidos en las playas de Puerto Colombia para todos los involucrados.

- Creación e instalación de señalización y mensajes que inciten al cuidado del medio ambiente en las playas y sus alrededores.

- Facilitar información (volantes), charla informal y comparendos pedagógicos.

- Implementación de material publicitario en los buses de transporte público que traen a los turistas hasta las playas.

- Organización de actividades culturales y deportivas, relacionadas con el cuidado del medio ambiente (torneos de deportes de playa, reinados ecológicos, concursos)

- Implementación de políticas de premiación e incentivos a los actores del escenario turístico que mantengan su establecimiento libre de contaminación apoyados por las autoridades locales.

Estrategias digitales:

- Comunicar y difundir mediante las diferentes redes sociales, actividades relacionadas al correcto manejo de los residuos sólidos con el apoyo de "influenciadores" bajo dinámicas y eventos que motiven a los habitantes a participar en estos programas.

- Crear hashtags y tendencias en relación con el manejo de los residuos sólidos.

- Seguir cuentas de personalidades influyentes y solicitarles acciones concretas por el bienestar de las playas de Puerto Colombia (Atlántico).

- Publicar y difundir contenidos "verdes" enfocados al manejo de los residuos sólidos en las playas de Puerto Colombia (Atlántico).

Estrategias de recolección:

- Campañas de limpieza los días viernes por parte de los actores del escenario turístico apoyados por la alcaldía municipal, fundaciones ambientales e instituciones educativas del municipio.

- Distribuir en las áreas de las playas recipientes para el manejo de residuos sólidos de acuerdo a su clasificación.

III Encuentro Nacional de Semilleros de Investigación de Ingeniería Industrial

Universidad Santo Tomás. Facultad de Ingeniería Industrial. 1 de noviembre de 2019 
- Establecer un sistema de recolección de los residuos sólidos programados mediante la creación de un vínculo estratégico entre la empresa de servicios públicos Triple AAA y el ente municipal garantizando la gestión eficaz y oportuna, involucrando directamente a los operadores turísticos.

\section{MEDIDAS DE SUPERVISIÓN, CONTROL Y EVALUACIÓN EN MATERIA DE RESIDUOS SÓLIDOS EN LAS PLAYAS DE PUERTO COLOMBIA (ATLÁNTICO).}

Supervisión del cumplimiento del plan de manejo ambiental: La entidad encargada, en este caso, las secretarias de turismo y medio ambiente del municipio, deberán comprobar la ejecución de cada una de las estrategias de mitigación ambiental, presentando informes en los que consten las conformidades y no conformidades ambientales, derivadas de las actividades de la empresa contratada para realizar dicha labor.

La empresa contratada deberá llevar los registros escritos de sus actividades ambientales en forma semestral y el plan de manejo ambiental con respecto a los residuos sólidos, estos deberán ser archivados por parte de los ministerios de turismo y medio ambiente del municipio, y deberán estar disponibles para su verificación por parte de la gobernación. En caso que, a pesar de cumplir con la correcta aplicación de las estrategias, los resultados del monitoreo arrojen mediciones negativas o perjudiciales, la entidad contratante y la empresa contratada, deberán reunirse inmediatamente y coordinar las modificaciones y ampliaciones de las estrategias del plan de marketing ambiental.

Monitoreo y control de la disposición de los residuos sólidos por parte de los actores en las playas: La empresa contratada deberá realizar mensualmente la evaluación de los índices de contaminación que poseen las playas, para visualizar detalladamente el progreso que se vaya obteniendo; estos índices serán determinados mediante la recolección, separación y posterior pesaje para determinar los tipos de residuos y la cantidad de los mismos, para esto se empleará lo formulado por el ICONTEC, el cual publicó la norma técnica Colombiana GTC24, gestión ambiental, residuos sólidos.

III Encuentro Nacional de Semilleros de Investigación de Ingeniería Industrial 


\section{Conclusiones}

A través de este proyecto se pretende que las playas de Puerto Colombia sean utilizadas de la manera correcta, que la gente se recree sanamente, que los niños se diviertan en la arena, que las personas disfruten del mar, que los negocios crezcan, que el municipio goce económicamente, pero sobre todas las cosas, que el patrimonio más rico, la naturaleza, las playas, sea cuidado para las próximas generaciones. Y esto solo se logrará a través del adecuado manejo de los residuos sólidos en las playas de Puerto Colombia mediante estrategias de marketing ambiental, enfocadas a tres áreas vitales, como lo son: educativas, digitales y de recolección; brindando programas y talleres enfocados al correcto manejo de los residuos sólidos; comunicando y difundiendo, mediante el uso de redes sociales, actividades relacionadas al correcto manejo de los residuos sólidos con el apoyo de "influenciadores" y, por último, garantizando la eficiencia del manejo de los residuos sólidos. Estas estrategias buscan crear conciencia ambiental y lograr establecer a las playas de Puerto Colombia como destino turístico ecológico potenciando su patrimonio y riqueza natural.

\section{Referencias Bibliográficas}

[1] R. Medioambiente, «Colombia ocupó puesto 42 en ranquin ambiental a nivel mundial,» El espectador, 2018.

[2] G. A. Ramírez, «Desempeño ambiental: una fortaleza de Colombia y un nuevo desafío para las empresas,» Revista Dinero, 2011.

III Encuentro Nacional de Semilleros de Investigación de Ingeniería Industrial

Universidad Santo Tomás. Facultad de Ingeniería Industrial. 1 de noviembre de 2019 


\title{
Análisis de las tecnologías en sistemas de abastecimientos de agua potable
}

\author{
Estiven González Sarmiento 5 \\ Jhoselin Roa Pérez ${ }^{6}$ \\ Luis Ortiz Ospino ${ }^{7}$
}

\section{Resumen}

El agua forma parte de todos los procesos naturales de la tierra, por lo que tiene un impacto en todos los aspectos de la vida. Debido a que cada organismo depende del agua, éste se convierte en el eje primordial del desarrollo de la sociedad a través de la historia. Así, la intención de este trabajo es hacer un proceso de vigilancia tecnológica, para analizar las iniciativas que intentan paliar la actual situación de crisis como lo es el abastecimiento de agua potable, haciendo insistencia en las tecnologías en sistemas de abastecimiento de agua potable, con el fin de identificar éstas, para establecer unas condiciones iniciales y así proponer alternativas tecnológicas para la aplicación en estos sistemas.

\section{Palabras Claves}

Vigilancia tecnológica, sistemas de abastecimiento, potabilización, tratamiento, agua potable.

\section{Problema de Investigación}

\footnotetext{
${ }^{5}$ Universidad Simón Bolívar, Sede Barranquilla. Semillero de Investigación e Innovación SI². Contacto: egonzalez58@unisimon.edu.co

${ }^{6}$ Universidad Simón Bolívar, Sede Barranquilla. Semillero de Investigación e Innovación SI².

Contacto: jroa10@unisimon.edu.co

${ }^{7}$ Universidad Simón Bolívar, Sede Barranquilla. Docente investigador de la faculta de Ingeniería Industrial.

Contacto: lortiz27@unisimonbolivar.edu.co
}

III Encuentro Nacional de Semilleros de Investigación de Ingeniería Industrial

Universidad Santo Tomás. Facultad de Ingeniería Industrial. 1 de noviembre de 2019 
En la actualidad el recurso hídrico está bajo presiones crecientes como consecuencia del crecimiento de la población mundial, una combinación de problemas económicos y socioculturales, lo cual afecta negativamente la calidad del agua; las carencias de medidas de control de la contaminación dificultan el uso sostenible del vital líquido [1]. La disponibilidad del agua es un problema actual y complejo en el que interviene una serie de factores que van más allá del incremento poblacional que demanda cada vez más este recurso para uso del consumo humano. El crecimiento urbano-industrial, la sobreexplotación y la contaminación de los recursos hídricos han generado conflictos y escasez de agua, afectando de manera significativa a ciudades y localidades. Los sistemas tradicionales de potabilización y purificación demandan de numerosos equipos y sistemas que provocan costos elevados. Es por esto, que las tecnologías sostenibles de bajo costo se convierten en una alternativa asequible [2]. Así, para el desarrollo de la investigación surgieron preguntas como, ¿Cuáles son las tecnológicas implementadas en los sistemas de abastecimiento de agua potable?

\section{Antecedentes teóricos}

El problema de la calidad de agua es tan importante como aquellos relativos a la escasez de esta, pero sin embargo se le ha brindado menos atención. El término calidad de agua se refiere al conjunto de parámetros que indican que el agua puede ser usada para diferentes propósitos. Es importante contar con un abastecimiento seguro y conveniente, y de satisfacción para el consumo humano, y la higiene personal, debe limitarse a normas adecuadas en cuanto a disponibilidad, cantidad, calidad y confiabilidad del abastecimiento [3]. Colombia tiene abundantes recursos hídricos y a pesar de contar con estos recursos persisten los problemas relacionados a la cobertura y eficiencia de la calidad de los abastecimientos de agua, su desenfrenada contaminación, el agotamiento de las fuentes subterráneas, el deterioro de las aguas dulces se ha convertido en un problema serio, ya que aproximadamente solo el $30 \%$ de la población consume agua con los estándares establecidos por la Organización Panamericana de la Salud (OPS). Esto también se debe a que los sistemas tradicionales de potabilización y purificación demandan de numerosos equipos y sistemas electromecánicos que provocan costos de explotación y

III Encuentro Nacional de Semilleros de Investigación de Ingeniería Industrial 
mantenimiento elevados, es por ellos que con la vigilancia tecnológica se busca mediante la observación y en el análisis del entorno científico, tecnológico y los impactos económicos presentes y futuros para identificar las amenazas y oportunidades de desarrollo de nuevas tecnologías en sistemas de abastecimiento [4].

\section{Objetivo General}

- Analizar las tecnologías en sistemas de abastecimiento de agua potable, con el fin de proponer estrategias para la mejora de la implementación en estos sistemas.

\section{Objetivos Específicos}

- Identificar las tecnológicas de sistemas de abastecimiento de agua potable, que permita el mapeo tecnológico.

- Elaborar perfiles tecnológicos en sistemas de abastecimiento de agua potable.

- Proponer alternativas tecnológicas para la aplicación en sistemas abastecimiento de agua potable.

\section{Metodología}

En la presente investigación se utilizó un diseño de investigación tipo documental a través de la consulta de documentos (base de datos, patentes, artículos científicos, informes, revistas), con el fin de realizar el análisis de tecnologías en sistemas de abastecimientos de agua potable. Para el logro del objetivo planteado se desarrolló un proceso de vigilancia tecnológica a través de la descripción y análisis de los procedimientos implementados para realizar las tareas de vigilancia y obtener las herramientas propias para recuperar, difundir y analizar los datos recopilados [5]. También, para el logro del objetivo de investigación se llevó a cabo tres fases metodológicas, en la cual la primera es la, identificación de los factores de las tecnologías de sistemas de abastecimiento de agua potable por medio de un mapeo tecnológico, que permita tener una visión panorámica de las tecnologías de abastecimiento de agua potable, conocer el posicionamiento de las tecnologías frente a las necesidades del mercado y cuáles son las tendencias tecnológicas. La

III Encuentro Nacional de Semilleros de Investigación de Ingeniería Industrial 
segunda fase metodológica constó de una elaboración de perfiles tecnológicos a través de una caracterización con el fin de identificar esas tecnologías para establecer unas condiciones iniciales y así en la tercera fase se propuso alternativas para el mejoramiento en la aplicación de los sistemas abastecimiento de agua potable.

\section{Análisis de resultados}

- Mapeo tecnológico: se inició con una revisión de los factores para la identificación de las tecnologías de sistemas de abastecimiento de agua potable, esto se obtuvo mediante la búsqueda de patentes en las bases de datos de Google y Patentscope. Se utilizó una ecuación de búsqueda ((TECHNOLOGY, SYSTEM, TREATING, CATERING, PURIFICATION, WATER) and (WATER TREATMENT, POTABLE WATER, WATER PURIFICATION, WATER QUALITY)), y se obtuvieron alrededor de 60 patentes en todo el mundo en una ventana de observación del 2011 al año 2019.

- Análisis bibliométrico: mediante palabras claves, se realizó una consulta de documentos a través de Scopus, por medio de la ecuación de búsqueda formulada (TITLE-ABS-KEY (technology) AND TITLE-ABS-KEY (system AND treating AND drinking AND water)), se obtuvieron una total de 120 artículos, informes y revistas, y 17249 patentes en la ventana de observación definida.

Este conjunto de datos que se obtuvo fue analizado mediante VOSviewer, en donde se realizó un análisis de co-ocurrencia teniendo como unidad de análisis las palabras claves del conjunto de datos obtenido. De esta manera el Software arrojó una visualización de red del conjunto de palabras analizadas.

III Encuentro Nacional de Semilleros de Investigación de Ingeniería Industrial

Universidad Santo Tomás. Facultad de Ingeniería Industrial. 1 de noviembre de 2019 


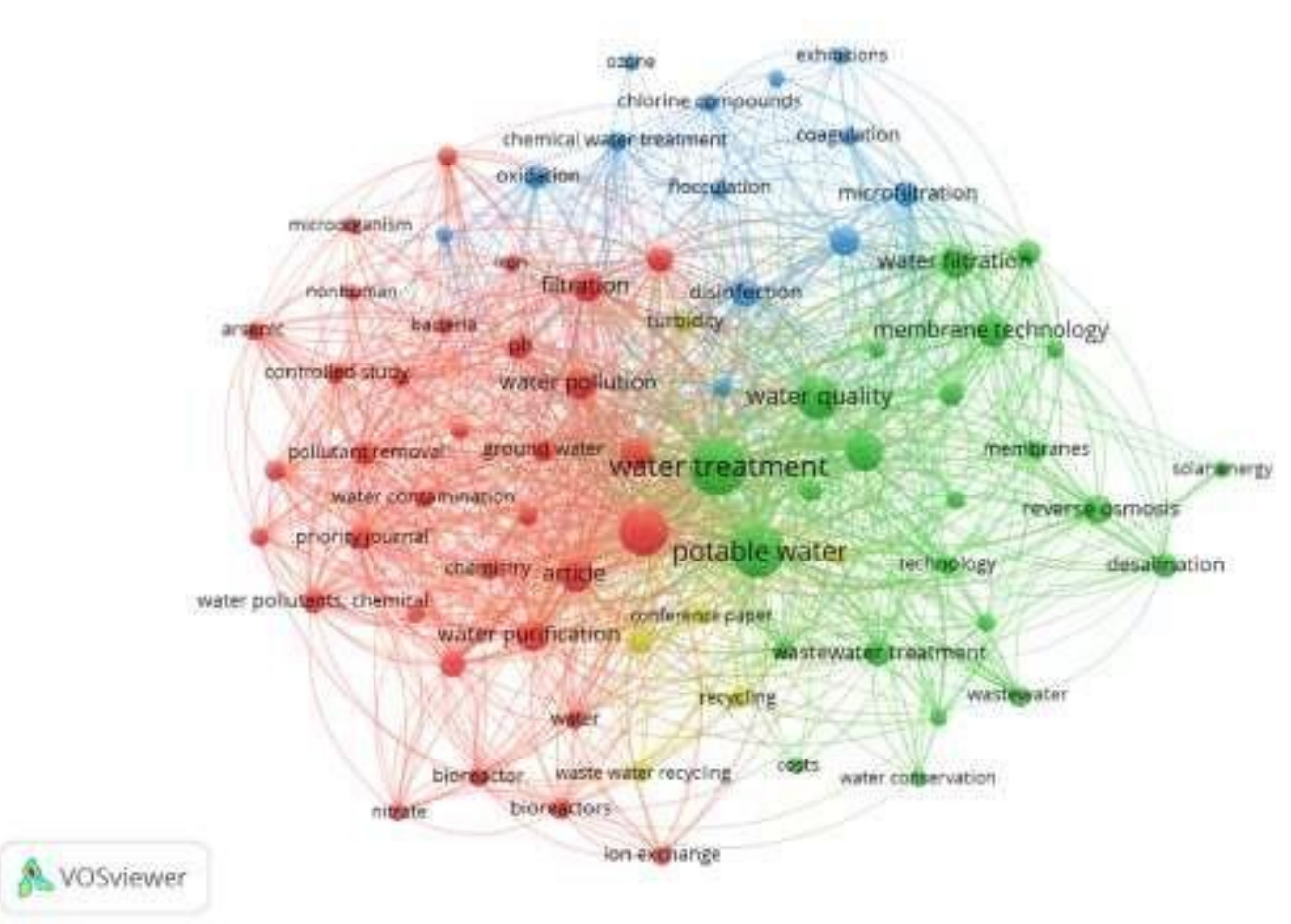

Fig. 1 Visualización de red

Este análisis bibliométrico es un mapa basado en la distancia, donde la distancia entre dos elementos refleja la fuerza de relación entre los mismos. En este mapa se está midiendo la frecuencia o nivel de ocurrencia y la fortaleza que existe entre las palabras. Así, se implementó un método de clusterización, donde los colores expresan la similaridad y nivel de relación, entre los elementos o nodos del clúster. De esta forma, este mapa de co-ocurrencia de palabras claves (palabras del autor, palabras indexadas) sirvió para conocer las relaciones entre palabras clave de 1a investigación, basado en la cercanía dentro del mapa.

En la Fig.1 se puede evidenciar que la investigación está centrada en WATER TRATAMEN, ya que es la palabra con mayor número de frecuencia, también esta POTABLE WATER, DRINKING WATER, WATER QUALITY, las palabras antes mencionadas son los nodos que más influencia y mayor tamaño tienen dentro de la red. Por lo tanto, los conjuntos de palabras centrales señalan o refleja el contenido central de la literatura de investigación. También, reflejan la estructura semántica del campo de investigación que se está abordando. Por estar construidas

III Encuentro Nacional de Semilleros de Investigación de Ingeniería Industrial

Universidad Santo Tomás. Facultad de Ingeniería Industrial. 1 de noviembre de 2019 
con base a palabras claves este mapa refleja descriptores que han sido seleccionados tanto por los autores como por las revistas.

Perfiles tecnológicos: se definió una ficha de perfil con las siguientes categorías:

- Tecnologías: tendencia de las patentes.

- Países: países donde se encuentran el mayor número de artículos y patentes.

- Tiempo: años en los cueles se encontró un mayor número de artículos y patentes.

Tabla 1 Ficha Perfil

\begin{tabular}{l|l}
\hline \multicolumn{1}{c|}{ Categorías } & \multicolumn{1}{c}{ Características } \\
\hline \hline \multirow{2}{*}{ Tecnologías } & $\begin{array}{l}\text { Tratamiento de aguas por procesos: ciclo natural inducido, sistema compacto, } \\
\text { Aprovechamiento eficiente del agua lluvia. } \\
\text { Generación de agua: dispositivos termoeléctricos. }\end{array}$ \\
\hline Tiempos & $2014,2016,2017$. \\
\hline Países & Estados unidos, Reino unido, China, Japón. \\
\hline
\end{tabular}

\section{Conclusiones}

Se identificaron las diferentes metodologías y técnicas de investigación que se han utilizado en las prácticas de sistemas de abastecimiento de agua potable relacionándola con la vigilancia tecnológica. Mediante este proceso de vigilancia, se obtuvieron las herramientas propias para el análisis de los datos recopilados, y de esta forma dio conocer el posicionamiento de las tecnologías frente a las necesidades del mercado y cuáles son esas tendencias tecnológicas actuales.

III Encuentro Nacional de Semilleros de Investigación de Ingeniería Industrial

Universidad Santo Tomás. Facultad de Ingeniería Industrial. 1 de noviembre de 2019 
Adicionalmente, tras el proceso de vigilancia, se recomienda que para la toma de decisiones de política pública inicialmente se hagan estudios de vigilancia tecnológica, con el fin de aterrizar al contexto, y tomar decisiones asertivas en la aplicación de estos sistemas. Segundo, realizar ejercicios de apropiación social de la tecnología para que realmente las personas se apropien de ellas y así tener un impacto esperado con el desarrollo tecnológico.

\section{Referencias Bibliográficas}

[1] Otero Carvajal, S. A. (2002). Creación y diseño de organismos de cuencas en la subcuenca del río Copán, Honduras (No. Thesis O87cr). CATIE, Turrialba (Costa Rica).

[2] Morató, J., Subirana, A., Gris, A., Carneiro, A., \& Pastor, R. (2006). Tecnologías sostenibles para la potabilización y el tratamiento de aguas residuales. revista lasallista de investigación, 3(1).

[3] Guzmán-Barragán, B. L., Días Bevilacqua, P., \& Nava-Tovar, G. (2015). Contextos locales de la vigilancia de calidad del agua para consumo humano: Brasil y Colombia. Revista de Salud Pública, 17, 961-972.

[4] Escorsa, P., Maspons, R., \& Llibre, J. (2001). De la vigilancia tecnológica a la inteligencia competitiva (Vol. 1). Madrid: Prentice hall.

[5] Hernández, R., Fernández, C., \& Baptista, M. (2014). Metodología de la investigación McGraw-Hill. México DF.

III Encuentro Nacional de Semilleros de Investigación de Ingeniería Industrial

Universidad Santo Tomás. Facultad de Ingeniería Industrial. 1 de noviembre de 2019 


\title{
Emitier: Una propuesta de un aplicativo en Visual Basic for Applications para la estimación de emisiones de gases contaminantes generados por fuentes móviles
}

\author{
Rojas Romero, Rafael Antonio ${ }^{8}$ \\ Msc. Jaime Arias, Yamile Adriana ${ }^{9}$
}

\section{Resumen}

Actualmente, la eficiencia ambiental ha tomado importancia en la gestión logística de las industrias que utilizan medios de transporte a lo largo de su cadena de suministro, exigiendo la implementación de controles a los aspectos ambientales asociados, para disminuir los impactos generados por las emisiones. Teniendo en cuenta que el uso de equipos de monitoreo de emisiones es costoso y restringido, este articulo expone un programa desarrollado en VBA para la estimación de emisiones bajo los parámetros y metodología TIER de la Agencia Ambiental Europea.

\section{Palabras Claves}

Contaminación; Inventario de emisión. Factor de Emisión. Factor de actividad. TIER.

\footnotetext{
${ }^{8}$ Universidad de la Salle, Bogotá. Semillero de Investigación en Gestión, Mejora y Análisis de Procesos. Contacto: rrojas05@unisalle.edu.co

${ }^{9}$ Universidad de la Salle, Bogotá. Semillero de Investigación en Gestión, Mejora y Análisis de Procesos. Contacto: yajaime@unisalle.edu.co
}

III Encuentro Nacional de Semilleros de Investigación de Ingeniería Industrial

Universidad Santo Tomás. Facultad de Ingeniería Industrial. 1 de noviembre de 2019 


\section{Problema de Investigación}

En Colombia, el uso de modelos para la estimación de emisiones de contaminantes no tiene alcance en todas las organizaciones que usan y gestionan flotas de vehículos para sus funciones logísticas. Aunque existen diversos modelos para esta estimación, el único que se encuentra caracterizado a una ciudad Colombiana como Bogotá es el International Vehicle Emissions Model (IVE); pero los datos de factores emisión son anticuados y obsoletos incluyendo hasta la tecnología de control de emisiones EURO II. [1].

La sociedad moderna exige a las organizaciones que mitiguen el impacto ambiental que generan sus acciones, entre estas las emisiones generadas por sus vehículos, por lo cual se requiere de un modelo con el que puedan diagnosticar su situación e integrarlo en el desarrollo de su sistema de gestión ambiental, incrementando su responsabilidad y compromiso social. Con base en lo anterior, ¿Es posible desarrollar un aplicativo que estime las emisiones de contaminantes generadas por una flota de vehículos, usando una metodología sencilla y de información de fácil identificación para las organizaciones?

\section{Antecedentes teóricos}

Los inventarios de emisiones funcionan como herramientas funcionales en los procesos de gestión de la calidad del aire y toma de decisiones, siendo el punto de partida para implementación, evaluación, ajuste y control de acciones para mejorar la calidad del aire. Existen diversos tipos de inventarios según su propósito: Reporte, estratégico, vigilancia, modelación, investigación y gestión ambiental corporativa. [1]. En el caso de emisiones provenientes de fuentes móviles, existen diferentes modelos para la elaboración de estos inventarios, donde los más conocidos son: Mobile, MOVES, COPERT III e IVE. [2].

De acuerdo con [1], para el funcionamiento de estos modelos es preciso al obtener los datos usando sistemas de monitoreo continuo de emisiones (CEMS); los cuales se ejecutan usando

III Encuentro Nacional de Semilleros de Investigación de Ingeniería Industrial

Universidad Santo Tomás. Facultad de Ingeniería Industrial. 1 de noviembre de 2019 
parámetros denominados factores de emisión. Los factores de emisión son las medidas de las emisiones con base a mediciones directas o balances de masa de una muestra representativa, la cual se interpreta como la relación entre un contaminante con una actividad o proceso. En caso de no contar con estos sistemas de monitoreo, se aplica la metodología TIER desarrollada por la Agencia Ambiental Europea en la Guía Para La Estimación De Inventarios De Emisiones De Contaminantes la cual tiene la capacidad para estimar emisiones de contaminantes como óxido de carbono (CO), NMVOC, NOx, material particulado (PM), N2O, amoniaco entre otros. [3].

La guía emplea una metodología para la estimación de emisiones según el nivel de complejidad denominado "TIER”, el cual está asociado a la cantidad y calidad de la información disponible y el alcance definido del inventario. Esta metodología solo debe ser usada en ausencia de información más detallada que la composición de los combustibles, como los modos de conducción, número de arranques, etc. [2].

Para la estimación de emisiones según [1] se usa la ecuación $E i=F A j m * F E i j k$, donde $E i$ es el resultado de las emisiones de un contaminante (i), FAjm es el Factor de Actividad teniendo en cuenta la distancia recorrida de categoría (j) y tecnología para control de emisiones (m). FEi,jk se define como el Factor de Emisión con base en la tecnología del vehículo (m) para control de emisiones tipo (i), de un vehículo de categoría (j).

\section{Objetivos de investigación}

1. Identificar la metodología de estimación de emisiones mediante el análisis de variables en los modelos de libre acceso que permitan obtener los factores y ecuaciones necesarias para el funcionamiento del aplicativo propuesto.

2. Diseñar métodos para el ingreso de los datos que permitan la caracterización de las fuentes móviles de contaminación usando la información disponible de estas.

III Encuentro Nacional de Semilleros de Investigación de Ingeniería Industrial

Universidad Santo Tomás. Facultad de Ingeniería Industrial. 1 de noviembre de 2019 
3. Estimar las emisiones generadas por las fuentes móviles de contaminación aplicando metodología, factores y ecuaciones identificados para obtener un reporte de estimaciones simple y funcional.

\section{Metodología}

1. Revisión de la literatura: Se realizó una consulta en diversos sistemas de información científica como Science Direct, Scopus y Redalyc usando conceptos clave como estimación de emisiones, modelos de emisión, factores de emisión e inventarios de emisiones.

2. Análisis de información: Se analizaron los modelos que son frecuentemente implementados en la elaboración de inventarios de emisiones de fuentes de contaminación móvil.

3. Selección de metodología: Se selecciónó la metodología para la estimación de emisiones, la cual con el uso de parámetros estandarizados como factores de emisión, actividad y características del vehículo, pudieran obtener la masa del contaminante emitido.

4. Diseño de formularios: Se diseñaron 4 formularios para la selección de funciones, 4 para el ingreso de información y 4 para los reportes de resultados.

5. Escritura del código: Las funciones del programa fueron desarrolladas en 4 módulos y escritas en el lenguaje de programación VBA de Excel, integradas a los formularios.

\section{Análisis de resultados}

1. Metodología selecta: La guía emplea una metodología para la estimación de emisiones según el nivel de complejidad denominado "TIER", el cual está asociado a la cantidad y calidad de la información disponible y el alcance definido del inventario. [2].

III Encuentro Nacional de Semilleros de Investigación de Ingeniería Industrial

Universidad Santo Tomás. Facultad de Ingeniería Industrial. 1 de noviembre de 2019 
Tabla 1. Parámetros de metodología TIER según su complejidad.

\begin{tabular}{|c|l|}
\hline COMPLEJIDAD & \multicolumn{1}{c|}{ PARÁMETROS } \\
\hline \multirow{3}{*}{ TIER 1 } & $\begin{array}{l}\text { Combustible como factor de actividad. } \\
\text { Factores de emisión según el tipo de vehículo. } \\
\text { Clasificación general de vehículos en Passenger Cars, Light Weight, Heavy-Duty } \\
\text { Vehicle, L-Cat. } \\
\text { Distancia de recorrido como parámetro de emisión. }\end{array}$ \\
\hline \multirow{3}{*}{ TIER 2 } & $\begin{array}{l}\text { Combustible como factor de actividad. } \\
\text { Tecnología de control de emisiones como complemento del factor de actividad. - } \\
\text { Clasificación detallada de vehículos en Passenger Cars, Light Weight, Heavy-Duty } \\
\text { Vehicle, Buses, L-Cat. } \\
\text { Distancia de recorrido como parámetro de emisión. }\end{array}$ \\
\hline
\end{tabular}

2. Diseño y funcionalidades del programa: Las emisiones que estima EMITIER se pueden desarrollar bajo la metodología TIER 1 o TIER 2, para variantes entre distancia total para un vehículo, o distancias para una flota de vehículos.

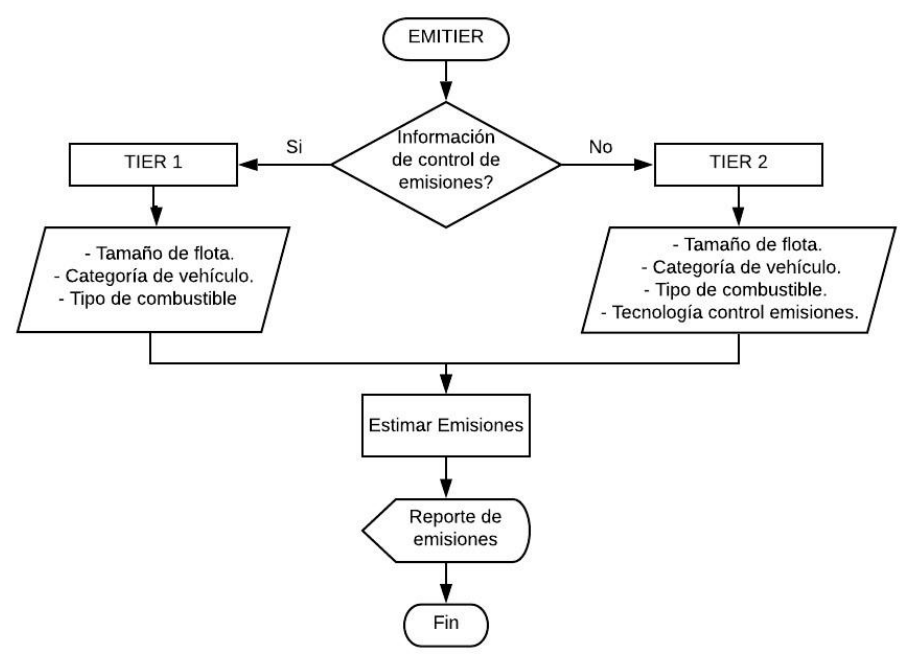

Fig 2. Flujograma de funcionamiento de EMITIER

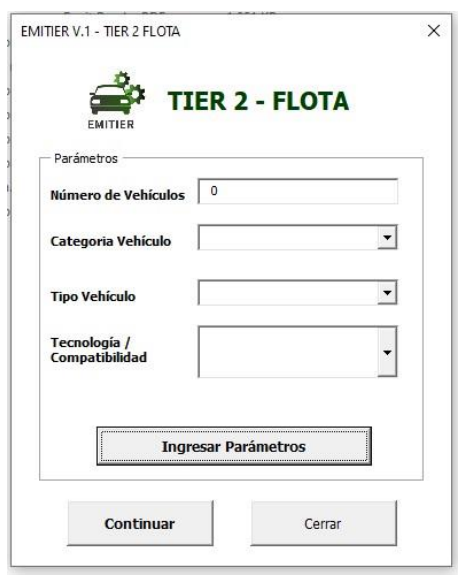

Fig 1. Formulario para el ingreso de parámetros.

3. Reporte de emisiones: El programa presenta un formulario para el reporte de las emisiones generadas por los vehículos de acuerdo con la metodología seleccionada, el

III Encuentro Nacional de Semilleros de Investigación de Ingeniería Industrial

Universidad Santo Tomás. Facultad de Ingeniería Industrial. 1 de noviembre de 2019 
cual puede exportarse en un libro nuevo de Excel con la descripción de contaminantes, emisiones totales y unitarias por vehículo.

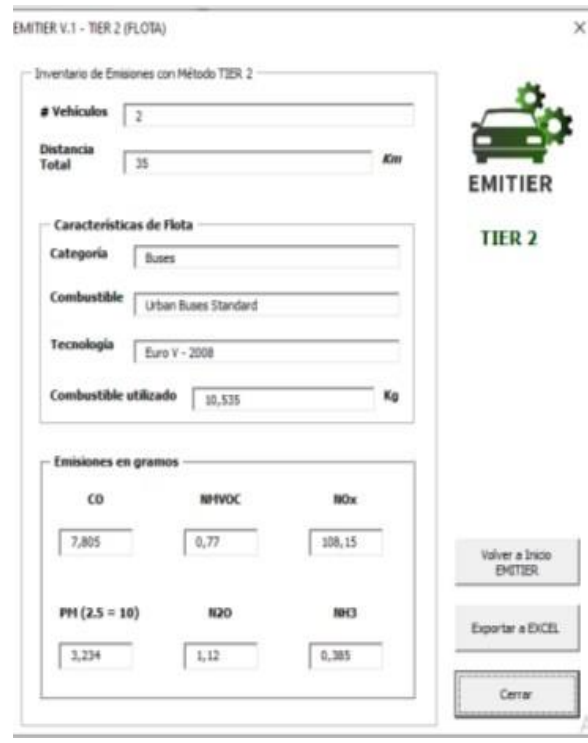

\begin{tabular}{|c|c|c|c|c|c|c|c|c|}
\hline \multicolumn{7}{|c|}{ TIER 2} & & \\
\hline Categoría & Tipo & $\begin{array}{l}\text { logía / } \\
\text { Compatib }\end{array}$ & $\begin{array}{l}\text { el } \\
\text { Comsuption } \\
(\mathbf{k}\end{array}$ & & $\begin{array}{l}\text { Emisione } \\
\text { (g) }\end{array}$ & & & \\
\hline \multirow{6}{*}{ Buses } & \multirow{6}{*}{$\begin{array}{c}\text { Urban } \\
\text { Buses } \\
\text { Standard }\end{array}$} & \multirow{6}{*}{$\begin{array}{c}\text { Euro V - } \\
2008\end{array}$} & \multirow{6}{*}{10,535} & CO & NMVOC & $\begin{array}{r}\text { NO } \\
\mathbf{x}\end{array}$ & & \\
\hline & & & & Mean & Mean & Mean & & \\
\hline & & & & 7,81 & 0,77 & 108,15 & & \\
\hline & & & & PM & $\begin{array}{c}\text { NO } \\
2\end{array}$ & $\begin{array}{c}\text { NH } \\
3\end{array}$ & & \\
\hline & & & & Mean & Mean & Mean & & \\
\hline & & & & 1 & 0,385 & 3,234 & & \\
\hline \multirow[t]{2}{*}{ Vehiculo } & Distancia & CO & NMVOC & $\begin{array}{r}\text { NO } \\
\mathbf{x}\end{array}$ & PM & $\begin{array}{c}\text { N O } \\
2\end{array}$ & $\begin{array}{c}\text { NH } \\
3\end{array}$ & FC \\
\hline & $(\mathrm{km})$ & (g) & (g) & (g) & (g) & (g) & (g) & $(\mathrm{kg})$ \\
\hline 1 & 12 & 2,676 & 0,264 & 37,08 & 1,1088 & 0,384 & 0,132 & 3,612 \\
\hline 2 & 23 & 5,129 & 0,506 & 71,07 & 2,1252 & 0,736 & 0,253 & 6,923 \\
\hline
\end{tabular}

Fig 3 y 4. Reporte de emisiones usando formularios en VBA y reporte exportado en libro nuevo de Excel.

\section{Conclusiones}

El desarrollo de modelos y aplicativos para la estimación de emisiones de contaminantes, funcionan como un método de diagnóstico, control y de formulación de estrategias para la reducción del impacto ambiental generado por las organizaciones, teniendo en cuenta que la calidad de esta información depende de las metodologías aplicadas y recursos invertidos.

III Encuentro Nacional de Semilleros de Investigación de Ingeniería Industrial

Universidad Santo Tomás. Facultad de Ingeniería Industrial. 1 de noviembre de 2019 
Para la estimación de emisiones de contaminantes bajo la metodología TIER la caracterización de la flota de vehículos es vital, al incrementar la complejidad de la solución y reducir la incertidumbre de los resultados.

Los resultados reportados que usan formularios, facilitan la lectura de la información requerida por el ejecutor del programa, sin embargo al exportarla a un nuevo libro incrementa su funcionalidad al poder identificar la eficiencia ambiental de cada vehículo usado en la gestión logística de la organización.

\section{Referencias Bibliográficas}

[1] M. Varón y P. A. Cárdenas, «Guía para la elaboración de inventarios de emisiones atmosféricas,» Bogotá, 2017.

[2] D. Valencia, M. Muñoz, A. Ramirez, L. Builes y C. Hoyos, «Modelo para la estimación de emisiones vehiculares como herramienta para la gestión ambiental institucional,» Producción más limpia, vol. 10, nº 1, pp. 22-39, 2015.

[3] European Environment Agency, EMEP/EEA air pollutant emission inventory guidebook 2016 - Update Jul. 2018, Luxemburgo: Publications Office of the European Union, 2016.

[4] G. Polichetti, «Effect of travel restricción on PM10 concentrations in Naples: One year of experience,» Atmospheric Environment, vol. 151, pp. 12-16, 2017.

III Encuentro Nacional de Semilleros de Investigación de Ingeniería Industrial

Universidad Santo Tomás. Facultad de Ingeniería Industrial. 1 de noviembre de 2019 


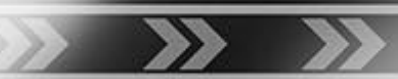

- 0.0 .0

\title{
PONENCIAS EN
}

\section{PRESENTACIÓN ORAL}

\author{
TRACK :GESTIÓN \\ ORGANIZACIONAL
}




\title{
Estudio de casos de emprendimientos locales apoyados por el centro de emprendimiento y desarrollo empresarial
}

\author{
Quintero Villamarín, Santiago ${ }^{1}$ \\ Mantilla León, Johan Reynaldo ${ }^{2}$ \\ Eduwin Andrés Flórez Orejuela ${ }^{3}$
}

\section{Resumen}

Este proyecto de investigación se centra en el estudio de casos de emprendimiento apoyados por el centro de emprendimiento y desarrollo empresarial en Bucaramanga. Inicialmente se estableció un formato para documentar los casos de emprendimiento bajo la metodología de estudio de casos, estableciendo aspectos que comparten todos los emprendimientos a documentar. Luego, se hizo la selección de casos a documentar basándose en tres criterios recomendados por un experto: Impacto local, Accesibilidad, Popularidad local. Los emprendimientos que fueron escogidos en la fase de preselección se escogieron revisando bases de datos del centro de emprendimiento y desarrollo empresarial en la Universidad Santo Tomás. Finalmente, se hizo la documentación de los diez casos de emprendimiento siguiendo el formato y concluyendo sobre los factores de éxito de los emprendimientos estudiados con el fin de replicarlos en nuevos proyectos.

\section{Palabras Claves}

Gestión Organizacional, Emprendimiento, Desarrollo Empresarial, Emprendimiento en Santander, Casos de Emprendimiento.

III Encuentro Nacional de Semilleros de Investigación de Ingeniería Industrial

Universidad Santo Tomás. Facultad de Ingeniería Industrial. 1 de noviembre de 2019 
1Universidad Santo Tomás, Sede Bucaramanga. Semillero de Emprendimiento.

Contacto: santiago.quintero@ustabuca.edu.co.

2 Universidad Santo Tomás, Sede Bucaramanga. Semillero de Emprendimiento. Contacto:

johanmantilla@ustabuca.edu.co.

3 Universidad Santo Tomás, Sede Bucaramanga. Docente titular de Emprendimiento y Desarrollo Empresarial.

Contacto: eduwin.florez@ustabuca.edu.co.

\section{Problema de Investigación}

Santander compone una gran parte de los emprendimientos a nivel nacional pues solo en el 2017 se registraron 14.756 empresas en la Cámara de Comercio de Bucaramanga, cifra que representa un 4,6\% de la creación de empresas en Colombia a año 2017. [1] [2] . No obstante, un indicador que contrarresta este indicador de crecimiento es el de cierre de empresas, pues en Santander se estima que un $85 \%$ de las empresas no superan los 5 años de operación [3], algo que es alarmante y que la Cámara de Comercio de Bucaramanga misma ha detectado y ha ido diseñando planes de acompañamiento y consultoría a Pymes con el fin de disminuir el porcentaje de cierre de empresas. La principal causa de este cierre de empresas tiene varias hipótesis. Hay quienes argumentan que se deben a falta de conocimientos en materias como producción, calidad, y similares y que los empresarios no están preparados para dar el siguiente paso hacia el crecimiento de su empresa por lo que terminan tomando decisiones que los hacen cerrar o caer en quiebra. En aras, de contribuir a solucionar este problema se propone un proyecto de investigación en el cual se documenten mediante una metodología de estudio de caso, diez (10) casos de emprendimiento localizados en Bucaramanga.

III Encuentro Nacional de Semilleros de Investigación de Ingeniería Industrial

Universidad Santo Tomás. Facultad de Ingeniería Industrial. 1 de noviembre de 2019 


\section{Antecedentes teóricos}

El emprendimiento tiene un tiempo de investigación relativamente corto comparado con otras áreas del conocimiento, no obstante, no se puede ignorar el hecho de que gran cantidad de intelectuales y académicos, se han enfocado en este tema como objeto de estudio, incluso aunque este se encuentre en una etapa "adolescente". Uno de los motores en cuanto a interés e inversión ha sido el mismo Estado, debido a que reconoce su importancia como eje económico en la sociedad, por lo que muestra interés en el emprendimiento como factor cultural que forme y eduque a los emprendedores, para que estos se enfrenten a la incertidumbre con herramientas que apoyen sus decisiones. [4]. El ejercicio del emprendimiento no es fácilmente descriptible, pues puede ser objeto de estudio desde diferentes niveles, personal, grupal y organizacional, también es campo variable en cuanto al contexto, y políticas que rodean al individuo. También puede ser objeto de estudio a partir el individuo, como ser psicológico formado por habilidades, cualidades y conocimientos que ofrecen herramientas para ejercer el trabajo emprendedor. Se piensa que estas herramientas pueden ser adquiridas junto a los pre saberes y experiencias de otros emprendedores que han logrado disminuir la incertidumbre en diferentes casos para ser objeto de enseñanza como lo planteo Howard Stevenson, quien se enfoca en el impacto que puede generar la formación de líderes comerciales por lo cual se considera imprescindible su enseñanza en la academia, en el momento que se observa las alternativas que poseen los líderes del futuro y se encuentra con dos grandes caminos, uno de ellos es el camino tradicional en el cual se han formado la mayor cantidad de líderes que contiene la sociedad, mediante el desarrollo personal en la escalera empresarial con mucho esfuerzo mediante pequeños pasos que generan desarrollo al interior de las organización y subiendo paulatinamente en la escala jerárquica. [5]. El segundo camino es mediante generadores de riqueza que observando una oportunidad comienzan un proyecto que crece con fuerza y dinamismo hasta consolidarse como una gran empresa que mediante modelos innovadores se concentra en el crecimiento personal ligado o de la mano del crecimiento empresarial, como es el caso de compañías como Apple. La conformación y crecimiento de nuevas empresas es un proceso complejo y muchas investigaciones han abordado el tema buscando comprender el proceso creando marcos de

III Encuentro Nacional de Semilleros de Investigación de Ingeniería Industrial 
referencia dinámicos que se adecuen y moldeen a experiencias similares para que haciendo uso de medidas correctivas se reduzca la incertidumbre que lleva en muchos casos al fracaso, los primero modelos de estudio concluyeron que el ejercicio del emprendimiento dependía de las características del individuo y su forma de observar el entorno para sacar provecho de este, observando oportunidades y encontrando retos que terminaba superando basado en actitudes y posteriores aptitudes que lo conducían a enfrentar los riesgos de forma decidida. [6]

\section{Objetivo General}

- Analizar casos de emprendimiento en Bucaramanga para el fomento de la mentalidad y cultura en la creación de empresas.

\section{Objetivos Específicos}

- Determinar los referentes de mentalidad y cultura emprendedora en Bucaramanga.

- Analizar los emprendimientos exitosos en Bucaramanga teniendo en cuenta la metodología de estudio de caso para emprendimiento.

- Elaborar la documentación de los casos analizados para que sirvan como referencia en la generación de mentalidad y cultura emprendedora

\section{Metodología}

En Ciencias Sociales, el estudio de caso es una estrategia de investigación que se centra en la comprensión de las dinámicas que se presentan en escenarios particulares. Por lo cual se considera que es una metodología adecuada para un estudio como el que se realizó. Para ello, se diseñó un formato que incluye aspectos comunes de los emprendimientos a estudiar. [7]. Después se realizó una búsqueda de información acerca de los casos de emprendimiento disponibles en las bases de datos del Centro de Emprendimiento Y Desarrollo Empresarial para una posterior selección mediante la matriz de priorización basada en criterios establecidos por un experto. En un último momento, se entrevistaron a los emprendedores en base a preguntas foco para documentar el caso.

III Encuentro Nacional de Semilleros de Investigación de Ingeniería Industrial

Universidad Santo Tomás. Facultad de Ingeniería Industrial. 1 de noviembre de 2019 


\section{Análisis de resultados}

Inicialmente, se diseñó el siguiente formato para realizar la recolección de datos:

\begin{tabular}{|c|c|}
\hline \multicolumn{2}{|l|}{ Caracterización de la empresa } \\
\hline Nombre & Nombre de la empresa \\
\hline Tiempo de operación & Responde a cuánto tiempo lleva la empresa en el mercado \\
\hline Directores & Gerente o persona a cargo de la empresa \\
\hline \multicolumn{2}{|l|}{ Documentación de caso } \\
\hline Introducción & Aquí se describe la empresa, sus características más importantes e inicios \\
\hline Etapa de crecimiento & Responde a cómo ha ido creciendo la empresa y estrategias usadas \\
\hline Problemas en el camino & Se describen problemáticas que hayan puesto en riesgo la empresa \\
\hline Solución de los problemas & Se describe cómo se afrontó los problemas del punto anterior \\
\hline Actualidad & Incluye cuál es el estado actual de la empresa, y qué visión tiene \\
\hline Conclusiones & Se destacan los aspectos más importantes del análisis del caso \\
\hline Referencias & Referencias \\
\hline
\end{tabular}

Tabla 1. Formato bajo metodología estudio de caso

Luego de esto, se listaron todos los emprendimientos locales más relevantes encontrados en las bases de datos del Centro Empresarial y Desarrollo Empresarial y se realizó la matriz de priorización

\begin{tabular}{|c|c|c|c|c|}
\hline \multirow{2}{*}{ Emprendimiento } & \multicolumn{4}{|c|}{ Criterio } \\
\cline { 2 - 5 } & Popularidad local & Accesibilidad & Impacto local & Total \\
\hline El vikingo & 5 & 5 & 5 & 15 \\
\hline Crezcamos & 4 & 5 & 5 & 14 \\
\hline Negrón & 5 & 4 & 5 & 14 \\
\hline Manos de azúcar & 3 & 5 & 4 & 12 \\
\hline Niña bonita & 3 & 5 & 4 & 12 \\
\hline Rosquetes Pinto & 5 & 1 & 5 & 11 \\
\hline
\end{tabular}

III Encuentro Nacional de Semilleros de Investigación de Ingeniería Industrial

Universidad Santo Tomás. Facultad de Ingeniería Industrial. 1 de noviembre de 2019 


\begin{tabular}{|c|c|c|c|c|}
\hline Kike Rodríguez & 3 & 4 & 4 & 11 \\
\hline Luxe Gold & 5 & 2 & 4 & 11 \\
\hline Terramonti & 3 & 3 & 4 & 10 \\
\hline Weekend Santander & 2 & 4 & 4 & 10 \\
\hline Bacca & 3 & 1 & 3 & 9 \\
\hline Bohor & 2 & 3 & 4 & 8 \\
\hline Freya & 2 & 2 & 3 & 7 \\
\hline Martina & 3 & 2 & 4 & 9 \\
\hline
\end{tabular}

Tabla 2. Matriz de priorización de casos a documentar

Finalmente, se realizó el trabajo de campo para documentar los 10 casos que obtuvieron mayor puntaje en la matriz.

\section{Conclusiones}

- Bucaramanga es un referente en mentalidad y cultura emprendedora en Colombia, ofrece una gran variedad de referentes en esta materia y mediante bases de datos del Centro de Desarrollo y Emprendimiento Empresarial, se logró identificar a diez emprendedores y conocer su trayectoria a fondo.

- Se estudiaron los emprendimientos bajo el formato establecido, viendo los principales problemas que tuvieron y cómo fueron resueltos estos problemas, así como también qué estrategias han implementado para el crecimiento, cómo ha sido éste y finalmente, cómo se ven a futuro.

- La documentación fue realizada con fuentes de primera mano lo cual es útil para abstraer los factores de éxito y replicarlos en nuevos proyectos.

\section{Referencias Bibliográficas}

[1 Cámara de Comercio de Bucaramanga, «Balance de la Economía de la Región,» 2017.

III Encuentro Nacional de Semilleros de Investigación de Ingeniería Industrial

Universidad Santo Tomás. Facultad de Ingeniería Industrial. 1 de noviembre de 2019 
[2 Cámara de Comercio de Bucaramanga, «14.756 empresas se crearon en ] Santander durante 2017,» Bucaramanga, 2016.

[3 N. Celedón, «En Santander se crean muchas empresas, pero de corto aliento,»] Vanguardia, 14 Agosto 2011.

[4 L. Zambrano, «Digital Unal,» 17 Noviembre 2016. [En línea]. [Último acceso: 2019]. [5 A. Castillo, «CCB,»12 Agosto 2017. [En línea].

[6 L. Portilla y H. Portilla, «Repositorio Salle,» 10 Febrero 2010. [En línea]. Available:

] http://repository.lasalle.edu.co/bitstream/handle/10185/3157/T11.10\%20P836m.pdf ?sequence $=1$.

[7 P. Martínez, «Redalyc,» 20 Julio 2006. [En línea]. Available:

] https://www.redalyc.org/pdf/646/64602005.pdf. 


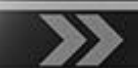

- 0.0 .0

\section{PONENCIAS EN}

\section{PRESENTACIÓN ORAL}

\section{TRACK :MEJORAMIENTO} DE PROCESOS 


\title{
Aplicación del método ERIN y rediseño de puesto de trabajo "porcionado" de carne
}

\author{
William Fernando Agudelo González ${ }^{10}$ \\ Santiago Giraldo Gámez ${ }^{2}$ \\ Mateo Gómez Duque ${ }^{3}$ \\ Elizabeth Pérez Mergarejo ${ }^{11}$
}

\section{Resumen}

El análisis ergonómico de los sistemas de trabajos contribuye con la disminución de las enfermedades musculoesqueléticas que afectan a los trabajadores. En esta investigación se realizó el análisis ergonómico al puesto de trabajo de porcionado de carne de una empresa de la industria de alimentos cárnicos. Fue utilizado el método Evaluación del Riesgo Individual ERIN para la evaluación ergonómica y fueron determinadas las posturas críticas de la tarea. Finalmente, se presenta una propuesta de intervención con el fin de disminuir el riesgo para los trabajadores de desarrollar desórdenes musculoesqueléticos, implementando nuevas herramientas para el desarrollo de sus actividades diarias.

\section{Palabras Claves:}

Desórdenes musculoesqueléticos, evaluación de puestos de trabajo, método ERIN.

\footnotetext{
${ }^{10}$ Universidad Pontificia Bolivariana, Sede Medellín. Semillero de Investigación en Productividad (SIPROC). Contacto: william.agudelog@upb.edu.co

${ }^{11}$ Universidad Pontificia Bolivariana, Sede Medellín. Docente asociado de Ergonomía y Seguridad y Salud en el Trabajo. Contacto: elizabeth.perezme@upb.edu.co
}

III Encuentro Nacional de Semilleros de Investigación de Ingeniería Industrial

Universidad Santo Tomás. Facultad de Ingeniería Industrial. 1 de noviembre de 2019 


\section{Problema de Investigación}

La evaluación ergonómica de puestos de trabajo es un factor fundamental para el desarrollo de las organizaciones. Busca la mejora continua de diversos indicadores, por ejemplo, la eficacia y la eficiencia de los trabajadores en su labor y de los indicadores de salud. Una de las disciplinas más utilizadas para rediseño de puestos de trabajo, es la ergonomía, de donde se derivan diferentes métodos para la resolución de problemas de salud y productividad. Sin embargo, se cuenta con pocos métodos fáciles de aplicar y de bajo costo para hacer un diagnóstico ergonómico en el lugar de trabajo. Pregunta de investigación: ¿El uso de métodos ergonómicos de evaluación fáciles de usar puede contribuir con la transformación de las condiciones de trabajo en las empresas?

En esta investigación se analizó el puesto porcionado de carne en una empresa del sector de transformación de alimentos cárnicos. En este puesto los trabajadores presentan afectaciones en diferentes partes del cuerpo, debido a las características poco ergonómicas del puesto, a la alta frecuencia de movimiento y las bajas temperaturas del área. Por estas razones se realizó la evaluación ergonómica en el puesto de trabajo, y considerando estos resultados se realizó la propuesta de intervención y se analizó su impacto ergonómico, productivo y económico.

\section{Antecedentes teóricos}

Los desórdenes musculoesqueléticos (DMEs) son enfermedades que afectan al sistema musculoesquelético causando dolor e incapacidad física y motora en las personas [1], por ejemplo, el síndrome del túnel del carpo. Los DMEs de origen laboral constituyen en la actualidad la mayor causa de discapacidad en los trabajadores a nivel mundial. La ergonomía es la disciplina científica que tiene mayor impacto sobre la disminución de estas enfermedades cuando se aplican sus principios en el diseño de los sistemas de trabajo [2].

III Encuentro Nacional de Semilleros de Investigación de Ingeniería Industrial

Universidad Santo Tomás. Facultad de Ingeniería Industrial. 1 de noviembre de 2019 
Son múltiples los factores de riesgo a los que se exponen los trabajadores durante la realización de sus tareas y que aumentan la posibilidad de padecer DMEs. Desde la ergonomía se han desarrollado métodos que evalúan el nivel de exposición a estos factores, por ejemplo: RULA, REBA, ROSA, OCRA y ERIN. Siendo este último método el utilizado en esta investigación. La elección del método Evaluación del Riesgo Individual (ERIN) se basó en que da respuesta a las necesidades actuales de las empresas, las cuales buscan que los ergónomos evalúen y diseñen los sistemas de trabajo de forma económica y rápida. ERIN fue desarrollado con el objetivo de apoyar la evaluación ergonómica de puestos de trabajo. Fue concebido para ser utilizado por personal no experto y que con un tiempo mínimo de entrenamiento pudieran realizar la evaluación masiva de puestos y tareas [3]-[5]. Una de las principales fortalezas de este método es que de forma rápida el evaluador puede identificar los factores de riesgo de DMEs presentes en los puestos e identificar las formas de mitigar la presencia de estos factores durante el proceso de evaluación. Esta fortaleza amplía el alcance en el uso del método, permitiendo usarlo en la evaluación y en la proyección de las propuestas de intervención.

\section{Objetivo General}

Desarrollar el análisis ergonómico al puesto de trabajo de porcionado de carne aplicando un método ergonómico de fácil aplicación y de bajo costo que permita la posterior transformación de las condiciones de trabajo.

\section{Objetivos específicos}

- Identificar la presencia de factores de riesgo de DMEs en el puesto de trabajo porcionado utilizando el método ergonómico de evaluación ERIN.

- $\quad$ Elaborar una propuesta de rediseño para el puesto de porcionado que disminuya el nivel de exposición a factores de riesgo de DMEs y mejore el desempeño del sistema.

\section{Metodología}

III Encuentro Nacional de Semilleros de Investigación de Ingeniería Industrial

Universidad Santo Tomás. Facultad de Ingeniería Industrial. 1 de noviembre de 2019 
El método principal en esta investigación fue ERIN. Se utilizó ya que evalúa los factores de riesgo presentes en el puesto de trabajo de porcionado de carne: postura del tronco, brazo, muñeca, cuello y su frecuencia de movimiento; el ritmo, dado por la velocidad de trabajo y la duración efectiva de la tarea; la intensidad del esfuerzo, resultado del esfuerzo percibido por el evaluador y su frecuencia, y la autovaloración -percepción del estrés referido por el sujeto sobre la tarea que realiza [3]-[5]. Se utilizó la hoja de trabajo ERIN para determinar el nivel de riesgo. Otros métodos:

- Diagrama de proceso: se utilizó para determinar las actividades en el puesto de trabajo.

- Cámara de video: se utilizó para obtener una precisión más alta en los criterios de evaluación. Cuestionarios estructurados: se utilizaron para obtener información específica de los trabajadores sobre la tarea.

- $\quad$ Norma ISO 14738: proporcionó los parámetros necesarios para un buen rediseño de puesto de trabajo [6].

- ACOPLA 95 (dimensiones antropométricas población colombiana): se utilizó como fuente de datos para el diseño físico [7].

- $\quad$ SolidEdge: se utilizó para proyectar el rediseño del puesto de trabajo.

\section{Análisis de los resultados}

En la tabla 1 se presenta el resumen de la evaluación con el método ERIN antes y después de las propuestas de intervención.

Tabla 1. Resultados de la evaluación con el método ERIN.

\begin{tabular}{ccc}
\hline Variables & Actual & Propuesta \\
\hline Postura y frecuencia movimiento del tronco & 4 & 4 \\
Postura y frecuencia movimiento del brazo & 5 & 2 \\
Postura y frecuencia movimiento de las muñecas & 6 & 4
\end{tabular}

III Encuentro Nacional de Semilleros de Investigación de Ingeniería Industrial

Universidad Santo Tomás. Facultad de Ingeniería Industrial. 1 de noviembre de 2019 
Postura y frecuencia movimiento del cuello

Ritmo
Intensidad del Esfuerzo
Autovaloración
Riesgo Global

Nivel de riesgo

$\begin{array}{rr}6 & 6 \\ 6 & 6 \\ 2 & 2 \\ 0 & 0 \\ 29 & 24\end{array}$

Alto Medio

El resultado de la evaluación actual, arrojó un riesgo alto, por lo cual de acuerdo al método ERIN se deben implementar cambios en corto plazo. Se encontró que la parte del cuerpo más comprometida fue la muñeca (puntaje de 6) y de segundo lugar el cuello (puntaje de 6), debido al constante movimiento y rapidez con que se realiza la tarea.

Los puntos más críticos dentro del puesto, fueron los criterios más importantes para el desarrollo del rediseño (Fig. 1), en cual se usó la norma ISO 14738 y el estudio ACOPLA 95. Dentro de estos parámetros que cambiaron en el rediseño están: la altura de la mesa donde se porciona la carne, la cual es de material inoxidable, la implementación de tolva en acero inoxidable, además ajustes en la pesa, para que la pantalla quedará a la altura de ojos de los trabajadores. Por último, uno de los puntos más importantes fue el cambio de cuchillos convencionales, por un cuchillo ergonómico tipo pistola y con hoja en acero inoxidable, para mejorar la posición de la muñeca en su postura neutra (Fig. 2).

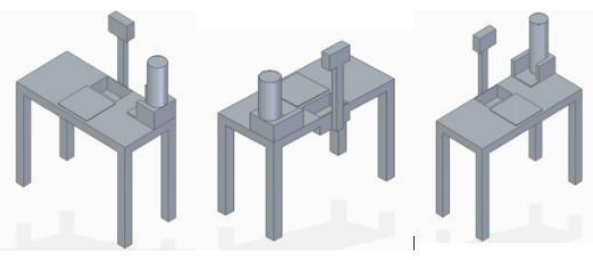

Figura 1 Rediseño del puesto de porcionado. Fuente propia.

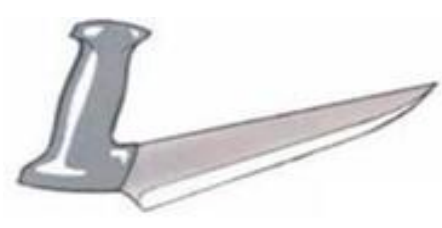

Figura 2 Cuchillo ergonómico. Fuente: propia.

\section{Conclusiones}

La intervención en la herramienta de trabajo (cuchillo) fue el aspecto principal que redujo la calificación arrojada por el método ERIN en el rediseño, pasando de un riesgo alto a un riesgo medio. El cuello no obtuvo modificaciones en su puntaje por la naturaleza de la tarea. El método

III Encuentro Nacional de Semilleros de Investigación de Ingeniería Industrial

Universidad Santo Tomás. Facultad de Ingeniería Industrial. 1 de noviembre de 2019 
ERIN permitió de forma práctica identificar los principales factores de riesgo y desarrollar propuestas de intervención ajustadas a las necesidades más urgentes del puesto de trabajo.

\section{Referencias Bibliográficas}

[1] I. Kuorinka and L. Forcier, Eds., Work related musculoskeletal disorders (WMSDs): a reference book for prevention. London, Bristol, PA: Taylor \& Francis, 1995.

[2] D. Colombini and E. Occhipinti, "Preventing upper limb work-related musculoskeletal disorders (UL-WMSDS): New approaches in job (re)design and current trends in standardization," Appl. Ergon., vol. 37, no. 4, pp. 441-450, Jul. 2006.

[3] Y. Rodríguez, "Individual Risk Assessment (ERIN): Method for the Assessment of Workplace Risks for Work-Related Musculoskeletal Disorders," in Handbook of Research on Ergonomics and Product Design, IGI Global, 2018, pp. 1-27.

[4] Y. Rodríguez, "ERIN: A practical tool for assessing exposure to risks factors for workrelated musculoskeletal disorders,” Adv. Intell. Syst. Comput., vol. 820, pp. 369-379, 2019.

[5] Y. Rodríguez, S. Viña, and R. Montero, "ERIN: A practical tool for assessing work-related musculoskeletal disorders," Occup. Ergon., vol. 11, no. 2-3, pp. 59-73, 2013.

[6] ISO 14738, "ISO 14738:2002 Safety of machinery - Anthropometric requirements for the design of workstations at machinery." ISO/TC 159/SC 3 Anthropometry and biomechanics, 2002.

[7] J. Estrada, J. Camacho, M. Restrepo, and C. Parra, "Parámetros antropométricos de la población laboral colombianaAcopla-95." Universidad de Antioquia. Instituto de Seguros Sociales, 1995.

III Encuentro Nacional de Semilleros de Investigación de Ingeniería Industrial

Universidad Santo Tomás. Facultad de Ingeniería Industrial. 1 de noviembre de 2019 


\title{
Análisis estadístico de la producción y exportación de la Cadena hortofrutícola en Colombia y proyecciones usando técnicas de pronóstico.
}

\author{
Walter Jeffrey Rodriguez Bohórquez ${ }^{12}$ \\ Diego Noel Betancourt Alonso 13 \\ Diana Catalina Moreno Guarín ${ }^{14}$
}

\section{Resumen}

El proyecto tiene como objetivo caracterizar estadísticamente la producción y exportación de la cadena productiva hortofrutícola en Colombia basado en los datos de las fuentes públicas. Con ello poder generar oportunidades estratégicas de investigación en el área agrícola basado en el potencial de los productos analizados. Para caracterizar estadísticamente la cadena hortofrutícola se necesitó de bases datos públicos con información actualizada; para lo cual se tomaron los datos de producción de Agronet y de exportación de Maro. Se requirió realizar una homogeneización de cada base para hacerlas similares y comparables. Posteriormente se identificaron los productos destacados (Frutas y hortalizas) respecto a producción y respecto a exportación y basado en ello se priorizaron los productos que poseen potencial en ambos aspectos; estos fueron, en frutas el Banano, el Aguacate, la Piña y la Naranja y en Hortalizas el Plátano, la Yuca y el Tomate. Con los datos obtenidos de Agronet de producción y de MARO de exportación de los productos priorizados, mediante el software Minitab 19 se graficó la serie de tiempo y se utilizaron técnicas para realizar un pronóstico hasta el año 2022. De esta manera se

\footnotetext{
${ }^{12}$ Universidad ECCI, Sede Bogotá. Contacto: walterj.rodriguezb@ecci.edu.co.

${ }^{13}$ Universidad ECCI, Sede Bogotá. Contacto: diegon.betancourtal@ecci.edu.co.

${ }^{14}$ Universidad ECCI, Sede Bogotá. Docente asociada Dirección de ingeniería industrial. Contacto: dmorenog@ecci.edu.co.
}

III Encuentro Nacional de Semilleros de Investigación de Ingeniería Industrial

Universidad Santo Tomás. Facultad de Ingeniería Industrial. 1 de noviembre de 2019 
recomienda trabajar en temas de investigación con la piña y el aguacate por su alza en producción y exportación.

\section{Palabras Claves}

Sector agrícola, Cadena Hortofrutícola, Productos priorizados, Producción, Exportación.

\section{Problema de Investigación}

Dado el surgimiento de diversos acontecimientos mundiales como la globalización, las cadenas de valor integradas, la rápida innovación tecnológica, las restricciones ambientales entre otros, la agricultura retorna a la agenda mundial; lo cual puede llegar a ser beneficioso para países como el nuestro, que tiene una dotación de recursos agrícolas no explotados plenamente [1]. Según la Sociedad de Agricultores de Colombia - SAC en el año 2018 el agro participó en el 6.2\% del PIB total, con un área cosechada de 4.1 millones de hectáreas y un volumen de producción de 54.6 millones de toneladas [2]. Sin embargo no toda la comida destinada al consumo humano se aprovecha, a lo largo de la cadena alimentaria se generan pérdidas y desperdicios de alimentos; en 2010 se perdieron en Colombia 1.426 .932 toneladas de frutas y verduras en la etapa de pos cosecha lo cual corresponde al $39 \%$ total de la oferta de frutas y verduras de ese año [3].

En Colombia además de la dispareja tenencia de tierras, se utilizan técnicas obsoletas que encarecen la operación y hacen que la tierra tenga una menor vida útil [4]. Estos inconvenientes puntuales del sector, son propios de la definición de un marco regulatorio; pertenecientes a la falta de planeación. No es posible concebir la reducción de las pérdidas, ni la distribución de suelos óptima si no hay correcta definición de los propósitos.

El Estado a través de instituciones públicas difunde información, datos, cifras y estadísticas de los sectores productivos, de interés para empresarios, entidades e investigadores, con el objetivo de contribuir a la orientación de las decisiones privadas y las políticas públicas. Estos datos y cifras presentan por lo general desactualizaciones, desaciertos, y diferencias entre ellas que pueden llegar a repercutir negativamente sobre las decisiones que se han tomado y se tomarán;

III Encuentro Nacional de Semilleros de Investigación de Ingeniería Industrial

Universidad Santo Tomás. Facultad de Ingeniería Industrial. 1 de noviembre de 2019 
ya sea políticas, ideas de negocio o investigaciones. ¿Es posible estandarizar un procedimiento para identificar y pronosticar estadísticas relevantes del agro que tenga replicabilidad y coherencia?

\section{Antecedentes teóricos}

La cadena hortofrutícola comprende desde la producción de bienes de origen agropecuario como frutas frescas, vegetales y granos, hasta la transformación industrial de bienes como jugos, enlatados, mermeladas, compotas, pulpas y salsas [5]. Dadas las condiciones topográficas y la diversidad de climas en el suelo colombiano este presenta las mejores circunstancias para cosecha [6]. Se estima de acuerdo a cifras dadas por la FAO durante el año 2011 anualmente se pierden 1300 millones de toneladas en comida las cuales representan el 33\% de la oferta anual. Para Colombia esta situación no es ajena, de la oferta total aproximada de 28,5 millones de toneladas ocurren pérdidas y desperdicios aproximados de 9,76 millones de toneladas [3]. Es imperativo de corregir las pérdidas y desperdicios, pues estas representan más de un tercio de la oferta, es necesario estudiar y planificar de manera correcta dado a que en muchas ocasiones las razones obedecen a problemas distintos al control de plagas y diversas anomalías ambientales.

\section{Objetivos de investigación}

Objetivo general: Caracterizar estadísticamente la producción y exportación de la cadena productiva hortofrutícola en Colombia para realizar una proyección y generar oportunidades estratégicas de investigación en el área.

\section{Objetivos específicos:}

- Definir y aplicar un procedimiento para la identificación de las estadísticas relevantes de bases de datos, su extracción y análisis

- Compilar, homogeneizar y analizar estadísticamente las series de datos extraídas de las bases de datos para establecer un sistema de productos priorizados.

III Encuentro Nacional de Semilleros de Investigación de Ingeniería Industrial

Universidad Santo Tomás. Facultad de Ingeniería Industrial. 1 de noviembre de 2019 
- Analizar los datos obtenidos y generar una proyección mediante técnicas de pronóstico al año 2022.

\section{Metodología}

- Selección de las bases de datos: Se escogió a Agronet para extraer datos de la producción, y a MARO para extraer los datos de las exportaciones de la cadena hortofrutícola.

- Extracción de datos: Se realizó la descarga de cada uno de los productos de acuerdo al reporte “Área, Producción y Rendimiento Nacional por Cultivo”, de Agronet, luego estas se unificaron en un solo archivo. Se realizó la descarga de las exportaciones en MARO, dicha base de datos permite realizar descargas por clasificación CIIU. Para el caso de frutas se realizó la descarga de: Cultivo de plátano y banano, y Cultivo de frutas tropicales y subtropicales. Y para el caso de hortalizas se realizó la descarga de Cultivo de hortalizas, raíces y tubérculos

- Procesamiento de datos: Se tomó la decisión para el análisis, de tener en cuenta únicamente la información desde el año 2010 hasta el año 2016 para Agronet; una vez fijada la línea de tiempo se realizó una tabla dinámica que permitió hallar la producción en Toneladas por producto y año a nivel nacional. Con los datos descargados de MARO también se realizó una tabla dinámica que permitió hallar la exportación en Kilogramo neto por producto y año (20102018).

- Homogeneización de datos: De los productos descargados, no todos pertenecen a frutas y hortalizas, y además existen ítems que incluye más de un producto o que un mismo producto se encuentre dividido en diferentes ítems. Por lo tanto, lo que se busca es tener una correcta clasificación y que cada ítem abarque solamente un producto (Fruta o hortaliza).

- $\quad$ Priorización de los productos: Se identificaron los productos en común de ambas bases y esos productos que coincidieron fueron determinados como los productos priorizados.

III Encuentro Nacional de Semilleros de Investigación de Ingeniería Industrial 
- Proyección a 2022: Para ello se utilizó el software Estadístico Minitab 19, el cual permite detectar tendencias, resolver problemas y descubrir información valiosa en los datos; se realiza la descarga de la versión de prueba, válida por 30 días.

\section{Análisis de resultados}

- Producción Nacional. Frutas: Ventaja significativa del banano respecto a los demás productos, por ser un producto permanente que se encuentra en 31 de los 32 departamentos del país [7] en parte eso explica el alto nivel de producción nacional por otra parte variaciones superiores a $10 \%$ en productos como el aguacate, mango y piña entre el periodo 2017 a 2018 debido a la asistencia técnica integral y los modelos tecnológicos implementados [7]. Coincidencia en cuanto a área sembrada y producción de los productos destacados, refleja cierta proporcionalidad, sólo presenta diferencias en cuanto a la denominación de la naranja con datos asociados a Asohofrucol donde figura en general como la línea de cítricos [7]

- Producción Nacional. Hortalizas : La tendencia creciente de la papa se debe en parte a un comportamiento superavitario [8]así mismo la Yuca como la segunda hortaliza más producida cabe notar que este ítem está compuesto por Yuca y Yuca industrial de igual forma el Plátano está compuesto por Plátano y Plátano de exportación su variación obedece a que el primero solo tiene registro durante los dos primeros años, sin importar el registro este producto al igual que el banano es dominante en la mayoría de las regiones y encabezan las listas, así mismo presentan altos niveles de crecimiento de área cultivada [7] por otra parte el plátano es considerado un factor ideal para la elaboración de productos fritos, que se considera elemento fundamental en la dieta de un Colombiano [9] así mismo el tomate constituye elemento vital en la dieta de cada colombiano y se presenta en las regiones de mayor producción [10]

III Encuentro Nacional de Semilleros de Investigación de Ingeniería Industrial 
- Exportación Frutas: Se encuentra coincidencia con los 5 productos destacados (Banano, Aguacate, Naranja, Lima y piña) y los resultantes de acuerdo al informe [11] así mismo que estos correspondían al $72.89 \%$ del total las exportaciones del sector por otra parte hechos significativos como [11] destaca el crecimiento de 2016 a 2017 de la naranja y el aguacate, y menciona que para la naranja es debido a que se duplicaron las exportaciones hacia a Ecuador y hacia las islas del caribe y para el caso del aguacate por la apertura de mercado hacia Bélgica y Portugal.

- $\quad$ Exportación Hortalizas: El Plátano al igual que el banano (Productos que en la mayoría de informes están incluidas en el mismo ítem) presentan una gran variabilidad en la cantidad de toneladas exportadas, pese a ello sigue siendo el producto perteneciente a hortalizas más exportado Se aprecia el crecimiento exponencial en las exportaciones del ñame tal y como lo indica también [12]. Por su parte la lechuga y la yuca en los últimos periodos muestran un ligero decrecimiento, mientras que el Tomate pese a su variabilidad muestra una ligera tendencia positiva en los últimos periodos.

\section{Conclusiones}

Para ultimar se concluye que un procedimiento válido para la selección correcta de una fuente de información y más en este contexto donde se necesita orientar la cifras al menor error posible es la determinación de parámetros tales como la actualización, volumen de datos por descarga y el carácter global de la información de este modo estos esclarecen el curso de la extracción y procesamiento para a posteriori arrojar recomendaciones como la base de datos MARO es la mejor porque define métodos de priorización y posibilita el agrupamiento de producto Por otra parte fue posible realizar los pronósticos de producción y exportación haciendo uso de uso de las diferentes técnicas de series de tiempo; las medidas de desempeño que ofrece la herramienta respecto al ajuste de la serie de datos permite evidenciar si este genera o no confiabilidad en los pronósticos. Basado en los pronósticos generados y en las medidas de desempeño se recomienda trabajar en temas de investigación con la piña y el aguacate por su alza en producción y exportación y con el tomate por su producción estable y su alza en exportación.

III Encuentro Nacional de Semilleros de Investigación de Ingeniería Industrial 


\section{Referencias Bibliográficas}

[1] J. J. Perfetti, Á. Balcazar, A. Hernández, and J. Leibovich, Políticas para el desarrollo de la agricultura en Colombia. 2013.

[2] SAC, "Sociedad de agricultores en Colombia," 2019. .

[3] Departamento Nacional de Planeación, "Pérdida y desperdicio,” Ria, vol. 39, p. 116, 2016.

[4] UPRA, "Mercado de tierras rurales productivas en Colombia," Unidad Planif. Rural Agropecu., pp. 95-119, 2015.

[5] Dirección Nacional de Planeación, “Cadena Hortofrutícola,” pp. 105-122, 2014.

[6] Procolombia, "Inversión en el sector hortofrutícola," 2016.

[7] Asohofrucol, "Revista de la asociación hortifrutícola de colombia, asohofrucol - fnfh," Bogotá D.C, p. 54, 2019.

[8] Asociacion hortifruticola de Colombia, "Balanza comercial 2016 vs 2015," no. 19, pp. 12-3, 2016.

[9] V. Yepes, "Plátano y banano, ideales para alimentos funcionales," 2019. .

[10] Ministerio de Salud, Perfil nacional de consumo de frutas y verduras. 2013.

[11] Asohofrucol, "Congreso Nacional de Productores de Plátano de Colombia Por quinta vez,” Bogotá D.C, p. 52, 2018.

[12] Asohofrucol, "Balance Del Sector Hortifruticultura," Minist. Agric. y Desarro. Rural, vol. 11, no. 3, pp. 287-301, 2018.

III Encuentro Nacional de Semilleros de Investigación de Ingeniería Industrial

Universidad Santo Tomás. Facultad de Ingeniería Industrial. 1 de noviembre de 2019 


\title{
Optimización del proceso de tindalización para Residuos \\ Orgánicos
}

\author{
John Alejandro Garnica Avila ${ }^{15}$ \\ Pedro Nel Martínez Henao ${ }^{16}$
}

\section{Resumen}

El siguiente documento presenta la metodología para optimización del proceso de tindalización de residuos orgánicos (TRO) desarrollado en centro de acopio del campus Nueva Granada (CNG), en el marco del proyecto de iniciación científica PIC-ING-2919 financiado por la Universidad Militar Nueva Granada (UMNG). Se realiza con el objetivo de optimizar el (TRO) y plantear mejoras en el proceso de obtención de agua tratada y material orgánico apto para la reutilización en otros procesos bien sea como abono o como material agregado para compostaje llegando a minimizar costos y tiempo de operación, se validan los resultados mediante la simulación de balanceo de la línea de producción. Para tal efecto, se parte de la caracterización de los equipos y material orgánico procesado. Como resultado práctico se identifican solo dos (2) modos de transformación de residuos orgánicos, X1(Proceso de tindalización) el cual permite aprovechar el agua destilada y reutilizarla en el siguiente proceso X2 (Proceso de manejo de lixiviados por lavado). De esta manera se decide desarrollar la optimización del proceso mediante programación lineal. Para los dos procesos se desea minimizar el costo de tratamiento y conocer la proporción de los lotes obtenidos en una jornada laboral de 8 horas; este último es el proceso es el más. Por último, se evidencian las recomendaciones en el lavado de material orgánico, manejo de lixiviados, aprovechamiento de la capacidad del reactor, cambio de la capacidad de la caldera y la relevancia de la bomba de vacío, para así llegar a un óptimo en la producción.

\footnotetext{
${ }^{15}$ Universidad Militar Nueva Granada, Campus Cajicá, Semillero SIDI. Contacto u5800701@unimilitar.edu.co

${ }^{16}$ Universidad Militar Nueva Granada, Campus Cajicá. Magister en Automatización Industrial, docente titular. Contacto: pedro.martinez@unimilitar.edu.co
}

III Encuentro Nacional de Semilleros de Investigación de Ingeniería Industrial

Universidad Santo Tomás. Facultad de Ingeniería Industrial. 1 de noviembre de 2019 


\section{Palabras claves}

Optimización, Balance de línea, Tindalización, lixiviados, Producción por lotes, residuos orgánicos.

\section{Introducción}

La importancia de optimizar los métodos convencionales para el tratamiento de residuos orgánicos se ve reflejada en el impacto ambiental que los subproductos ofrecen a la biodiversidad, dicho impacto es sustentable y beneficioso tanto para el ámbito académico a través de una gestión ambiental, como para la economía local minimizando costos y creando oportunidades para la comunidad relacionada.

La tindalización, es un proceso de esterilización por medio de calor discontinuo que junto con la lixiviación hacen parte del funcionamiento de la planta de acopio de la UMNG, el producto final de estos dos procesos es material que puede ser usado para la remediación de suelos con los parámetros necesarios en los cultivos de hortalizas. Optimizar estos procesos garantiza que la productividad de la planta se incremente, de forma que el producto tenga un alcance comercial, dicha optimización se logra a través de una metodología que incluye varios estudios como la caracterización del proceso de tindalización, la investigación de operaciones aplicada, y la toma de decisiones para un resultado eficiente de la planta de acopio.

\section{Planteamiento del problema de investigación}

El impacto de la transformación de los residuos sólidos aumenta cada vez más a través de los años gracias a procesos que enfatizan en aprovechar al máximo los componentes de los residuos que ofrecen posibilidad de reincorporarse al ambiente, no es suficiente la adecuada separación de residuos para sacar un producto biodegradable e incluirlo en la economía local. Dentro de la jerarquía en la gestión de residuos, tratar los residuos se ha convertido en una oportunidad para que se investigue y se diseñe la forma de aprovechamiento más adecuada del residuo. La tindalización es uno de los procesos que buscan

III Encuentro Nacional de Semilleros de Investigación de Ingeniería Industrial

Universidad Santo Tomás. Facultad de Ingeniería Industrial. 1 de noviembre de 2019 
la eliminación de fertilizantes líquidos y destrucción de agentes patógenos y aguas residuales que generen riesgos al medio ambiente, con un segundo propósito ambiental para los productos que este proceso genera. En la Universidad Militar Nueva Granada sede Campus Cajicá, se encuentra el centro de acopio de residuos, donde se instaló maquinaria para el tratamiento de los residuos orgánicos por esterilización a calor, de manera que el producto se reutilice para compostaje en las mismas instalaciones del campus; ahora bien, no se está aprovechando al máximo y se busca darle un mejor uso a través de la optimización de procesos, esto implica el análisis de utilización de la maquinaria, registro de tiempos de intervención y costos operativos del proceso para definir la solución con una mayor producción. Como problema de investigación se buscan alternativas de mejora que permitan aumentar la eficiencia de la maquinaria instalada por medio de sistemas lineales para plantas de producción. Se plantea la linealización para la selección de dos procesos en la optimización del manejo de residuos en la planta 1. Proceso de tindalización, 2. Proceso de manejo de lixiviados por lavado, y se busca minimizar el costo de tratamientos de los materiales en el manejo de residuos orgánicos. Como resultado se obtiene la minimización del costo de tratamientos en materiales orgánicos, se aprovecha el agua destilada en el proceso de tindalización con uso en el procedimiento del lavado de material orgánico para el proceso de lixiviados. Se obtiene el subproducto para la fabricación de compostaje, que sirve como nutriente y estabilizante del suelo ya que ayuda a remediar la carencia de materia orgánica de éstos y contribuye físicamente a su fijación.

\section{Desarrollo de antecedentes}

Si bien no existe una teoría completamente definida para la lixiviación, puede considerarse los siguientes procesos para la separación de residuos orgánicos de uno o más compuestos presentes en un sólido poniéndolos en contacto con una fase líquida [1].

Ahora bien, para la minimización de residuos orgánicos como una política ambiental empresarial como lo expone Cardona [2] es que existe una forma diferente de producir los bienes que la sociedad requiere, utilizando de manera eficiente los recursos naturales sin producir residuos que amenacen la biodiversidad, la salud humana y que generen valor agregado mediante una gestión ambiental adecuada haciendo un manejo de gestión para la minimización de los residuos permitiendo minimizar costos y mejorar la rentabilidad de la empresa. Según el modelo de optimización conceptual para el

III Encuentro Nacional de Semilleros de Investigación de Ingeniería Industrial 
aprovechamiento sustentable de residuos orgánicos presentado por Castañeda \& Rodríguez [3] como una herramienta de apoyo para la toma de decisiones en la planificación y gestión de residuos sólidos orgánicos; obtiene un modelo mediante el aprovechamiento de compostaje aeróbico y lombricultivos, optimizando el sistema con el ahorro de emisiones de gases efecto invernadero y la reducción total de costo de disposición final de residuos sólidos orgánicos en rellenos sanitarios. En el presente trabajo, se emplea la metodología de medición de la eficiencia de equipos (OEE) presentado por Mohr [4] cuyo trabajo tuvo como objetivos:

- Detectar las fallas más comunes a fin de mejorar los puntos débiles de la planta • Reducir los costos relacionados con las pérdidas de mantenimiento y calidad

- Establecer un costo efectivo de mantenimiento.

Conviene subrayar el trabajo sobre la medición continua de la calidad del vapor desarrollado por Rageh [5] y que sirve como referente de comparación para el proceso de tindalización, la cual se ocupa de la medición, el análisis y búsqueda adecuada de los parámetros físicos para analizar la calidad de la esterilización por vapor saturado. Este trabajo tiene como objetivo determinar el sistema de parámetros críticos del generador de vapor para operar de acuerdo con La norma CSN 285 en un sistema completamente aislado y estable. Por otra parte, es indicado hacer una breve reseña de los conceptos y lenguaje referente a los modelos matemáticos de optimización [6]. Si bien la investigación operativa tiene varias estrategias de abordar la solución a problemas (lineal, no lineal, enteras, estocásticas, multiobjetivo) y que han evolucionado a la aplicación de la inteligencia artificial, la cual permite una convergencia más eficiente a la solución de problemas de optimización.

\section{Propósito y fundamentación}

Mediante el proceso de tindalización se busca hacer la eliminación de lixiviados y destrucción de patógenos y aguas residuales que generan riesgos al medio ambiente.

La importancia de generar en el proceso de tindalización un material orgánico que sirva como agregado o como sustrato para la elaboración de abono en el cultivo de plantas es una necesidad apremiante en la que la UMNG está apoyando investigaciones las cuales se desarrollan en las áreas de ingeniería ambiental e ingeniería industrial y el cual es utilizado en el programa de horticultura para la siembra de hortalizas.

III Encuentro Nacional de Semilleros de Investigación de Ingeniería Industrial

Universidad Santo Tomás. Facultad de Ingeniería Industrial. 1 de noviembre de 2019 
Otro manejo del sustrato generado es la utilización para la elaboración de adoquines mediante la utilización de resinas epóxicas que sirvan como material aglutinante del material agregado el cual es molido y prensado.

\section{Objetivos de investigación}

Objetivo general: Optimizar el proceso de tindalización en el manejo de residuos orgánicos que se realiza en el centro de acopio de la UMNG haciendo el análisis de utilización de la maquinaria emplazada, registro de tiempos de intervención y costos operativos del proceso, de forma que el subproducto se emplee en otros procesos de impacto ambiental dentro de la misma universidad.

\section{Objetivos específicos}

- Optimizar el proceso de tindalización de residuos orgánicos manejado en el centro de acopio de la UMNG

- Simular el proceso de tindalización para el manejo de residuos orgánicos y hacer el balanceo de línea.

- Proponer alternativas de mejora que permitan aumentar la eficiencia de la maquinaria instalada en el centro de acopio.

\section{Metodología}

La primera parte de a metodología empleada abarca la recolección de información, tanto referencias de proyectos afines terminados y temáticas ambientales, como sistemas de operación óptimos para distribuciones de planta, posterior a la recolección de varias ideas se aborda la problemática evidenciando cada uno de los factores que se pueden mejorar por medio del perfeccionamiento de operaciones, se realiza el diagrama del proceso de tindalización actual, Fig.(1) se toman tiempos y distancias requeridas en dicho proceso, se realiza también un diagrama de flujo en el proceso de tindalización del estado actual de la planta con todos los componentes y equipos, Fig.(2) .

III Encuentro Nacional de Semilleros de Investigación de Ingeniería Industrial

Universidad Santo Tomás. Facultad de Ingeniería Industrial. 1 de noviembre de 2019 


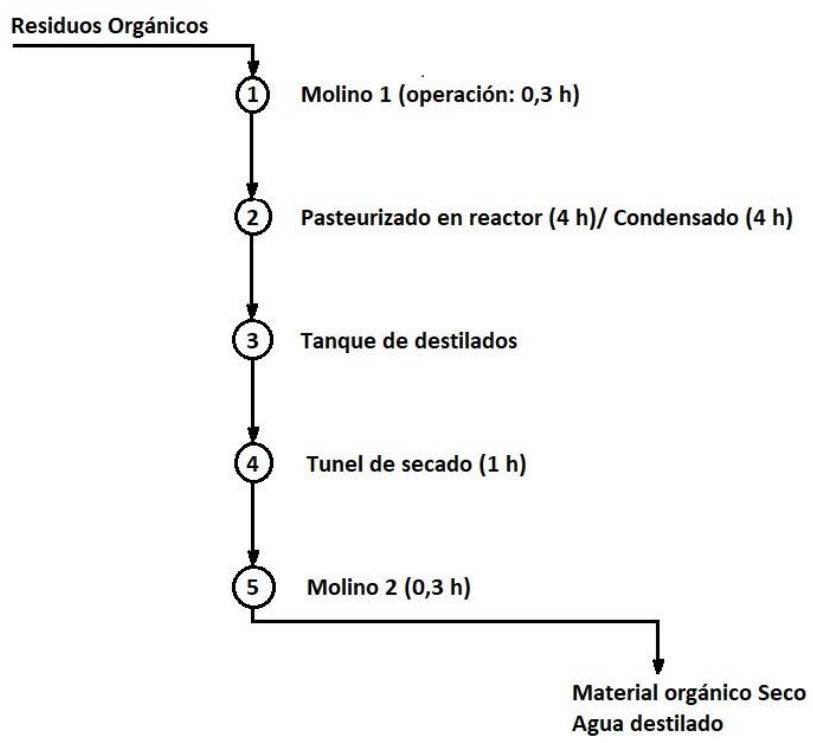

figura 1. Diagrama proceso de Tindalización actual en (CNG). Fuente: Propia

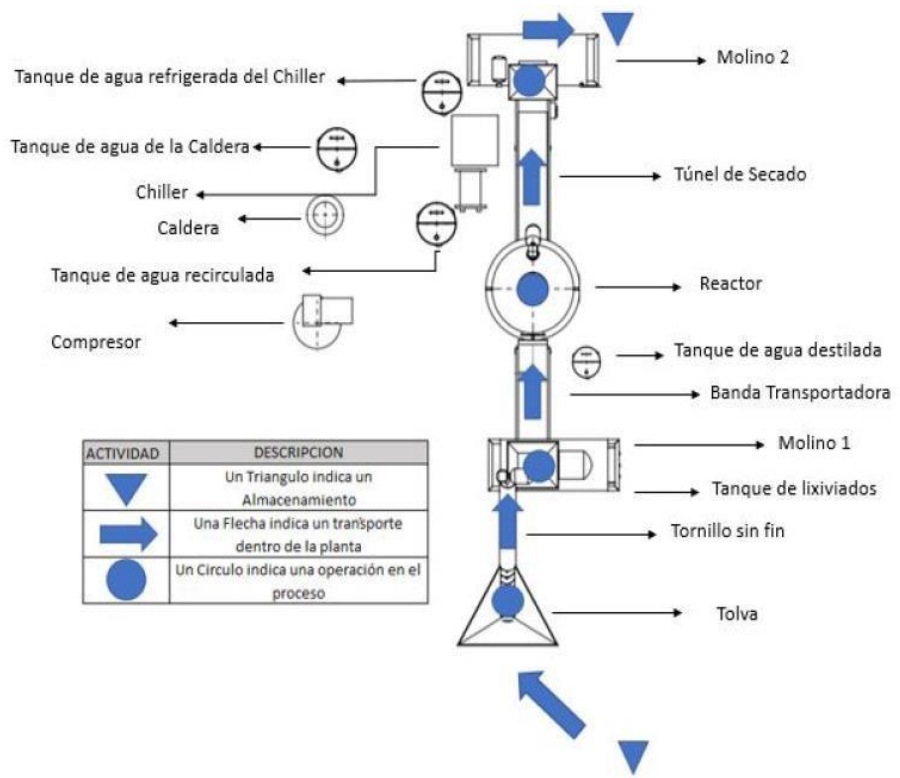

figura 2.

Diagrama de flujo en el proceso de Tindalización existente en (CNG). Fuente: Propia

En el diagrama de flujo se identifica cada actividad mediante símbolos, números y flechas A lo largo de la línea de flujo del material o proceso. Por lo tanto, permite medir los tiempos del proceso y cantidad de

III Encuentro Nacional de Semilleros de Investigación de Ingeniería Industrial

Universidad Santo Tomás. Facultad de Ingeniería Industrial. 1 de noviembre de 2019 
producto desarrollado en una unidad de tiempo. Otra ventaja de este diagrama es que permite identificar problemas y plantear mejoras en el proceso.

El empleo de software de simulación permite indicar flujos entre pasos que mueven elementos físicos y permiten cambios adicionales para agilizar el comportamiento del proceso y manejo de datos continuos. con el fin de visualizar el porcentaje de utilización se realiza la toma de tiempos de cada equipo, siguiendo el proceso paso por paso. Fig. (3)

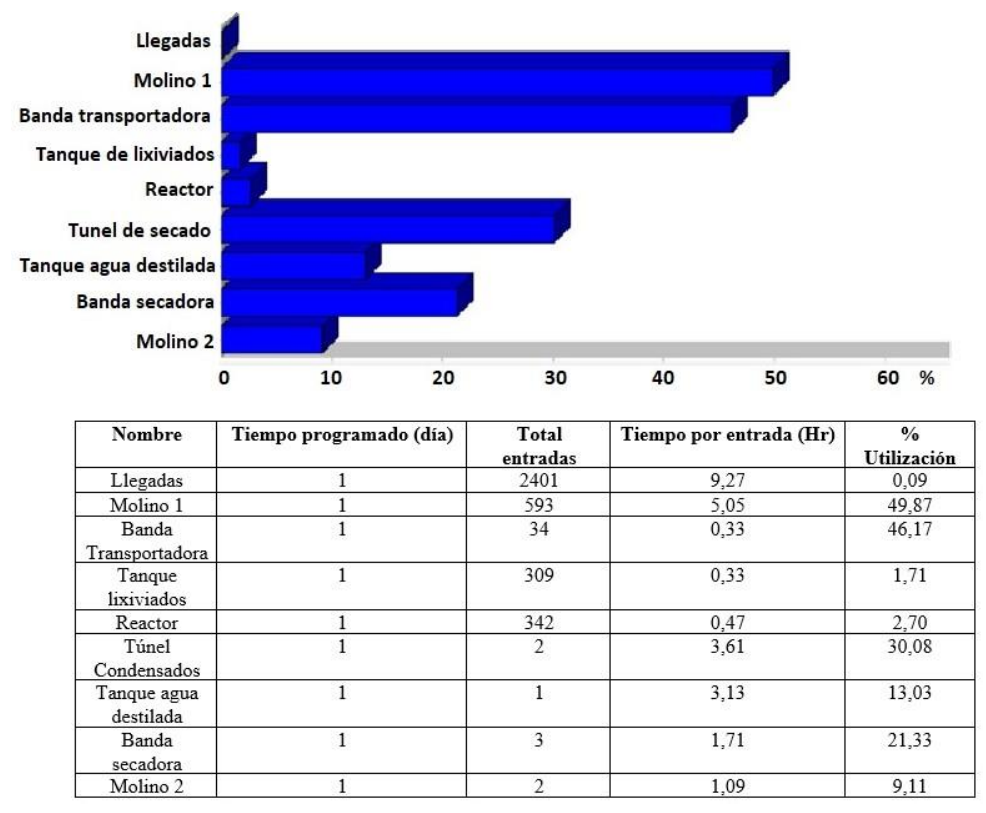

figura 3. Porcentaje de utilización de equipos. Fuente: Propia

Como se observa en la figura 3, el desbalanceo que se presenta en la línea de proceso tiene un rango porcentual de utilización de los equipos que oscila entre 1.71\% y $49.87 \%$ siendo valores que hacen que la planta operativamente sea muy ineficiente y los costos de operación sean muy elevados. Asimismo, el reactor pasa a ser un equipo central del proceso, se requiere ser ajustado en su operación mediante el cambio de caldera y un sistema de refrigeración de mayor capacidad. Por consiguiente, en la Fig. (4) se ilustra un flujo de proceso para una producción por lotes donde el molino 1 pueda ser utilizado para un trabajo más continuo en la fase inicial para la molienda del material orgánico y al final del proceso para la molienda del residuo de agregado seco que se obtiene cuando el material orgánico ha sido esterilizado.

III Encuentro Nacional de Semilleros de Investigación de Ingeniería Industrial 


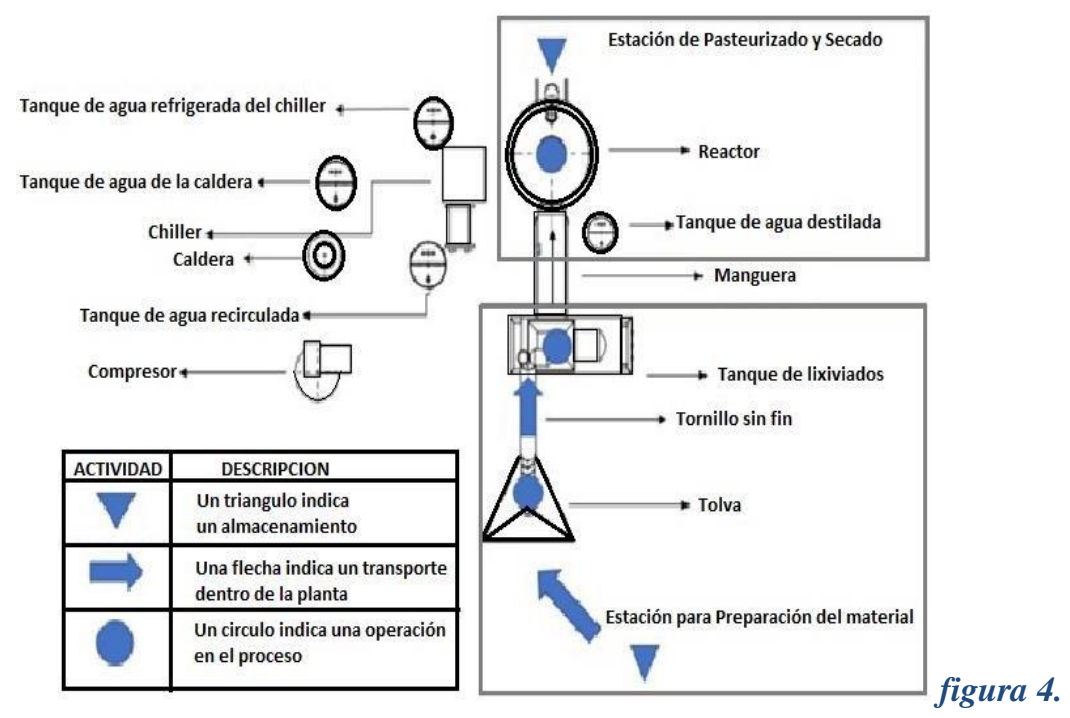

Diagrama de flujo propuesto para la planta de tindalización. Fuente: propia

También se elimina el túnel de secado y dicho proceso es realizado en el reactor; lo que evita mayor tiempo en el transporte de material y aprovechamiento para evaporar la humedad residual que queda en el material orgánico ya esterilizado. Una vez se organiza la información se propone un diagrama de flujo nuevo donde se eliminan componentes, se realiza el diagrama de Gantt para el proceso de tindalización

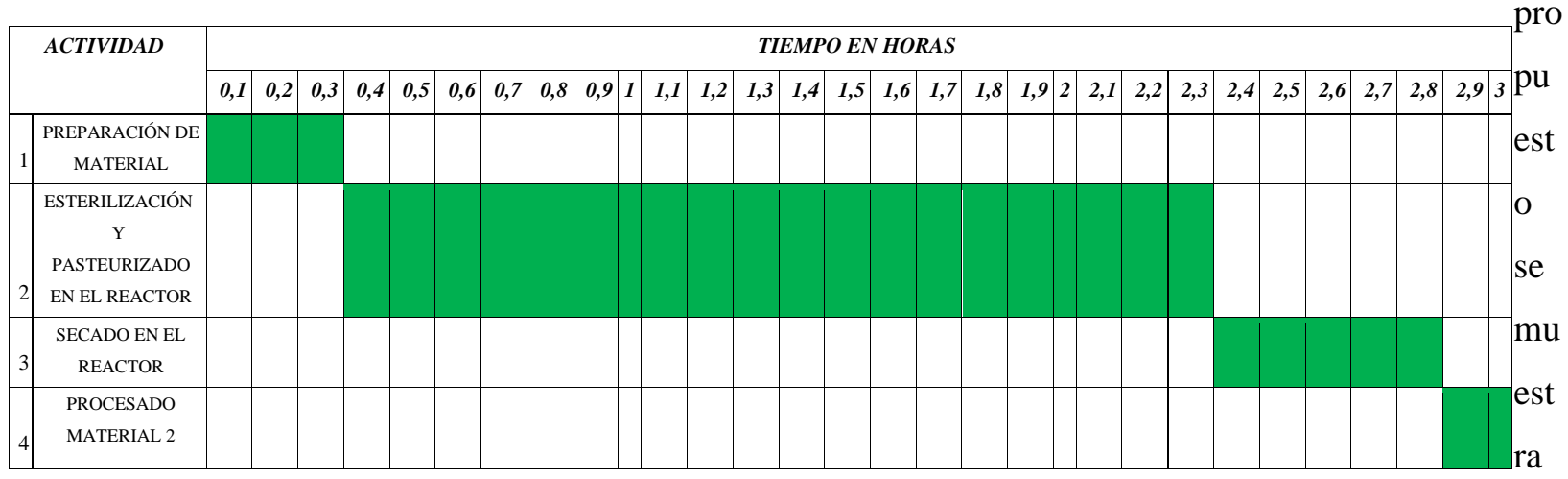

en la Tabla. (1) reduce el tiempo de operación de 7.8 h de operación a 3 h de operación por cada ciclo de trabajo efectuado.

Tabla 1. Diagrama de Gantt ajustado. Fuente: propia

III Encuentro Nacional de Semilleros de Investigación de Ingeniería Industrial

Universidad Santo Tomás. Facultad de Ingeniería Industrial. 1 de noviembre de 2019 
se obtiene un nuevo porcentaje de utilización de equipos ajustado, la Fig. (5) muestra los resultados de simulación donde se hace evidente un mejor balanceo de la línea en el proceso de tindalización, lográndose en el reactor un porcentaje de utilización del $87.54 \%$ y en molino 1 un porcentaje de utilización del $86.7 \%$ el cual es un valor aceptable de utilización el porcentaje faltante de utilización normalmente es utilizado para ajustes de equipo, puestas a punto y para intervenciones previstas en el mantenimiento preventivo. y con estos datos se procede a la investigación de operaciones para linealizar la selección de los dos procesos en el manejo de residuos sólidos.

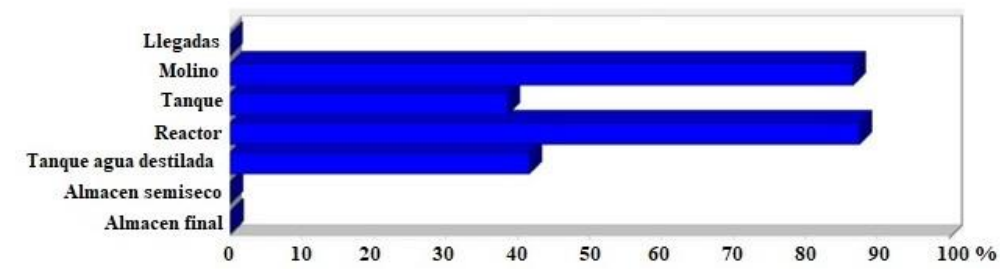

\begin{tabular}{|l|c|c|c|c|}
\hline Nombre & $\begin{array}{c}\text { Tiempo } \\
\text { programado } \\
(\mathbf{H r})\end{array}$ & $\begin{array}{c}\text { Total } \\
\text { entradas }\end{array}$ & $\begin{array}{c}\text { Tiempo por } \\
\text { entrada }\end{array}$ & $\begin{array}{c}\% \\
\text { Utilización }\end{array}$ \\
\hline Llegadas & 4,03 & 0,84 & 3 & 0 \\
\hline Molino & 3,78 & 0,87 & 1 & 86,70 \\
\hline Tanque & 3,09 & 0,39 & 1 & 38,58 \\
\hline Reactor & 4,20 & 0,88 & 1 & 87,54 \\
\hline Tanque agua destilada & 2,00 & 0,42 & 1 & 41,67 \\
\hline Almacén semiseco & 2,00 & 0,21 & 1 & 0,08 \\
\hline Almacén final & 1,67 & 0,14 & 1 & 0,14 \\
figura 5.
\end{tabular}

Porcentaje de utilización de equipos en línea de proceso ajustada. Fuente: propia figure 5.

Percentage of use of equipment in adjusted process line. Own source

Las fases principales de la implementación de la investigación de operaciones en la práctica comprenden:

1. La definición del problema

2. La construcción del modelo

3. La solución del modelo

4. La validación del modelo

5. La implementación de la solución

Linealización para la selección de dos procesos en la optimización del manejo de residuos orgánicos X1: Proceso de tindalización

X2: Proceso de manejo de lixiviados por lavado

III Encuentro Nacional de Semilleros de Investigación de Ingeniería Industrial

Universidad Santo Tomás. Facultad de Ingeniería Industrial. 1 de noviembre de 2019 
Para los procesos seleccionados, en la tabla 2 se presentan los productos que se obtienen en cada uno de los procedimientos.

Tabla 2. Registro para la Selección de procesos. Fuente: propia

Table 2. Registration for Process Selection. Own source

\begin{tabular}{|c|c|c|c|c|}
\hline Producto & X1 & X2 & Unidades & Rango \\
\hline Agregado (material orgánico) & 48 & 50 & $\mathrm{Kg}$ & $\geq 98$ \\
\hline Agua (Lixiviado tratado) & & & & \\
& 200 & 300 & $\mathrm{Kg}$ & $\leq 500$ \\
\hline Aceite esencial & 0,25 & 0 & $\mathrm{Kg}$ & $\geq 0,2$ \\
\hline Costo & $\$ 7045$ & $\$ 3028$ & & \\
\hline
\end{tabular}

Se desea minimizar el costo de tratamientos de los materiales en el manejo de residuos orgánicos. El planteamiento del problema queda representado por las ecuaciones registradas en la tabla 3 y figura 6 .

Tabla 3. Ecuaciones de linealización de los procesos. Fuente: propia

Table 3. Linearization equations of the processes. Own source

\begin{tabular}{|l|c|c|c|c|c|}
\hline & X1 & X2 & Igualdad & Valor & Ecuación \\
\hline Minimizar & 7045 & 3028 & & & Min 7045X1+3028X2 \\
\hline Restricción 1 & 48 & 50 & $\geq$ & 98 & $48 X 1+50 X 2 \geq 98$ \\
\hline Restricción 2 & 200 & 300 & $\leq$ & 500 & $200 X 1+300 X 2 \leq 500$ \\
\hline Restricción 3 & 0,25 & 0 & $\geq$ & 0,25 & $0,25 X 1 \geq 0,25$ \\
\hline
\end{tabular}

III Encuentro Nacional de Semilleros de Investigación de Ingeniería Industrial

Universidad Santo Tomás. Facultad de Ingeniería Industrial. 1 de noviembre de 2019 


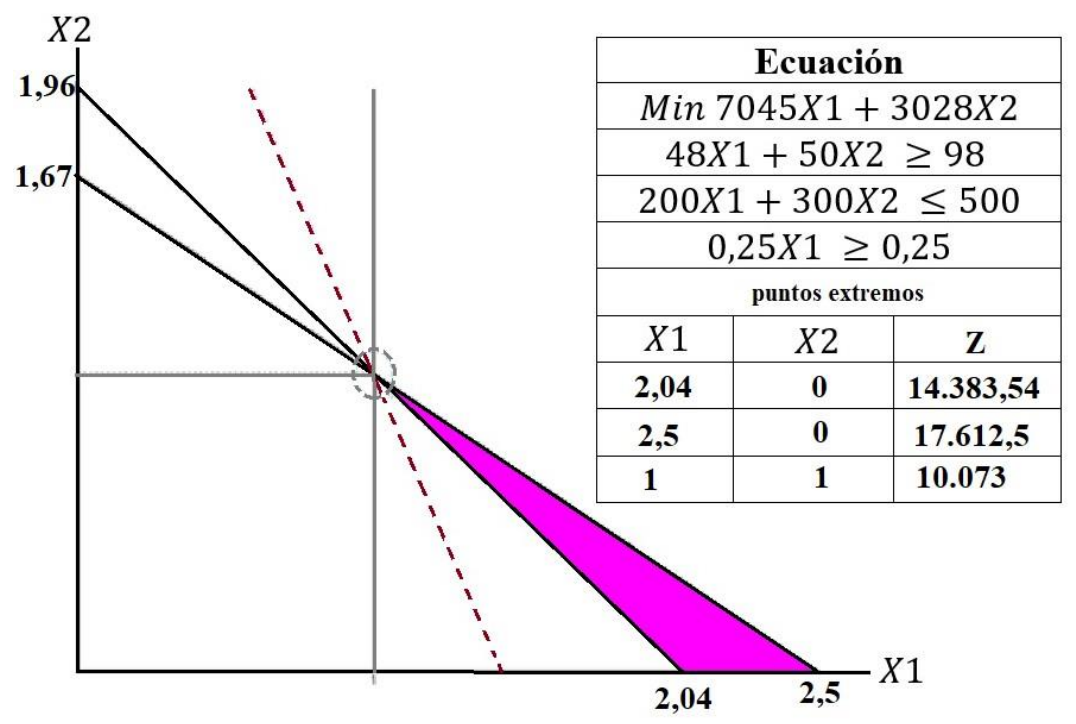

figura 6. Diagrama de linealización de los procesos Fuente propia. figure 6.

Linearization diagram of the processes. Own source

Factores que afectan la velocidad de extracción en el proceso de tindalización

- Temperatura

- Concentración del solvente

- Tamaño de partículas

- Porosidad del material

- Agitación

\section{Costos generados en el manejo de lixiviados}

Tabla 4. Costos de material procesado por kilogramo. Fuente: propia

\begin{tabular}{|c|c|}
\hline Material & Costo/Kg \\
\hline $\begin{array}{c}\text { Agregado } \\
\text { (Material orgánico) }\end{array}$ & 41 \\
\hline Agua & 3,26 \\
\hline Aceite & 17.700 \\
\hline
\end{tabular}

III Encuentro Nacional de Semilleros de Investigación de Ingeniería Industrial

Universidad Santo Tomás. Facultad de Ingeniería Industrial. 1 de noviembre de 2019 


\section{Procedimiento alterno para el manejo de lixiviados}

La lombricultura en pro de crecimiento utiliza a la lombriz como transformadora de desechos biológicos, esta se comporta como un cuidador y restaurador de la tierra y consume estiércoles y residuos vegetales y animales, allí es donde entra el producto del lixiviado, que brinda nutrientes, disminuye la contaminación química y permite la reincorporación de residuos a un proceso de compostaje para que el suelo sea fértil.

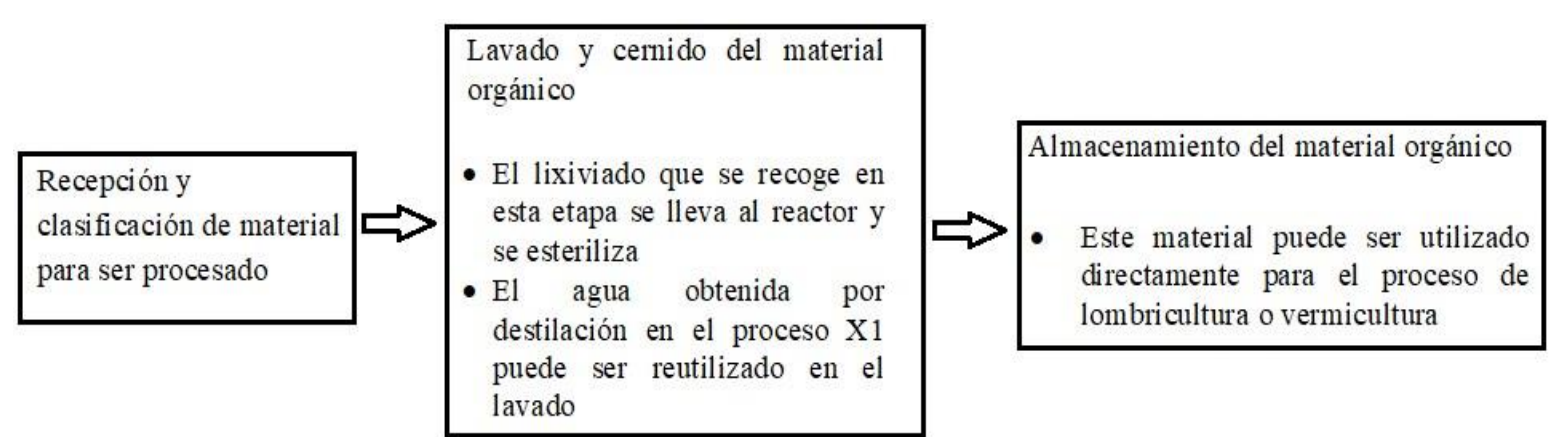

figura. 7. Proceso de manejo de lixiviados. Fuente: propia

figure. 7. Leachate management process. Own source

\section{Resultados y discusión}

La figura 3 evidencia el porcentaje de utilización de cada equipo requerido en el proceso de tindalización, según lo anterior, puede observarse que el reactor solo es utilizado el $2.7 \%$ del tiempo, esto hace que este equipo sea un cuello de botella con un tiempo de utilización total de 4 horas. Otro problema adicional es que la operación del reactor está supeditada a la operación de otros equipos que lo alimentan, como la caldera que suministra el vapor, siendo un equipo con una potencia muy baja de 4 BHP. Según cálculo termodinámico se requiere una caldera de 14 BHP. Por otra parte, la torre de enfriamiento que suministra el agua refrigerante tiene un compresor de $1 \mathrm{hp} \mathrm{y} \mathrm{el} \mathrm{sistema} \mathrm{requiere} \mathrm{un} \mathrm{equipo} \mathrm{de} 9 \mathrm{HP}$.

El molino 1 tiene una eficiencia de utilización del 49,87\% y el molino 2 del 9.11\%. Por consiguiente, la saturación del sistema y represamiento de material se debe a la poca eficiencia del reactor.

III Encuentro Nacional de Semilleros de Investigación de Ingeniería Industrial

Universidad Santo Tomás. Facultad de Ingeniería Industrial. 1 de noviembre de 2019 
Volviendo al tema de optimización que nos ocupa, el diagrama de lineación que se indica en la figura 6 para los procesos X1 (Proceso de tindalización por esterilización) y X2 (Proceso de manejo de lixiviados por lavado) la minimización de costos se obtiene al aprovechar el agua destilada obtenida en el proceso X1 para ser reutilizada para el lavado del material orgánico en el proceso X2.

El diagrama de lineación que se indica es el resultado para los procesos X1 (Proceso de tindalización por esterilización) y X2 (Proceso de manejo de lixiviados por lavado) la minimización de costos se obtiene al aprovechar el agua destilada obtenida en el proceso X1 para ser reutilizada para el lavado del material orgánico en el proceso X2.

\section{Conclusiones}

1. Para el lavado del material orgánico en el proceso X2, se puede utilizar el agua generada en el proceso de destilación del proceso X1; lográndose reducir costos en \$ 10073 con un incremento de la producción de $250 \mathrm{~kg}$ a $498 \mathrm{~kg}$.

2. Se evidencia optimización de la planta fundamentando un proceso de fabricación por lotes, el personal y los equipos que realizan una misma función general se pueden agrupan en una misma área, lográndose un porcentaje de utilización del $87.1 \%$ el cual es aceptable para una planta de proceso para el tratamiento de residuos orgánicos; ahora bien, el 12.9\% restante puede ser aprovechado para puesta a punto de los equipos o para la gestión del mantenimiento preventivo.

3. Para el lavado del material orgánico en el proceso X2, se puede utilizar el agua generada en el proceso de destilación del proceso X1; lográndose reducir costos en \$ 10073 con un incremento de la producción de $250 \mathrm{~kg}$ a $498 \mathrm{~kg}$

4. Puede evidenciarse en la figura 5 que, fundamentando un proceso de fabricación por lotes, el personal y los equipos que realizan una misma función general se pueden agrupan en una misma área, lográndose un porcentaje de utilización del $87.1 \%$ el cual es aceptable para una planta de proceso para el tratamiento de residuos orgánicos; ahora bien, el 12.9\% restante puede ser aprovechado para puesta a punto de los equipos o para la gestión del mantenimiento preventivo.

III Encuentro Nacional de Semilleros de Investigación de Ingeniería Industrial

Universidad Santo Tomás. Facultad de Ingeniería Industrial. 1 de noviembre de 2019 
5. Considerando la hipótesis de que el personal y los equipos que realizan una misma función general se agrupen en una misma área como se muestra en la figura 4, se puede establecer para $\mathrm{X} 1$ dos subprocesos así: Preparación de material:

- $\quad$ Recepción de material en la tolva

- Transporte mediante el tornillo sin fin

- Molienda del material orgánico

- Tanque para la recolección de sólidos y lixiviados

Estación de pasteurizado y Secado en el reactor:

- Tindalización de material biológico en el reactor

- Evaporación de agua y secado de material biológico

- Destilación y recolección de agua

6. El procedimiento alterno para el manejo de residuos orgánicos y lixiviados por el método de lavado (X2) que se ilustra en la figura 7, es un proceso que facilita la clasificación del material orgánico y donde el producto sólido puede servir para el cultivo de lombricultura, el cual mediante un proceso metabólico produce humus y compost, considerado el mejor abono orgánico para la agricultura.

\section{Referencias Bibliográficas}

[1] Transferencia de Calor y Masa 2, «Lixiviación Liquido - sólido,» de Operaciones Unitarias en Ingeniería Quimica e Ingenier;ia Alimentos, 2015.

[2] M. M. Cardona Gallo, «Minimización de residuos: una política de gestión ambiental empresarial,» Producción + Limpia, vol. 1, nº 2, pp. 46-58, 2006.

[3] S. Castañeda Torres y J. P. Rodríguez Miranda, «Modelo de aprovechamiento sustentable de residuos sólidos orgánicos en Cundnamarca, Colombia,» Universidad y Salud, vol. 19, nº 1, pp. 116126, 2017.

[4] P. A. Mohr Barria, «Propuesta de metodología para la medición de eficiencia general de los equipos en líneas de proceso de sección mantequilla en la industria láctea,» Universidad Austral de Chile, Puerto Mott-Chile, 2012.

III Encuentro Nacional de Semilleros de Investigación de Ingeniería Industrial 
[5] A. Rageh, «Continuous measurement of the quality of steam,» Department of Biomedical Engineering - BRNO University of Technology, Brno-Královo Pole, Chequia, 2014.

[6] A. Ramos, P. Sánchez, J. M. Ferrer, J. Barquín y P. Linares, «Modelos matemáticos de optimización,» Universidad Pontificia de Comillas - Escuela Superior de Ingeniería, departamento de organización Industrial, Madrid- España, 2010.

III Encuentro Nacional de Semilleros de Investigación de Ingeniería Industrial

Universidad Santo Tomás. Facultad de Ingeniería Industrial. 1 de noviembre de 2019 


\title{
Perspectivas del uso y producción de biopolímeros en \\ Colombia
}

\author{
Laura Jimena Moreno ${ }^{17}$ \\ Yohn Fredy Ruiz Rincón ${ }^{2}$ \\ Ana Janeth Suárez Zamora ${ }^{3}$ \\ Gloria Astrid Nausa Galeano ${ }^{18}$
}

\section{Resumen}

Los biopolímeros son macromoléculas de origen natural que pueden ser empleados para suplir o reemplazar polímeros de origen petroquímico en diversos sectores de la industria. La gran ventaja que ofrecen estos materiales es que son de rápida degradación, mitigando el efecto de los residuos petroquímicos acumulado. El presente trabajo pretende consolidar el estado del arte de la comercialización y el desarrollo de nuevos materiales biopoliméricos en Colombia; haciendo énfasis en aplicaciones innovadoras, principales centros de investigación involucrados y proyectar una estrategia para el futuro.

\section{Palabras Claves}

Polímero, Biopolímero, Biodegradabilidad, Plástico, Petroquímico

\footnotetext{
${ }^{17}$ Universidad ECCI, Sede Bogotá. Contacto: lauraj.moreno0@ecci.edu.co

${ }^{18}$ Universidad ECCI, Sede Bogotá, Docente de Planta Ingeniería Industrial. Contacto: gnausag @ecci.edu.co
}

III Encuentro Nacional de Semilleros de Investigación de Ingeniería Industrial

Universidad Santo Tomás. Facultad de Ingeniería Industrial. 1 de noviembre de 2019 


\section{Problema de Investigación}

Los polímeros de origen petroquímico ocupan un renglón importante del comercio mundial. Debido a la versatilidad en su estructura química, estos pueden ser empleados en diversos campos de aplicación. Adicionalmente, los bajos costos de producción asociados con la obtención de monómeros de origen petroquímico y su posterior polimerización, han hecho de los polímeros sintéticos un producto de alta demanda. Para los últimos cuatro años, el crecimiento anual promedio de la producción mundial fue del $3.8 \%$, proyectando unos 500 millones de toneladas para el año 2020 [1]

El incremento en la producción de estos materiales, repercute directamente en la generación de residuos; amenazando la estabilidad de ecosistemas marítimos y terrestres y la salud humana.

En consecuencia, existen trabajos tendientes al desarrollo de materiales sustitutos, entre ellos, los biopolímeros. Estos son macromoléculas orgánicas, biodegradables; de interés para la industria porque pueden cumplir con los requerimientos que cubren actualmente los polímeros sintéticos.

Este artículo pretende mostrar una visión general del sector, haciendo énfasis en las perspectivas para Colombia.

\section{Metodología}

Para la caracterización del sector de interés, se hizo una investigación en diferentes fuentes documentales. Se realizó una búsqueda sistemática en Science Direct y Google Scholar, utilizando los descriptores: polymer, biopolymer, plastic y petrochemical. Con la primera se obtuvieron 1357 resultados y 11600 en el segundo. Los resultados de artículos y patentes se refinaron de acuerdo con la fecha de publicación, para emplear solo productos desde 2010.

Adicionalmente, se hizo una búsqueda en los repositorios de diferentes universidades colombianas con programas académicos relacionados. Específicamente se indagó en los repositorios de la Universidad Nacional de Colombia y la Universidad del Valle, en donde se encontraron 13 tesis.

III Encuentro Nacional de Semilleros de Investigación de Ingeniería Industrial

Universidad Santo Tomás. Facultad de Ingeniería Industrial. 1 de noviembre de 2019 


\section{Resultados y Análisis}

Los polímeros, son compuestos orgánicos de alto peso molecular, conformadas por unidades estructurales repetitivas, llamadas monómeros.

La estructura química de los polímeros es responsable de las propiedades que los distinguen de los demás materiales. En general, los polímeros se caracterizan por tener una excelente resistencia mecánica [3], así como bajo punto de fusión, baja densidad, pobre conductividad eléctrica y térmica, además de una poca reactividad química [4]. En consecuencia, los polímeros tienen un gran y variado campo de aplicación en diferentes industrias, en donde sobresalen la farmacéutica, agrícola, biomédica, y de alimentos por el uso de envases y empaques [5].

La producción mundial de polímeros alcanzó los 348 millones de toneladas para el año 2017 [6] y se estima que, en el año 2020, se superarán los 500 millones de toneladas anuales [1]. En cuanto a la distribución mundial, China es el principal productor con un 29.4\%, seguido de los países europeos con un $18.5 \%$ y NAFTA (México, EE. UU y Canadá) con un $17.7 \%$. [1]

La alta resistencia a la corrosión, al agua y a la descomposición bacteriana que también los convierte en un residuo difícil de eliminar [7]. Se estima que el tiempo de vida medio de degradación para un polímero puede estar entre los 0,5 y los 600, de acuerdo con su estructura química y el producto final al que corresponda [8].

El 36\% de los plásticos sintéticos producidos a nivel mundial se emplean en la fabricación de envases de un solo uso [9]. Por consiguiente, el volumen de generación de residuos de este tipo de materiales se ha convertido en un problema mundial. Se proyecta que para el año 2050, existan alrededor de 8.300 millones de toneladas de residuos [10].

Es por esta razón que los esfuerzos de científicos y empresarios han empezado a volcarse hacia el desarrollo de nuevos materiales que mantengan las propiedades mecánicas y químicas de los polímeros

III Encuentro Nacional de Semilleros de Investigación de Ingeniería Industrial

Universidad Santo Tomás. Facultad de Ingeniería Industrial. 1 de noviembre de 2019 
de origen petroquímico, pero que permitan una degradación mucho más rápida. La solución, podrían ser los biopolímeros.

Los biopolímeros son macromoléculas orgánicas, que tienen origen biológico. Se clasifican en dos tipos: Los que pueden ser extraídos directamente a partir de un organismo vivo y los que requieren ser sintetizados pero se originan a partir de un recurso renovable [11]. El primer tipo de biopolímeros incluye las proteínas (colágeno, queratina, albumina o caseína, entre otras) y algunos polisacáridos (almidón, celulosa, quitosano, alginatos, carragenatos y pectinas) [12].

El segundo tipo incluye al Ácido Poliláctico (PLA), el Poli-3-Hidroxibutirato (PHB), la Poliamida 11 (PA-11), el Polietileno (PE) y el Polietileno Tereftalato (PET) obtenidos a partir de fuentes biológicas, y algunos poliésteres (Polihidroxialcanoatos o PHA) [13]. Este tipo de biopolímeros se obtiene a partir de un proceso de fermentación en donde un sustrato es metabolizado por un microorganismo que puede o no ser recombinante [14].

El interés en la obtención y comercialización de biopolímeros se fundamenta en la rapidez de su degradación, que puede variar entre unas cuantas semanas o meses [14]. La descomposición puede darse por diversos factores [15], como la acción de la luz, la temperatura o el agua (biopolímeros que se degradan como el PLA) [16]; por el uso de compostaje (biopolímeros compostables, como el acetato de celulosa); o por la intervención de microorganismos como bacterias, hongos y algas (biopolímeros biodegradables como el PHA) [17].

La producción de biopolímeros a nivel mundial presenta una tendencia al alza (Figura 1) y se estima para que para el año 2023, alcance unas 2616 toneladas [18]. Asia lidera el mercado global, con más del 50\% de la producción.

En lo que respecta a las aplicaciones, los bienes de consumo corresponden al mayor campo de uso de biopolímeros con el 28\% de la producción global para el año 2018. Las siguientes aplicaciones por volumen de producción son la construcción, con un $21 \%$ de participación, el sector automotriz con un $19 \%$, el de embalaje con un $15 \%$, el de textiles con un $11 \%$ y otros con $6 \%$ [18].

III Encuentro Nacional de Semilleros de Investigación de Ingeniería Industrial

Universidad Santo Tomás. Facultad de Ingeniería Industrial. 1 de noviembre de 2019 
En el segmento de bienes de consumo destacan bolígrafos, cajas, zapatos; que son fabricados con PE, PET, PLA, entre otros. En la construcción, sobresale el Policloruro de Vinilo (PVC) de origen biológico; mientras que en el sector automotriz se emplean poliamidas, policarbonatos y fibras textiles en PET y PLA [18].

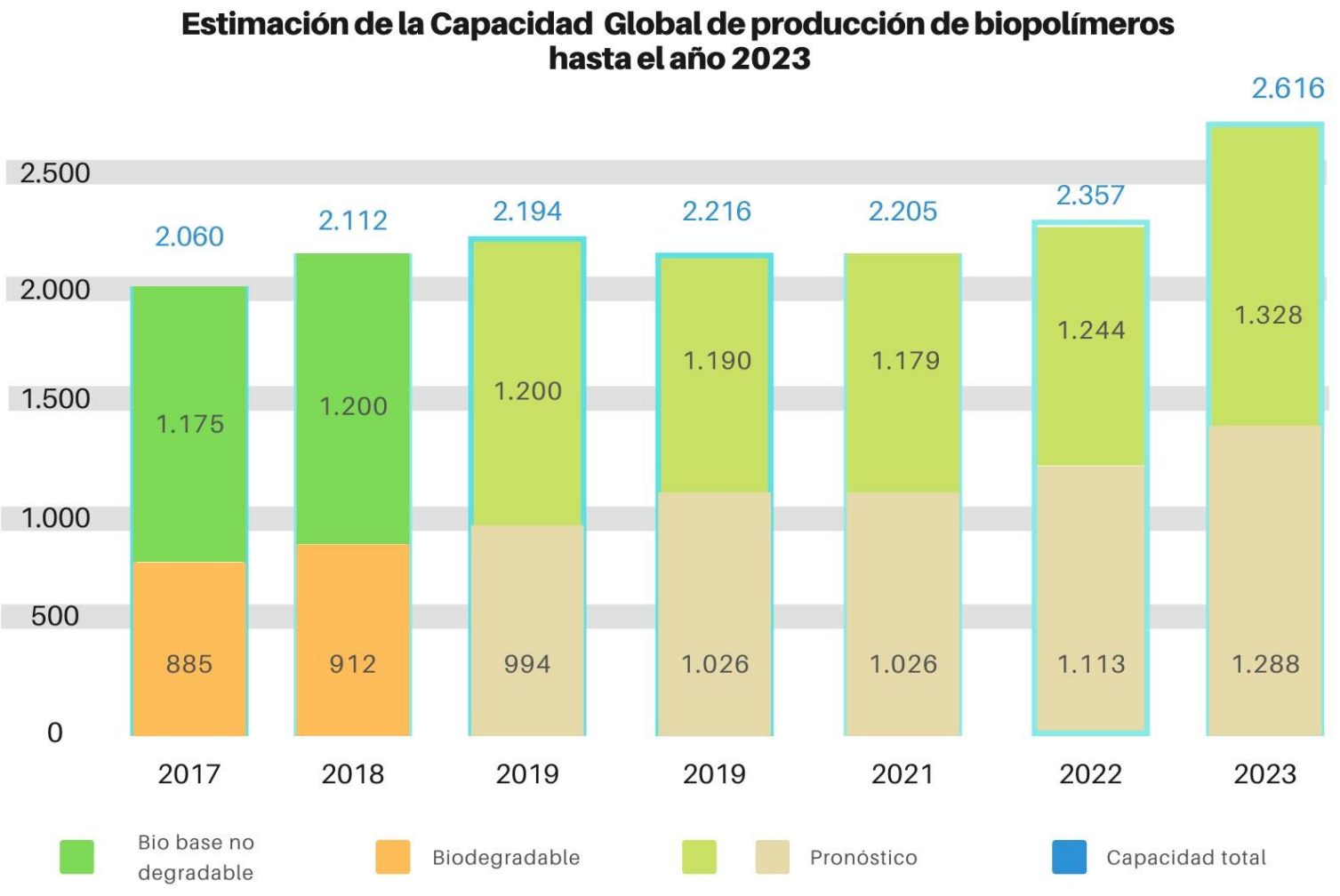

Figura 1. Estimación de producción mundial de biopolímeros hasta 2023

En lo que respecta a los embalajes, tanto los envases rígidos como los flexibles son elaborados a partir de biopolímeros como PET, PE o PLA [18] Del mismo modo, las vajillas desechables son elaboradas en la actualidad a partir de PLA y toda una gama de otros poliésteres biodegradables (Adipato-Tereftalato de Polibutileno (PBAT), Polibutileno Succinato (PBS) [18]En este sentido, se destaca la produción de empaques con permeabilidad de algunos gases, permitiendo un aumento de tiempo de vida útil de frutas y verduras frescas, manteniendo las características de frescura, color y aroma [19].

III Encuentro Nacional de Semilleros de Investigación de Ingeniería Industrial

Universidad Santo Tomás. Facultad de Ingeniería Industrial. 1 de noviembre de 2019 
En Colombia, el impacto generado por los desechos plásticos no es diferente a la tendencia mundial. Del consumo anual per cápita, que asciende a los 24 kilos, el 56\% corresponde a productos de uso único [20]. Adicionalmente, solo el $7 \%$ del plástico que se consume en el país se recicla, generando una gran cantidad de residuos que terminan en rellenos sanitarios o fuentes hídricas [20] [21]. Es así como, los ríos Amazonas y Magdalena se encuentran entre los 20 más contaminados por plástico en el mundo [22].

En respuesta a esta problemática, en marzo de 2019 en Colombia se radicó un proyecto de ley con el que se busca prohibir la producción y distribución de los plásticos de un solo uso; sin embargo no ha tenido trámite [23]. Adicionalmente, el decreto 2198 de 2017, obliga al consumidor a pagar un impuesto de 30 pesos por cada bolsa de plástico [24]. Igualmente, la resolución 1407 de 2018 obliga al sector productivo de envases y empaques de cartón, plástico y vidrio a desarrollar un plan para el aprovechamiento y reutilización de los mismos [24]. Por último, algunos municipios del país han avanzado en la prohibición del uso de plásticos de un solo uso [25] [26].

La comunidad científica colombiana ha respondido a la problemática ambiental asociada al uso de plásticos de origen petroquímico con el desarrollo de diversos materiales de características similares a la de los polímeros tradicionales [27]. Es el caso de la universidad del Valle, donde obtuvieron la patente para producir un biopolímero a base de quitina - glucano. De otro lado, se han realizado esfuerzos tendientes a la obtención de biopolímeros por fermentación, a partir de almidón de yuca y papa [28]. En la misma región de occidente, la universidad del Cauca ha realizado investigaciones desde hace varios años en busca del desarrollo de nuevas tendencias en productos biodegradables a base de almidón de yuca como lo son los productos desechables [29].

En particular, cabe destacar la participación de la Universidad Nacional de Colombia, en investigaciones tendientes a encontrar avances para el desarrollo de biopolímeros. Como ejemplo, un trabajo que dio como resultado la elaboración de empaques comestibles con Bilac® (polímero obtenido a partir de la cepa bacteriana Leuconostoc mesenteroides, usando como materias primas sacarosa y glucosiltransferasa) [30]. De otro lado, un desarrollo realizado en la misma institución, logró la obtención de un biopolímero del tipo dextrano que acelera el tránsito intestinal, a partir de azúcar de caña

III Encuentro Nacional de Semilleros de Investigación de Ingeniería Industrial

Universidad Santo Tomás. Facultad de Ingeniería Industrial. 1 de noviembre de 2019 
[31]. Otro estudio que se destaca, es la investigación que muestra el potencial de uso del almidón de millo acetilado, en la industria farmacéutica y de alimentos, como agente excipiente [32] . Sobresale otra investigación en el área de biomédica, en el estudio de un biomaterial polimérico de conducción iónica, basado en policaprolactona para posibles aplicaciones en ingeniería de tejidos óseos [33]. Por último, en el campo de la farmacéutica, se obtuvo el desarrollo de vehículos de tamaños submicrónicos de PLGA (copolímero de los ácido láctico y glicólico) que permiten el transporte y liberación controlada de Nacetil cisteína (NAC) preferencialmente al tejido óseo [34].

Recientemente, se ha buscado elaborar productos de mayor valor agregado, en particular en aplicaciones médicas y farmacéuticas. Se destacan los dispositivos terapéuticos cardiovasculares, ortopédicos, oftalmológicos y dentales, sustitutos de piel, sistemas de liberación de fármacos y sensores para propósitos de diagnóstico. Los Biopolímeros más empleados para este tipo de aplicaciones han sido; El poli (ácido láctico) (PLA), poli (ácido glicólico) (PGA) y sus copolímeros poli (ácido láctico-co-glicólico) (PLGA) [35].

A nivel comercial, se destacan dos empresas que llevan más de diez años en el mercado de los biopolímeros. Ecogreen, quien importa y comercializa productos elaborados a base de almidón de maíz, y Greenpack, que se dedica a la importación, diseño, fabricación y comercialización de empaques biodegradables a partir de PLA [36]

\section{Conclusiones}

La preocupación mundial por la acumulación y los efectos nocivos de los residuos plásticos de origen sintético aún no parece alcanzar todas las esferas necesarias para generar un cambio integral. En consecuencia, el mercado sigue estando dominado por los materiales de origen petroquímico, debido principalmente a los bajos costos tanto de materias primas como de procesamiento. Sin embargo, las investigaciones han posibilitado el desarrollo de productos biodegradables de distintos usos que han empezado a sustituir los polímeros derivados del petróleo.

Particularmente en Colombia, hay reportes de trabajos relacionados con la obtención de biopolímeros de rápida degradación en diferentes campos de aplicación. Si bien se ha alcanzado buenos resultados a nivel

III Encuentro Nacional de Semilleros de Investigación de Ingeniería Industrial

Universidad Santo Tomás. Facultad de Ingeniería Industrial. 1 de noviembre de 2019 
laboratorio, estos productos no han sido llevados a escala industrial, debido a la falta de interés por parte del sector productivo y de los elevados costos asociados, en comparación con los materiales y procesos tradicionales.

De otro lado, existen algunas políticas gubernamentales tendientes a promover la integración de estos productos innovadores dentro de la vida cotidiana de los consumidores. El objetivo es aportar elementos en pro del desarrollo sostenible, mediante la implementación de programas y actividades que ayuden a disminuir la generación de residuos que impactan negativamente el medio ambiente y la salud humana.

En conclusión, una problemática de grandes implicaciones y de extrema complejidad como la expuesta en el presente documento, requiere de una estrategia de solución multidimensional que incluya a todos los actores involucrados. El gobierno colombiano debe continuar incentivando la investigación y el desarrollo de productos biodegradables que cumplan con los requerimientos de la industria. Para garantizar que estas innovaciones puedan llegar a escenarios comerciales, es necesario generar espacios de trabajo y diseñar esquemas de beneficios que atraigan a los empresarios y posibiliten la generación de empresa y de puestos trabajo que puedan soportar el impacto causado por la disminución en la producción de polímeros de origen petroquímico.

\section{Referencias Bibliográficas}

[1] Greenpeace, "Datos sobre la producción de plásticos,” 2019. [Online]. Available: https://es.greenpeace.org/es/trabajamos-en/consumismo/plasticos/datos-sobre-laproduccion-deplasticos/.

[3] MIGUEL ÁNGEL GARCÍA VEGA, “El viejo sector del plástico se resiste a morir,” 2018.

[4] juan carlos Ospina arias, Fundamentos de envases y embalajes, vol. 1, no. 1. 2015.

[5] J. Méndez and M. T. Bautista, "Relationship between structure and properties of polymers," Educ. química, vol. 21, no. 4, pp. 291-299, 2013.

[6] Plastics Europe, "Plastics-the Facts 2018 An analysis of European plastics production, demand and waste data," 2018.

III Encuentro Nacional de Semilleros de Investigación de Ingeniería Industrial 
[7] P. Beatriz, "La degradación de los plásticos," Rev. Univ. Eafit.

[8] Greenpeace, "Tiempos plásticos." [Online]. Available: https://archivoes.greenpeace.org/espana/es/Trabajamos-en/Parar-lacontaminacion/Plasticos/Datossobre-la-produccion-de-plasticos/index.html.

[9] UN Environment, "Hoja informativa para Diseñadores de Políticas."

[10] M. Fundación para el conocimieto, "Un Universo invisible bajo nuestros pies Plasticosfera: Un desastre monumental para la biosfera y la salud humana," no. 0, pp. 1-11, 2019.

[11] M. Fernando Valero-Valdivieso, Y. Ortegón, and Y. Uscategui, "Biopolímeros: Avances y perspectivas biopolymers: Progress and prospects," vol. 80, pp. 171-180, 2013.

[12] B. Díaz Santoyo, "Efecto de la concentración de aceite de candelilla," 2018.

[13] C. Álvarez, “Análisis de la producción de polihidroxibutirato usando lactosuero como materia prima," p. 104, 2015.

[14] C. Sanabria and D. Sarmiento, "Evaluación de la obtención de polihidroxialcanoatos (phas) partiendo del residuo de almidón de papa por medio de bacillus subtilis a nivel laboratorio," 2017.

[15] P. Academy, "GENERAL La Diferencia entre Degradable , Biodegradable y Compostable Buscar Entradas recientes," no. 55, pp. 1-3, 2019.

[16] A. V. G. QUIÑÓNEZ, The properties of strong-coupling impurity bound magnetopolaron in an anisotropic quantum dot, vol. 25, no. 26. 2011.

[17] L. M. V. R. Cruz Morfin, Martínez Tenorio, "Biopolímeros y su integración con polímeros convencionales."

[18] Nova Institute, "Biobased Building Blocks and Polymers - Global Capacities, Production, and Applications-Status Quo and Trends 2018-2023," Bio based, 2019. [Online]. Available: www.bio-based.eu/reports.

[19] R. Raquel et al., "Envases Inteligentes Para La Conservación De Alimentos," Ra Ximhai, 2012.

[20] Greenpeace Colombia, "Colombia \#MejorSinPlásticos."

[21] Diario Occidente, "En Colombia se recicla solo el 7\% del plástico," 2019.

III Encuentro Nacional de Semilleros de Investigación de Ingeniería Industrial

Universidad Santo Tomás. Facultad de Ingeniería Industrial. 1 de noviembre de 2019 
Greenpeace, "Islas de plástico," 2019. [Online]. Available:

https://www.greenpeace.org/colombia/issues/plasticos/1514/no-podemos-dejar-quelas-islasplasticas-se-repitan-en-toda-nuestra-costa/.

https://sostenibilidad.semana.com/medioambiente/articulo/colombia-da-un-paso-hacia-laprohibicion-de-los-plasticos-de-unsolo-uso/43504. [Accessed: 18-Oct-2019].

[24] Actualícese, "Impo Consumo de bolsas plásticas fue reglamentado con el Decreto 2198 de 2017," 2018.

[25] G. de Boyacá, "Gobierno de Boyacá prohíbe plásticos de un solo uso en su contratación." [Online].

Available: http://www.boyaca.gov.co/prensapublicaciones/noticias/31422301-gobierno-de-boyac $\tilde{A}_{i}$-proh $\tilde{A}-$ be-plã $i$ sticos-de-unsolo-uso-en-su-contrataciÃ $\tilde{A}^{3}$. [Accessed: 31-Aug-2019].

[26] Laura Sierra Musse, "Estos son los lugares de Colombia que no quieren más plástico _ ¡PACIFISTA!,” 2019. [Online]. Available: https://pacifista.tv/notas/lugares-colombianoplastico/.

[27] A. C. Lemos Delgado and A. Mina Cordoba, "Polihidroxialcanoatos (PHA's) producidos por bacterias y su posible aplicación a nivel industrial," Inf. Técnico, vol. 79, no. 1, p. 83, Jun. 2015.

[28] J. Meneses, C. Corrales, and M. Valencia, "Síntesis y caracterización de un polímero biodegradable a partir del almidón de yuca," Rev. EIA, no. 8, pp. 57-67, 2007.

[29] U. del Cauca, "Noticias y actualidad," pp. 1-5, 2019.

[30] C. G. Mendoza., "El abuso de la cocaína y su efecto en el sistema inmune y citoquininas del suero.," MoleQla Rev. Ciencias la Univ. Pablo Olavide, vol. 21, no. 21, pp. 31-34, 2016.

[31] S. Cobos de Rangel, Olga; Buitrago, Gustavo; Ospina, "Los biopolímeros, compuestos que mejoran la salud."

[32] A. Sulbarán, G. E. Matiz, and Y. Baena, "Acetilación del almidón de millo

(Pennisetum glaucum) y evaluación de su aplicación como posible excipiente," Rev. Colomb. Ciencias Químico-Farmacéuticas, vol. 47, no. 2, pp. 255-276, Oct. 2018.

E. Correa, "16. Biopolimeros de conduccion ionica para aplicacion en tejidos oseos." 
[34] R. Janneth and L. Salas, "Producción de nanopartículas de PLGA para el transporte de medicamentos especifico a tejido óseo," 2016.

[35] M. Guillermo, R. Cort, B. M. Vallejo, and J. E. Perilla, "Los biopolímeros como materiales para el desarrollo de productos en aplicaciones farmacéuticas y de uso biomédico Biopolymers as materials for developing products in pharmaceutical applications and biomedical uses," vol. 28, no. 1, pp. 57-71, 2008.

[36] "Biopolímeros les hacen dura competencia a los plásticos convencionales - Medellín Colombia - ELTIEMPO.COM.” [Online]. Available: https://www.eltiempo.com/colombia/medellin/biopolimeros-les-hacen-duracompetencia-a-losplasticos-convencionales-146548. [Accessed: 18-Oct-2019]. 


\title{
Diseño, puesta a punto y validación del proceso de curvado rápido (Hyperbending) para vidrio blindado automotriz.
}

\author{
Edwin Gonzales ${ }^{19}$ \\ Manuel Castiblanco ${ }^{20}$ \\ Julian David Torres ${ }^{3}$
}

\section{Resumen}

El trabajo presentado en este documento consiste en presentar el diseño, puesta a punto y validación de un proceso de curvado realizado de manera diferente al convencional, la meta que se desea lograr con este nuevo enfoque es poder curvar una pieza conformada por cuatro lites (cristales de vidrio) en noventa minutos. En primer lugar se presenta una descripción general del proceso de curvado convencional y del nuevo proceso de curvado (hyperbending). Se da una explicación detallada de la sintonización de las variables del proceso y del papel que juegan dentro de la calidad del vidrio blindado. Finalmente se presentan los resultados obtenidos de las pruebas de validación realizadas a producto terminado.

\section{Palabras Claves}

Vidrio blindado, vidrio soda lime, curvado vidrio, recocido, templado, termo endurecido.

\section{Problema de Investigación.}

En el proceso de fabricación de vidrio blindado, se puede evidenciar que el 80\% del consumo de energía usado para producir una pieza es utilizado en el proceso de curvado; adicionalmente el $25 \%$ del tiempo de producción se consume en esta área, esto significa que cualquier mejora significativa que se pueda

\footnotetext{
${ }^{19}$ Director industrial. AGP de Colombia

${ }^{20}$ Gerente de innovación, mantenimiento e ingeniería de procesos. AGP de Colombia ${ }^{3}$ Ingeniero de innovación de procesos. AGP de Colombia
}

III Encuentro Nacional de Semilleros de Investigación de Ingeniería Industrial

Universidad Santo Tomás. Facultad de Ingeniería Industrial. 1 de noviembre de 2019 
realizar en este proceso impacta positivamente los costos de fabricación y los tiempos de entrega. Por tal motivo, se propone la implementacion de un proceso productivo con un enfoque diferente al utilizado actualmente.

\section{Curvado convencional}

El proceso de curvado convencional consiste en formar un solo bloque de capas de vidrio que entran como un solo conjunto al horno de curvado, entre las diferentes capas de vidrio se aplica talco con el fin de evitar que dos cristales adyacentes se peguen en el momento en el que la temperatura supera el punto de transición vítrea. En la figura 1 se puede ver un diagrama esquemático del proceso convencional.

Figura1. Proceso de curvado convencional

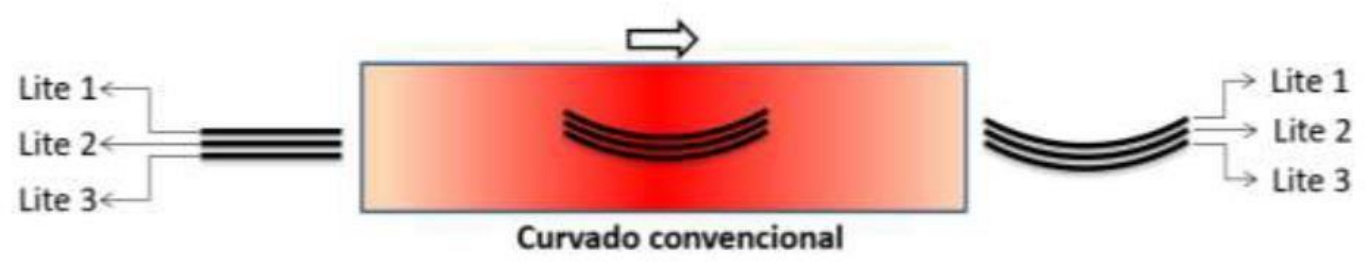

En la Figura 1, el conjunto formado por los lites 1, 2 y 3 ingresa al horno para ser calentado lentamente hasta alcanzar una temperatura aproximada de $600^{\circ} \mathrm{C}$; ya que el vidrio es extremadamente sensible a los cambios bruscos de temperatura, el calentamiento y enfriamiento de la pieza debe realizarse mediante un aumento o disminución controlado de temperatura. Debido a la masa de la pieza y a la naturaleza térmica del vidrio, el proceso de calentamiento, curvado y enfriamiento para una pieza nivel 3 dura alrededor de 16 horas.

\section{Antecedentes teóricos.}

El vidrio blindado es un multi-laminado de vidrios y polímeros especiales que es altamente resistente a impactos y que permite ver a través de él. El mercado de los vehículos blindados ha tomado una dirección que busca mimetizarse en su entorno el cual es el tráfico de las ciudades, de esta forma dificulta al atacante la identificación de su objetivo. También existe el requerimiento por parte de los usuarios de

III Encuentro Nacional de Semilleros de Investigación de Ingeniería Industrial

Universidad Santo Tomás. Facultad de Ingeniería Industrial. 1 de noviembre de 2019 
tener una mejor experiencia en el uso del vehículo blindado, es decir, que además de suplir una necesidad de seguridad cuente con un espacio cómodo que ofrezca los avances tecnológicos y formas estilizadas de los carros modernos. Este requerimiento se ha traducido para la industria del vidrio blindado en fabricar vidrios de geometrías complejas que se adapten a los nuevos estilos automovilísticos.

El procedimiento central de la fabricación de un vidrio blindado es darle su curvatura. El curvado toma lugar después de cortar el vidrio plano, para lograr la geometría deseada del vidrio se eleva su temperatura de forma tal de que los átomos de su estructura adquieran la energía suficiente para que el vidrio pase de un estado sólido a un estado viscoso, en este momento es posible otorgarle la geometría deseada. Debido a la naturaleza del vidrio, una vez se reduzca la temperatura el vidrio mantendrá dicha forma. El principal vidrio utilizado en el blindaje de automóviles es el soda lime, debido a su bajo costo y fácil adquisición.

Para poder generar la curvatura deseada al vidrio es necesario disminuir su viscosidad hasta el punto que fluya bajo su propio peso es de alrededor de $1010 \mathrm{~Pa}^{*}$ s. Esta viscosidad se da a temperaturas mayores a la temperatura de transición vítrea que Según (Beveridge, Doménech, \& Pascual, 2003) encuentra alrededor de $560^{\circ} \mathrm{C}$.

\section{Patentes}

Se realizó una búsqueda de patentes para láminas de vidrio de grandes tamaños se encontraron las siguientes invenciones que sobresalen.

- Glass sheet press bending system (KR1019870008803): Este método consiste en un calentamiento previo de la lámina de vidrio para luego ser comprimido entre un molde superior y uno inferior. (Nitschke, 딘 엠, 다비드 비. , 존 에스., \& 하롤드 에이., 1987).

- Method for bending a glass sheet and a bending mould (KR1020030023694): Método de curvado por gravedad que es sostenido en su lugar mientras ocurre el calentamiento por un componente que se encuentra en la mitad del molde y baja progresivamente hasta volverse parte del molde en sí. (LAMMI, LAMMI , \& VAEHAE , 2003).

- Method and device for bending glass sheets (KR1020010033247): Este método consiste en curvar el vidrio pano previamente precalentado al succionar el aire entre el vidrio y el molde, logrando que el

III Encuentro Nacional de Semilleros de Investigación de Ingeniería Industrial

Universidad Santo Tomás. Facultad de Ingeniería Industrial. 1 de noviembre de 2019 
vidrio adopte la forma del molde. En la Figura 5 se muestra un esquema de la invención. (DIEDEREN, OLLFISCH , HEINING, DAHLHOFF , KORSTEN , \&

RADERMACHER , 2001)

\section{Objetivos de investigación.}

\section{Objetivo general:}

- Fabricar una pieza blindada nivel 3 en un tiempo máximo de 90 minutos

Objetivos específicos:

- Diseñar y construir un horno de curvado.

- Determinar los rangos de operación de las variables térmicas del proceso

- Realizar los entandares de operación para que el proceso pueda ser utilizado por el departamento de producción

\section{Metodología.}

El enfoque metodológico para el desarrollo del proyecto fue la aplicación de la norma IATF 16929. Las principales etapas de desarrollo del proyecto son: 1. Montaje del horno, 2. Definición de variables de proceso, 3. Estimación de capacidad del proceso, 4. Reducción de tensión en borde, 5. Blindaje de piezas, 6. Pruebas de durabilidad, 7. Industrialización y estandarización del proceso, 8. Entrega del horno a producción.

Se identificaron en la tabla 1 los siguientes riesgos sobre el producto, así como las acciones claves para mitigarlos. Estos riesgos tienen en cuenta el peor escenario que se puede dar, es decir, cuando el efecto del modo de falla se presenta en el cliente final.

Tabla 1 Riesgos identificados

\begin{tabular}{|l|l|l|l|l|l|}
\hline Componente/Riesgo & Despliegue & Occión clave & Impacto & Probabilidad & Calificación \\
\cline { 2 - 5 } & Identifica & Interactúa & & & \\
\hline
\end{tabular}

III Encuentro Nacional de Semilleros de Investigación de Ingeniería Industrial

Universidad Santo Tomás. Facultad de Ingeniería Industrial. 1 de noviembre de 2019 


\begin{tabular}{|c|c|c|c|c|c|c|c|}
\hline Delaminación del producto & Innovación & \begin{tabular}{|l|} 
Laboratorio - \\
Ingenieria
\end{tabular} & Calidad del producto & $\begin{array}{l}\text { 1) Medicion de diferencias superficiales al } \\
100 \% \text { de las piezas. 2) Realizacion de pruebas } \\
\text { de durabilidad a una muestra tomada de la } \\
\text { produccion realizada. }\end{array}$ & Alto & Alto & Alto \\
\hline Rotura de cristales en pieza blindada & Innovación & & Calidad del producto & $\begin{array}{l}\text { 1) Medicion de esfuerzos superficiales al } \\
100 \% \text { de las piezas. 2) Medicion de esfuerzos } \\
\text { de tencion en borde al } 100 \% \text { de las piezas } \\
\text { producidas. 3) Medicion de diferencias } \\
\text { superficiales al } 100 \% \text { de piezas. 4) prueba de } \\
\text { vibraciones mecanicas a una muestra de la } \\
\text { piezas producidas. }\end{array}$ & Alto & Medio & Alto \\
\hline Rendimiento balistico & Innovación & R\&D & Calidad del producto & $\begin{array}{l}\text { 1) Realizacion de pruebas balisticas a una } \\
\text { muestra tomada de la produccion realizada. 2) } \\
\text { Medicion de esfuerzos superficiales. }\end{array}$ & Alto & Medio & Alto \\
\hline Deformacion en herramentales & Innovación & $\begin{array}{l}\text { Ingenieria - } \\
\text { Matriceria }\end{array}$ & Calidad de producto & $\begin{array}{l}\text { Verificacion del herramental contra el vidrio } \\
\text { patron despues de cada ciclo de curvado }\end{array}$ & Alto & Medio & Alto \\
\hline
\end{tabular}

\section{Criterios de aceptación para la aprobación del proceso}

La aceptación del proceso de fabricación depende de los resultados obtenidos en las pruebas de validación del producto. Cada una de las pruebas listadas en la Tabla 2 deben ser superadas y deben quedar certificadas por escrito por el departamento que las realice. Los resultados obtenidos se pueden ver en la Tabla.

Tabla 2. Pruebas realizadas

\begin{tabular}{|c|l|l|}
\hline \begin{tabular}{c} 
Característica $\begin{array}{c}\text { A } \\
\text { evaluar }\end{array}$ \\
\hline \multirow{5}{*}{ Durabilidad }
\end{tabular} & \multicolumn{1}{|c|}{ Actividad relacionada } & \multicolumn{1}{c|}{ Criterio de aceptación } \\
\cline { 2 - 3 } & Prueba bake & No se registran burbujas antes de los $120^{\circ} \mathrm{C}$ \\
\cline { 2 - 3 } & Prueba cambios de temperatura & $\begin{array}{l}\text { Las probetas no presentan agrietamiento, burbujas o } \\
\text { delaminación. }\end{array}$ \\
\cline { 2 - 3 } & Prueba ebullición & $\begin{array}{l}\text { Las probetas no presentan agrietamiento, burbujas o } \\
\text { delaminación. }\end{array}$ \\
\cline { 2 - 3 } & Prueba envejecimiento acelerado choque térmico & $\begin{array}{l}\text { La probeta no debe presentar agrietamiento, burbujas o } \\
\text { delaminación. }\end{array}$ \\
\cline { 2 - 3 } & $\begin{array}{l}\text { Prueba de resistencia a la } \\
\text { humedad }\end{array}$ & $\begin{array}{l}\text { Las probetas no presentan agrietamiento, burbujas o } \\
\text { delaminación. }\end{array}$ \\
\cline { 2 - 3 } & Prueba de vibraciones & $\begin{array}{l}\text { Las probetas no presentan agrietamiento, burbujas, } \\
\text { humedad o delaminación. }\end{array}$ \\
\cline { 2 - 4 } & $\begin{array}{l}\text { Pruebas de repetibilidad de } \\
\text { superficies }\end{array}$ & $\begin{array}{l}\text { Los lites de la prueba no deben presentar diferencias entre } \\
\text { si superiores a 0,6 mm }\end{array}$ \\
\hline Balística & Pruebas balísticas & Ningún proyectil penetro la pieza blindada \\
\hline
\end{tabular}

Todas las pruebas realizadas fueron aprobadas, lo cual indica que el producto desarrollado cumple con las características deseadas para ser comercializado en Colombia.

\section{Análisis de resultados}

III Encuentro Nacional de Semilleros de Investigación de Ingeniería Industrial

Universidad Santo Tomás. Facultad de Ingeniería Industrial. 1 de noviembre de 2019 
Capacidad geométrica del proceso (Delaminación de producto). La capacidad geométrica del proceso se presenta en términos de igualdad superficial entre lites curvados separadamente de una misma pieza. Para realizar la validación de la capacidad geométrica del proceso se curvaron 125 lites de la misma pieza, con el mismo molde, las mismas temperaturas de curvado y las mismas velocidades de enfriamiento. La toma de las medidas superficiales se realizó con brazo ROMER y con escáner GOM 3D. El proceso de curvado se monitoreo con dos sensores diferentes con el fin de evaluar el que produce el mejor resultado.

Sensor Opto NCDT 1700 - Medición realizada con escáner 3D (Mejor desempeño). Para la prueba del sensor NCDT 1700 se curvaron 55 lites en las condiciones descritas anteriormente, la medición de las superficies se realizó con el escáner GOM 3D y el análisis de los datos se realizó con el software del escáner. La desviación máxima encontrada es de alrededor de $0.45 \mathrm{~mm}$. Adicionalmente si se realiza una distribución de datos se encuentra que el $90 \%$ de la superficie registra una desviación menor a 0.3 mm

Con la desviación encontrada se realizaron pruebas de durabilidad y según el resultado, se definieron las tolerancias del proceso. Las diferencias superficiales resultantes entre lites para poder blindar y garantizar la calidad del producto no deben exceder el valor de $0.6 \mathrm{~mm}$; si este valor es mayor, aumenta la probabilidad de que el producto se delamine durante su operación.

Esfuerzos superficiales. Durante el curvado de cada lite de las pruebas se registraron los esfuerzos superficiales en el cristal y se generaron las cartas de control para tener un valor de referencia de la compresión en la superficie del vidrio. Para el caso del vidrio blindado automotriz se requiere que los esfuerzos superficiales del vidrio estén entre 0 y 7000 psi de compresión; esto garantiza que la fractura del vidrio en caso de un impacto balístico sea similar a la fractura característica de un vidrio recocido o termoendurecido. Los resultados obtenidos muestran que, con respecto al proceso convencional, el valor de la compresión promedio en el vidrio aumenta en un 40\%, obteniendo un valor de compresión máximo de 700 psi. La importancia de medir los esfuerzos de compresión sobre la superficie del vidrio radica en garantizar que el producto no presentará fallas por tensión; adicionalmente si los limites descritos anteriormente (0 - 7000 psi) son superados, el rendimiento balístico de la pieza puede disminuir.

III Encuentro Nacional de Semilleros de Investigación de Ingeniería Industrial 


\section{Conclusiones}

- La tolerancia de fabricación para las piezas blindadas en términos superficiales es de $0.6 \mathrm{~mm}$, con esto se garantiza que la pieza blindada no se va a delaminar durante su operación.

- Las temperaturas de operación del horno de curvado son de vital importancia ya que si se opera en temperaturas fuera del rango especificado se corre el riesgo de templar el cristal y disminuir su resistencia balística

- El tiempo de curvado logrado es de aproximadamente 90 minutos, esto representa una reducción del tiempo total del $90.6 \%$.

- Al igual que las temperaturas de operación, la velocidad de enfriamiento es de vital importancia ya que si se salen del rango definido se corre el riesgo de crear esfuerzos residuales en la superficie del cristal que comprometan la integridad mecánica de la pieza blindada.

\section{Referencias Bibliográficas}

[1] J. Barr. The Glass Tempering Handbook.

III Encuentro Nacional de Semilleros de Investigación de Ingeniería Industrial

Universidad Santo Tomás. Facultad de Ingeniería Industrial. 1 de noviembre de 2019 


\title{
Elaboración de un jabón de tocador con extracto de cúrcuma utilizando aceite reciclado
}

\author{
Francis Yuranny Chaverra Martinez ${ }^{21}$ \\ Camilo Mayo Martinez ${ }^{22}$ \\ Lina Marcela Mosquera Chaverra ${ }^{23}$
}

\section{Resumen}

Los aceites reciclados hacen parte de la preparación diaria de los alimentos, sin embargo este producto usado es vertido directamente a la fuente generando impactos ambientales negativos. En la ciudad de Quibdó no existe planta de tratamiento de aguas residuales por lo que este producto va a para a la fuente hídrica sin ningún tratamiento previo. Se propone la elaboración de un jabón de tocador con extracto de cúrcuma utilizando aceite reciclado como materia prima, proceso que inicia con la limpieza y purificación del aceite, seguido de la obtención del extracto, determinación del índice de saponificación y se finaliza con la obtención del producto, utilizando fragancias sintéticas para el aroma y el aprovechamiento del colorante amarillo que contiene la cúrcuma. El índice de saponificación obtenido fue de $195.4 \mathrm{mg} \mathrm{KOH} / \mathrm{g}$ de aceite, con un valor de $\mathrm{pH}$ en la sexta semana de 9.4 en promedio. Esta propuesta propicia el crecimiento ecológico debido al aprovechamiento de materiales de desecho

\section{Palabras Claves}

Jabón de tocador, cúrcuma, aceite reciclado, índice de saponificación.

\footnotetext{
${ }^{21}$ Estudiante Programa de Ingeniería Industrial - UNICLARETIANA

${ }^{22}$ Estudiante Programa de Ingeniería Industrial - UNICLARETIANA

${ }^{23}$ Ingeniera Química, Magíster en Desarrollo Sostenible y Medio Ambiente. Docente facultad de Ingeniería UNICLARETIANA
}

III Encuentro Nacional de Semilleros de Investigación de Ingeniería Industrial

Universidad Santo Tomás. Facultad de Ingeniería Industrial. 1 de noviembre de 2019 


\section{Problema de Investigación}

El aumento poblacional, así como los cambios en el estilo de vida, provocan la mayor producción de desechos causando varios impactos en el medio ambiente y en la salud. En las últimas décadas la gestión de residuos se convirtió en un problema importante, y se han diseñado varios procesos para el tratamiento de los residuos orgánicos (Félix et al., 2017). Ejemplo de ello es el aceite de cocina usado. El aceite vegetal es uno de los productos principales en la canasta familiar, según el DANE, 2018, el peso de los aceites y grasas en el consumo nacional aumento en los últimos años del $2.4 \%$ a $3.6 \%$, siendo los aceites vegetales los de mayor importancia al llegar al $3.324 \%$.

En los procesos de cocción todo el aceite quemado es desechado a los drenajes sin ningún tratamiento previo, Fennema, 1993, afirma que un litro de aceite convierte 1 millón de litros de agua potable en agua inutilizable, ya que el aceite flota en el agua y se hace difícil su separación, contribuyendo así a problemas de contaminación debido a la ausencia de mecanismos de recolección de este residuo orgánico. La ciudad de Quibdó no cuenta con una Planta de Tratamiento de Aguas Residuales, por lo que estos aceites y otros contaminantes van a parar a la fuente hídrica sin ningún tratamiento previo. Desde la UNICLARETIANA se pretende abordar este problema desde el punto de vista ambiental, a través de la transformación de este residuo a una materia prima (jabón de tocador); el punto de vista social, permitirá el avance en procesos que fomentan la conservación del medio ambiente y la inclusión de las comunidades.

Así se busca elaborar un jabón utilizando aceite reciclado y el aprovechamiento de especies vegetales como la cúrcuma debido a las propiedades que ofrece la especie vegetal, ya que es un potente antioxidante, y por tanto puede utilizarse como prevención de los procesos oxidativos responsables de muchas enfermedades degenerativas como el envejecimiento prematuro de la piel, los antioxidantes de la cúrcuma desempeñan un papel importante contra la lucha del envejecimiento (León, 2010). La fabricación de este producto se vuelve muy atractivo por la materia prima utilizada.

\section{Pregunta de investigación}

\footnotetext{
${ }^{24}$ Consumo de aceites vegetales tiene asiento en la canasta familiar. Recuperado de https://www.vanguardia.com/deportes/mundial-de-futbol/consumo-de-aceites-vegetales-tienen-asiento-en-lacanasta$\underline{\text { familiar-KCvl67963 }}$
}

III Encuentro Nacional de Semilleros de Investigación de Ingeniería Industrial

Universidad Santo Tomás. Facultad de Ingeniería Industrial. 1 de noviembre de 2019 
¿Comó elaborar un jabón de tocador con extracto de cúrcuma a partir de aceite de cocina reciclado?

\section{Descripción del proyecto}

Se estudia las características del aceite reciclado y la de especie vegetal cúrcuma para la elaboración de un jabón de tocador. En la elaboración de este jabón de tocador se utilizaron materiales como aceite de cocina reciclado. Se aprovechó las propiedades de la cúrcuma (colorante como extracto). Esencias sintéticas fueron utilizadas en este proceso. Este proyecto hace parte del Semillero de Investigación SIPRI, adscrito al programa de Ingeniería Industrial de la UNICLARETIANA. Se pretende que sea transferido a las comunidades en Quibdó, con el objetivo de darle una buena finalidad al residuo (aceite de cocina) que es la transformación de esta materia prima en un producto de uso cotidiano.

\section{Antecedentes teóricos}

Químicamente, el jabón es la sal sódica o potásica de un ácido graso, que se obtiene por hidrólisis alcalina de los ésteres contenidos en los materiales grasos. Si se escinde una grasa con un álcali, en lugar de con agua, se obtienen glicerina y una sal o jabón del metal alcalino con el ácido graso. Esta reacción se llama saponificación y es la base de la industria del jabón. Partiendo de esta definición, C.E. Guerrero González, en el 2014, diseñó una planta de fabricación de jabón a partir de aceites vegetales usados. Por otro lado, hay quienes les apuestan a perspectivas verdes, basadas en la reutilización de materiales de desecho, tal es el caso de S. T. Maotsela, et al., 2019, basaron su perspectiva verde en la reutilización de materiales de desecho como sebo de res y aceites vegetales de cocción para la fabricación de jabón. El aceite de cocina de desecho purificado, junto con el sebo de res se mezcló con aceite de coco, todos en diferentes proporciones. De igual forma, Félix, et al., en el 2017, quienes, a través de la reutilización de materiales de desechos, como las cáscaras de almendras, cáscaras de naranja y aceite de cocina usado elaboraron un jabón, validando un alto potencial en el campo de la educación ambiental; además afirman que la idea puede replicarse puede ser útil para la gestión de residuos, y puede apoyar el desarrollo de proyectos comunitarios con un enfoque ecológico. Debido a que el jabón es obtenido de la reacción de lípido saponificable de la cual se producen ácidos grasos y glicerina. Autores como M. Arias, 2018., realizaron la saponificación de aceites de cocina usados, obteniendo así jabones, donde demostró que con solo $250 \mathrm{ml}$ de aceite usado se logró obtener $225 \mathrm{~g}$ de jabón.

III Encuentro Nacional de Semilleros de Investigación de Ingeniería Industrial

Universidad Santo Tomás. Facultad de Ingeniería Industrial. 1 de noviembre de 2019 


\section{Objetivos de investigación}

\section{Objetivo general}

Elaborar un jabón de tocador con extracto de cúrcuma a partir de aceite de cocina reciclado

\section{Objetivos Específicos}

Determinar diferentes técnicas para la limpieza y purificación del aceite reciclado

Obtener el extracto de cúrcuma como aditivo para la elaboración del jabón de tocador Determinar el índice de saponificación del producto

\section{Metodología}

Fase 1. Determinación de las materias primas

Los productos utilizados como principales materias primas para la obtención del jabón fueron aceite de cocina usado y la especie vegetal cúrcuma. Reactivos como Hidróxido de sodio, agua y Cloruro de sodio hicieron parte del proceso. Fase 2. Limpieza y purificación del aceite de cocina.

Para la limpieza del aceite inicialmente se filtró para la eliminación de partículas. El aceite se lavó en solución de salmuera caliente ( $\mathrm{NaCl}$ al 5\%), se utilizó un embudo de separación. Se agregó gotas de una esencia sintética para minimizar el olor del aceite reciclado.

Fase 3. Obtención del extracto de cúrcuma

$\mathrm{Al}$ rizoma de la cúrcuma se le extrajo la cáscara. La parte interna se trituró y se dispuso en pequeñas cantidades de agua hasta obtener una mezcla bien espesa, esta se sometió a calentamiento para alcanzar una muestra sólida.

Fase 4. Determinación del índice de saponificación

Se siguió la metodología utilizada por Walkita et al., 2014.

Fase 5. Obtención del producto final

La coloración del producto final la dio el extracto de cúrcuma, aprovechando así el poder de la especie en cuanto a colorante se refiere. Para el aroma del producto final, se utilizó fragancias sintéticas, $10 \mathrm{ml}$ aproximadamente.

Fase 6. Medición de pH

III Encuentro Nacional de Semilleros de Investigación de Ingeniería Industrial

Universidad Santo Tomás. Facultad de Ingeniería Industrial. 1 de noviembre de 2019 
Se realizan mediciones de $\mathrm{pH}$ por un tiempo de tres meses aproximadamente, o hasta obtener un $\mathrm{pH}$ totalmente neutro (7.0), garantizando así su uso en la piel, evitando reacciones adversas.

\section{Análisis de resultados}

Los experimentos se hicieron por triplicado, los cuales fueron promediados. En la tabla 1 se presentan los resultados de las formulaciones realizadas.

Tabla 1. Formulaciones realizadas para la obtención del jabón de tocador

\begin{tabular}{|c|c|c|c|c|c|c|c|}
\hline \multirow{2}{*}{ Formulación } & \multirow{2}{*}{$\begin{array}{c}\text { Masa del } \\
\text { jabón }(\mathrm{g})\end{array}$} & \multicolumn{2}{|c|}{ Semana 2} & \multicolumn{2}{|c|}{ Semana 4 } & \multicolumn{2}{c|}{ Semana 6 } \\
\cline { 3 - 8 } & Masa $(\mathrm{g})$ & $\mathrm{pH}$ & Masa $(\mathrm{g})$ & $\mathrm{pH}$ & Masa $(\mathrm{g})$ & $\mathrm{pH}$ \\
\hline 1 & 173.5 & 151.9 & 11.45 & 139.3 & 10.57 & 124.5 & 9.8 \\
\hline 2 & 183.6 & 157.17 & 11.32 & 105.6 & 10.18 & 98.4 & 9.3 \\
\hline 3 & 195.6 & 167.48 & 11.0 & 123.7 & 10.1 & 110.5 & 9.2 \\
\hline
\end{tabular}

Fuente: autor

De la tabla anterior se infiere que hay una disminución de la masa total del jabón en cada una de las semanas medidas, de igual forma se presenta una disminución del $\mathrm{pH}$, llegando a obtener un promedio de un pH igual a 9.4. Se espera que se presente una disminución en el pH hasta alcanzar un valor neutro 7.0, conservando una textura suave y totalmente sólido.

En cuanto a la determinación del ínide de saponificación este fue de $195.4 \mathrm{mg} \mathrm{KOH} / \mathrm{g}$ de aceite, valor similar al obtenido por Félix et al., 2017, el cual arrojó un valor de $196.3 \mathrm{mg} \mathrm{KOH/} \mathrm{g} \mathrm{de} \mathrm{aceite.}$

\section{Conclusiones}

A través de esta experiencia se propocia el crecimiento de pensamientos ecológicos debido al aprovechamiento de materiales de desecho para la elaboración de un jabón de tocador; adicional se aprovecha las propiedades de especies vegetales con ciertas propiedades características como es el uso de

III Encuentro Nacional de Semilleros de Investigación de Ingeniería Industrial

Universidad Santo Tomás. Facultad de Ingeniería Industrial. 1 de noviembre de 2019 
la cúrcuma, especie vegetal con poder antioxidante que ayuda a a prevenir el envecimiento prematuro en la piel. Se hace necesario realizar pruebas con especies vegetales que ayuden a la fijación de olor, así el producto tendrá será de un carácter más natural. Debido que en esta prueba se utiliza el aceite de cocina reciclado se deben buscar alternativas para la eliminación del olor a fritura en el aceite.

Las materias primas para el desarrollo del producto son fáciles de adquirir, lo que permitirá obtener un producto verde, de buena calidad y económico.

\section{Referencias Bibliográficas}

Arias Rodríguez, M. Y. (2017). Evaluación de tècnicas de saponificación artesanal de aceites de cocina usados provenientes del municipio de Charalá.

C.E. Guerrero González, "Diseño de una planta de fabricación de jabón a partir de aceites vegetales usados", Tesis de pregrado, Ingeniería Química, Universidad de Almería, Almería, Esp, 2014

Félix, S., Araújo, J., Pires, A. M., \& Sousa, A. C. (2017). Soap production: A green prospective. Waste management, 66, 190-195.

Fennema, O., Donhowe, G. (1993). Permeabilidad al vapor de agua y al oxígeno de las películas de cera. Revista de la American Oil Chemists 'Society, 70 (9), 867-873. León, C. 2010. Proyecto para la Extracción de la Cúrcuma Longa en el Ecuador, Quito. Maotsela, T., Danha, G., \& Muzenda, E. (2019). Utilization of Waste Cooking Oil and Tallow for Production of Toilet "Bath" Soap. Procedia Manufacturing, 35, 541-545.

Wakita, K., Kuwabara, H., Furusho, N., Tatebe, C., Sato, K., \& Akiyama, H. (2014). A comparative study of the hydroxyl and saponification values of polysorbate 60 in international food additive specifications. American Journal of Analytical Chemistry, 5(03), 199.

III Encuentro Nacional de Semilleros de Investigación de Ingeniería Industrial

Universidad Santo Tomás. Facultad de Ingeniería Industrial. 1 de noviembre de 2019 


\title{
Modelo de Gestión Estratégico de Inventarios IQR para \\ Pymes
}

\author{
TGPS. Maryury Lorena Cárdenas Ortiz \\ TGPS. Jeny Alexandra Ariza Mancilla \\ MSC. María Eugenia Fonseca
}

\section{Resumen}

Los procesos de innovación empresarial se fundamentan en la gestión de conocimiento. En la actualidad, las compañías se encuentran en la búsqueda de generar valor mediante nuevos productos para garantizar el posicionamiento y la sostenibilidad. En este artículo se analizan los sistemas de gestiones de inventario pertenecientes a las pymes, pequeñas y medianas empresas, dentro de su proceso de producción requieren métodos de inventarios con el propósito de tener control eficiente, en que se determine variedad y stock razonable en sus productos. Su principal deficiencia es que carecen de una debida gestión y administración de sus registros como la diferencia entre el físico y el contable. Ahora bien, con el fin de evitar el conteo físico y mantener una competitividad en el mercado, es necesario encontrar técnicas y herramientas tecnológicas que permitan reducir los niveles de relación y lograr mayores niveles de eficiencia.

\section{Palabras Claves}

Innovación, gestión de inventarios, stock, herramientas tecnológicas, Industria 4.0.

\section{Problema de Investigación}

III Encuentro Nacional de Semilleros de Investigación de Ingeniería Industrial

Universidad Santo Tomás. Facultad de Ingeniería Industrial. 1 de noviembre de 2019 
En la actualidad, las compañías fabrican, distribuyen, comercializan mercancías y/o servicios, a través de estrategias de control en existencias, con el objeto de tener una eficiente rotación de inventarios, sin embargo, para las PYMES resulta costoso la implementación de acciones de control en sus inventarios, y en observaciones previas a sus stock se evidencian limitaciones en los procesos de control en sus inventarios, stocks afectados por distintos factores: disminución de ventas, pérdida de mercancía, caducidad, entre otros; generando así detrimento en el valor de sus activos y, por tanto, en sus inversiones. Esta investigación se encuentra en curso con la PYME los Dulces de Samu, empresa distribuidora de dulces al detal y al menudeo, ubicada en el barrio centenario de la ciudad de Bogotá, surge la siguiente pregunta problema: ¿Cómo diseñar un modelo estratégico de inventarios para el control del stock utilizando las Tecnologías de Información y Comunicación en las Pymes?

\section{Antecedentes teóricos}

El análisis del proceso de inventarios, se puede realizar mediante un diagnóstico, identificando fortalezas y debilidades en las diferentes áreas relacionadas con el manejo de registros, generando escenarios de mejora continua mediante la integración de un sistema conjunto, involucrando aspectos como plan de compras, revisión de clientes, anunciar la calidad de los productos a través de plataformas, eventos, ferias entre otros; ofrecer modalidades de pago con el fin de garantizar el crecimiento de la organización.

En el margen de analítico de la gestión estratégica de inventarios, se realiza una investigación documental sobre las nuevas metodologías de gestión. Una de las metodologías con mayor implementación es la identificación de los artículos críticos que usa el análisis $\mathrm{ABC}$, el proceso consiste en categorizar los productos del stock en tres clases del sistema ABC, las cuales se determinan de acuerdo al valor de su consumo, lo que beneficia a la toma de decisiones estratégicas y operacionales, “en la competencia por la globalización, ningún sistema produce la información adecuada, lo que puede cambiar es cómo se realiza el trabajo, tiempos y movimientos de E Taylor" [1]. Al reducir los tiempos del proceso, automáticamente se reducen los costos. Para el siglo XXI, el sistema ABC ha evolucionado en el desarrollo de un Sistema de Gestión basado en actividades (ABM); la gestión se centra en la planificación, ejecución y la medida de las actividades definidas por una empresa. Esta técnica se basa en la cadena de valor al centrarse en el análisis de las actividades que se realizan en una empresa, en la

III Encuentro Nacional de Semilleros de Investigación de Ingeniería Industrial

Universidad Santo Tomás. Facultad de Ingeniería Industrial. 1 de noviembre de 2019 
búsqueda de la mejora continua, revisar e identificar y suprimir actividades que en el paso del tiempo no han contribuido en generar importancia al servicio del cliente interno o externo.

\section{Objetivos de investigación}

\section{Objetivo General}

Diseñar una propuesta de un Modelo de Gestión Estratégico de Inventarios para las Pymes, mediante la intermediación de las TIC.

\section{Objetivos Específicos}

- Definir estrategias para el Modelo de Gestión de Inventarios.

- Diseñar un pronóstico de los inventarios de las PYMES.

- Diseñar el prototipo TIC para el Modelo de Gestión de Inventarios.

\section{Metodología}

Desarrollo de la Innovación

1. Sistema de Gestión de Inventario

III Encuentro Nacional de Semilleros de Investigación de Ingeniería Industrial

Universidad Santo Tomás. Facultad de Ingeniería Industrial. 1 de noviembre de 2019 


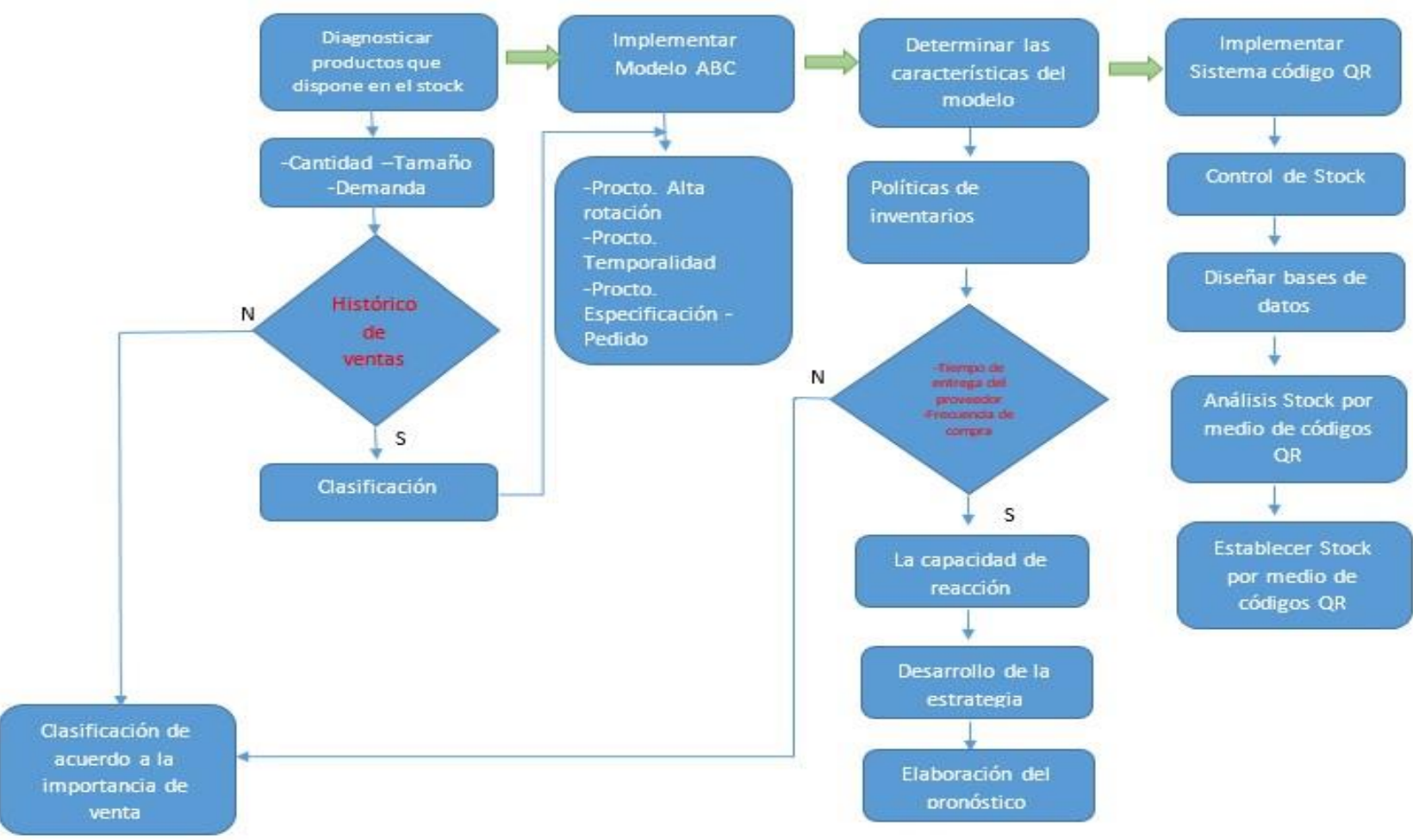

Ilustración 1. Sistema de Gestión de inventarios a implementar. Fuente: Las Autoras

Tabla 1. Modelo para la Gestión de Inventarios a Implementar

\begin{tabular}{l|l}
\hline Fase I & $\begin{array}{l}\text { Realizar un análisis a partir de las cantidades de los productos que se } \\
\text { disponen en el stock, teniendo en cuenta un histórico de ventas de los } \\
\text { productos que tienen la Pyme. }\end{array}$ \\
\hline Fase II & $\begin{array}{l}\text { Una vez realizado el diagnóstico, se propone un modelo ABC, que } \\
\text { permite clasificar los productos de acuerdo al volumen de ventas para } \\
\text { determinar la su alta rotación, la temporalidad (si solo se adquieren } \\
\text { por alguna temporada en el año) y por especificación o pedido } \\
\text { (referencias específicas); en caso de no contar con un registro de } \\
\text { ventas, su clasificación se realiza con base en grado de prioridad }\end{array}$ \\
\hline
\end{tabular}

III Encuentro Nacional de Semilleros de Investigación de Ingeniería Industrial

Universidad Santo Tomás. Facultad de Ingeniería Industrial. 1 de noviembre de 2019 


\begin{tabular}{|c|c|}
\hline & establecida. \\
\hline Fase III & $\begin{array}{l}\text { Se determinan las características y procesos a desarrollar en el } \\
\text { modelo de gestión de inventarios, teniendo en cuenta un análisis } \\
\text { previo sobre el tipo de Stock que maneja la empresa basándose en la } \\
\text { información anterior. }\end{array}$ \\
\hline \multirow{2}{*}{$\begin{array}{l}\text { Establecer } \\
\text { políticas de } \\
\text { inventario }\end{array}$} & $\begin{array}{l}\text { En caso de tener las frecuencias o tiempos de entrega por parte de los } \\
\text { proveedores, las políticas de inventario serían precisas. }\end{array}$ \\
\hline & $\begin{array}{l}\text { De lo contrario, las políticas deben ser adecuadas con el paso del } \\
\text { tiempo haciéndolo eficiente y acorde a la necesidad. }\end{array}$ \\
\hline \multirow[t]{2}{*}{$\begin{array}{l}\text { Capacidad de } \\
\text { reacción }\end{array}$} & En cuánto tiempo puedo reaccionar a las necesidades de los clientes. \\
\hline & $\begin{array}{l}\text { Como estrategia se puede detener la producción de producto o } \\
\text { adquirirlo, al reducir los costos de mano de obra. }\end{array}$ \\
\hline \multirow{5}{*}{$\begin{array}{l}\text { Elaboración del } \\
\text { Pronóstico }\end{array}$} & Determinar qué tipo de información cuenta la empresa. \\
\hline & Definir el periodo de tiempo que se va a pronosticar. \\
\hline & Análisis del costo-beneficio. \\
\hline & $\begin{array}{l}\text { Con la información anterior se establece qué tipo de pronóstico se } \\
\text { aplica a la empresa. }\end{array}$ \\
\hline & $\begin{array}{l}\text { Construcción y evaluación del modelo de pronóstico propuesto. Se } \\
\text { aplica el modelo. }\end{array}$ \\
\hline Fase IV & $\begin{array}{l}\text { Una vez establecidas todas las características del modelo de } \\
\text { inventarios, se realizará la ejecución e implementación de una } \\
\text { herramienta tecnológica, en este caso el sistema QR, lo cual permitirá } \\
\text { desarrollar de manera eficiente el proceso. }\end{array}$ \\
\hline
\end{tabular}

III Encuentro Nacional de Semilleros de Investigación de Ingeniería Industrial

Universidad Santo Tomás. Facultad de Ingeniería Industrial. 1 de noviembre de 2019 


\begin{tabular}{l|l}
\hline Implementación & Establecer bases de datos. \\
\cline { 2 - 2 } del sistema $Q R$ & $\begin{array}{l}\text { Crear los códigos QR con características especiales, por medio de } \\
\text { herramientas TIC. }\end{array}$ \\
\cline { 2 - 2 } & Asignar códigos QR a los productos.
\end{tabular}

Asignar códigos QR a los productos.

\section{Gestión del Proceso IQR}

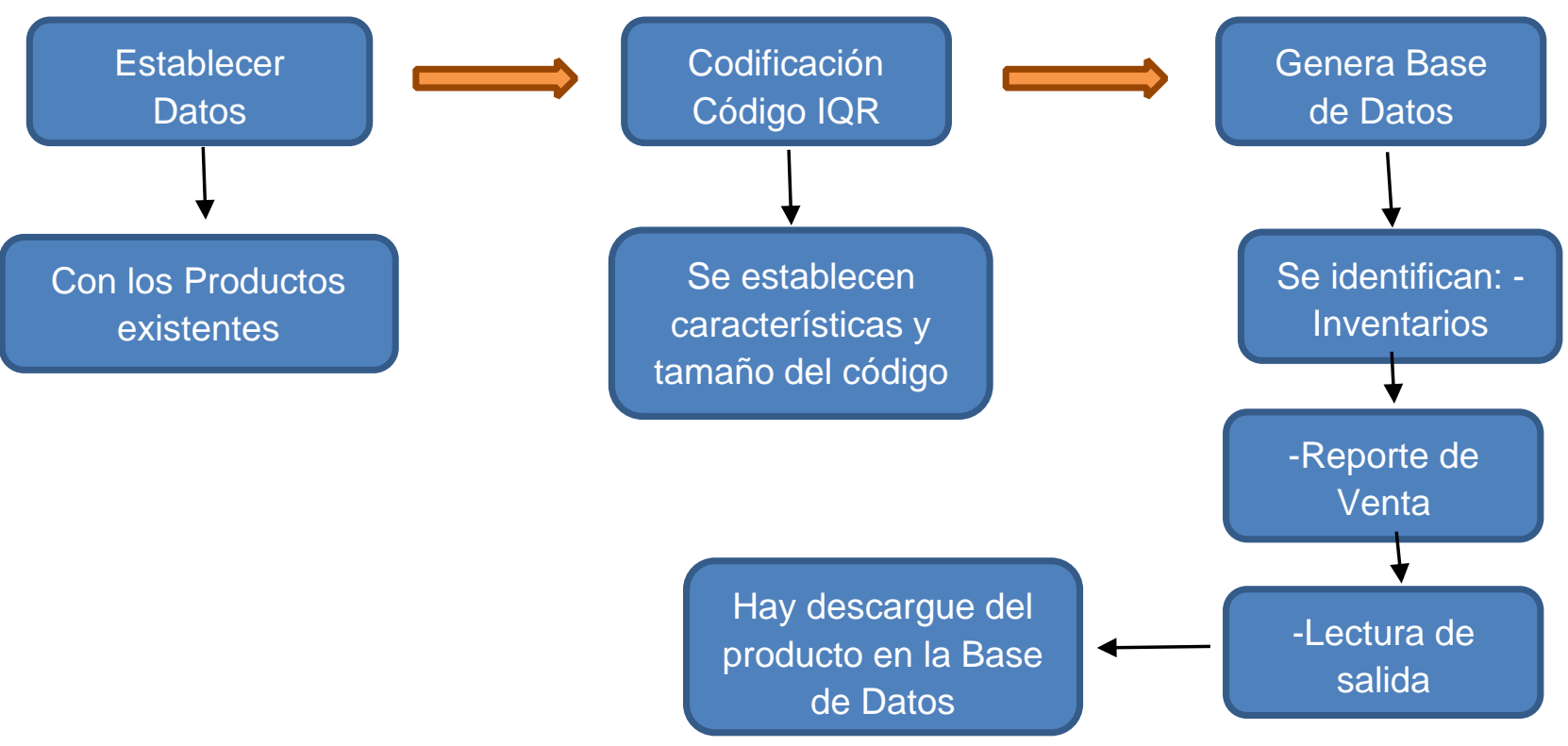

Ilustración 2. Gestión del proceso IQR. Fuente: Autoras

\subsection{Análisis del proceso de inventarios}

El análisis del proceso de inventarios se puede realizar mediante un diagnóstico, identificando fortalezas y debilidades en las diferentes áreas relacionadas con el manejo de inventarios, generando escenarios de mejora continua mediante la integración de un sistema conjunto. Del mismo modo el análisis de la gestión estratégica de inventarios se realiza mediante una investigación documental sobre las nuevas metodologías de gestión. Una de las metodologías con mayor implementación, es la identificación de los artículos críticos que usan el análisis $\mathrm{ABC}$. Este proceso consiste en categorizar los productos del stock en tres clases del sistema $\mathrm{ABC}$, se determinan de acuerdo al valor de su consumo, esto beneficia a la

III Encuentro Nacional de Semilleros de Investigación de Ingeniería Industrial

Universidad Santo Tomás. Facultad de Ingeniería Industrial. 1 de noviembre de 2019 
toma de decisiones estratégicas y operacionales, "en la competencia por la globalización, ningún sistema produce la información adecuada, lo que puede cambiar es cómo se realiza el trabajo, tiempos y movimientos de E Taylor" [1].

Para realizar el proceso de la Gestión de Inventarios mediante los IQR, inicialmente se debe realizar una base de datos con características definidas que resalten el código de los productos. Es válido mencionar que, estos códigos se determinaron con una peculiaridad específica de manera alfanumérica. Para ello se tuvo en cuenta:

- Categorización, la información fue desarrollada teniendo en cuenta las necesidades de la Pyme, con el fin de delimitar la información y agruparla.

- Caracterización, esta es utilizada en la descripción del producto en la que se determina el nombre del producto, el peso de cada empaque y de las unidades que tiene cada paquete.

- Tipo 1 y 2, esta se realiza para ser más específicos en las diferentes características de los productos como, por ejemplo: nacionales o importados.

Una vez determinadas estas características se establecen las políticas de inventario en las que se establece el stock mínimo y máximo para cada producto, se establecen los periodos de compra, entre otros aspectos. Con esta información se instauran los parámetros que permiten determinar la gestión del inventario y generar así una base de datos.

También, al determinar la base de datos, se procede a generar los códigos IQR de cada uno de los productos. El IQR que se genera contiene la información específica de cada producto. Luego de establecidos los IQR se procede a integrar la Base de Datos creada anteriormente en la aplicación la cual va a funcionar de la siguiente forma:

- Al ingresar al aplicativo este nos va a solicitar un usuario y contraseña que fue suministrado a la persona encargada de los Dulces de Samu.

- Al ingresar tenemos varias opciones para generar el ingreso de algún producto al inventario o la descarga del producto de inventario.

- El proceso de cargue o descargue de los productos de la base de datos (Inventario), se realiza por medio de la lectura del IQR. Además, por medio del aplicativo se puede ver el estado del inventario.

III Encuentro Nacional de Semilleros de Investigación de Ingeniería Industrial

Universidad Santo Tomás. Facultad de Ingeniería Industrial. 1 de noviembre de 2019 


\section{Análisis de resultados}

Contribuir al proceso de inventarios con una gestión metodológica práctica y flexible, ayudados de las TIC y de los códigos IQR, hace que la PYMES puedan obtener rotaciones en sus mercancías a menor costo. Normalmente para la gestión de inventarios se piensa en grandes inversiones de dinero para la adquisición de máquinas registradoras, lectoras de barras, entre otros insumos, sin contar el tiempo que conlleva a realizar el conteo del inventario. Con la propuesta de la tecnología QR, los costos de inversión disminuirán, llegando a ser cero, usando solo un teléfono inteligente para su conteo, actualización de inventarios y como software la hoja de cálculo, con la viabilidad de tener stocks en tiempo real.

\section{Conclusiones}

Analizando el proceso de gestión de inventarios en el cual se realizó un diagnóstico, se identificaron fortalezas y debilidades en las diferentes áreas relacionadas; generando escenarios de mejora continua a través de la integración de un sistema conjunto. Se involucraron aspectos como: plan de compras, revisión de proveedores, por medio de plataformas digitales; creando la posibilidad de realizar un sistema de gestión de inventarios con la intermediación de las TIC, en este caso los códigos IQR, los cuales permiten almacenar la información, lectura rápida y de fácil acceso.

No obstante, al implementar los IQR, en el sistema de inventarios, se almacenó la información de cada uno de los productos establecidos con características especiales.

El Sistema de Gestión de Inventarios IQR, permitirá a las Pymes tener control de su inventario y conocer su stock, permite visualizar en tiempo real el comportamiento de su inventario.

\section{Referencias Bibliográficas}

[1] U. U. A. Latina, «Universidad America Latina,»12 $05 \quad 2018$ [En línea]. Available: http://ual.dyndns.org/Biblioteca/Costos_II/Pdf/Unidad_05.pdf.

III Encuentro Nacional de Semilleros de Investigación de Ingeniería Industrial

Universidad Santo Tomás. Facultad de Ingeniería Industrial. 1 de noviembre de 2019 
[2] H. D. Oyola y V. L. Chica, «Diseño e Implementación de un Sistema de Citas de Optometría, Manejo de Especificaciones y Características de Monturas Usando Tecnología QR Code para la Óptica Visión e Imagen del Caribe S. A. S.,» 2015. [En línea]. Available:

http://repositorio.unicordoba.edu.co/handle/123456789/481?show=full.

III Encuentro Nacional de Semilleros de Investigación de Ingeniería Industrial

Universidad Santo Tomás. Facultad de Ingeniería Industrial. 1 de noviembre de 2019 


\title{
Fuerza de agarre según edad y género en un grupo de trabajadores de la ciudad de Bogotá.
}

\author{
Danna Jiménez ${ }^{25}$ \\ Linda Narváez ${ }^{26}$ \\ Ing. Magda Monroy ${ }^{27}$
}

\section{Resumen}

El proyecto de investigación aborda la valoración de la fuerza de agarre de un grupo de trabajadores de la población industrial y su relación con las variables de edad y género. El estudio contó con la participación de 84 trabajadores, con edades entre los 18 y 68 años, con vinculación laboral activa, que cumplieran los criterios de inclusión. Se evidenció que los hombres jóvenes de este grupo de trabajadores del sector industrial presentan una mayor fuerza de agarre en la mano derecha y que esta disminuye de acuerdo a la edad.

\section{Palabras Claves}

Fuerza de agarre, género, edad, población industrial.

\section{Problema de Investigación}

\footnotetext{
${ }^{25}$ Universidad Santo Tomás, Sede Bogotá. Estudiante de Ingeniería Industrial. Semillero de Mejoramiento de Procesos. Contacto: dannajimenez@usantotomas.edu.co.

${ }^{26}$ Universidad Santo Tomás, Sede Bogotá. Estudiante de Ingeniería Industrial. Semillero de Mejoramiento de Procesos. Contacto: lindanarvaez@usantotomas.edu.co.

${ }^{27}$ Universidad Santo Tomás, Sede Bogotá. Docente Tiempo Completo Facultad de Ingeniería Industrial. Líder de investigación. Contacto: magdamonroy@usantotomas.edu.co.
}

III Encuentro Nacional de Semilleros de Investigación de Ingeniería Industrial

Universidad Santo Tomás. Facultad de Ingeniería Industrial. 1 de noviembre de 2019 
En la última década, Colombia ha implementado normatividad referente a la Seguridad y Salud en el Trabajo (SST) que le han permitido inspeccionar, controlar y prevenir los aspectos que a esta repercute en pro de brindar a los trabajadores de la población colombiana un adecuado ambiente laboral [1]. Sin embargo, es escasa la información estadística que se presenta acerca de la SST en el país, específicamente en relación a las capacidades físicas de la población colombiana y su contribución a la aparición de enfermedades laborales prevalentes como los desórdenes musculoesqueléticos (DME). Lo anterior, incentiva a generar nuevas investigaciones orientadas bajo los estudios realizados en el extranjero, en donde se presenten objetivos, poblaciones impactadas, métodos de recolección de información, variables identificadas y resultados, de manera que se logre promover información para el diseño de

nuevas herramientas que permitan identificar las características y capacidades físicas de la población colombiana. El Semillero de Mejoramiento de Procesos (SiMeP) de la Facultad de Ingeniería Industrial de la Universidad Santo Tomás realizó una recolección de información demográfica, social, sintomatológica, y midió la fuerza de agarre y dimensiones antropométricas de la mano en algunas empresas del sector industrial de la ciudad de Bogotá, con el fin de presentar un diagnóstico inicial sobre las capacidades físicas de sus trabajadores, específicamente la fuerza máxima de agarre, y su comportamiento de acuerdo con la edad y el género de los colaboradores. En consecuencia el presente estudio pretende dar respuesta al siguiente interrogante: ¿Cómo se relaciona la fuerza de agarre con las variables edad y género de un grupo de trabajadores del sector industrial?

\section{Antecedentes teóricos}

El Boletín Médico de Postgrado Vol. XVII registra un artículo de científico en el que se reconocen los valores de la fuerza de la mano en adultos sanos, tomando de referencias las variables de edad y género. El estudio fue aplicado a 212 adultos sanos: 124 hombres $(58,49 \%)$ y 88 mujeres $(41,51 \%)$ con edades comprendidas entre 18 y 55 años. Los resultados más significativos arrojan que los hombres presentaron mayor fuerza de agarre en mano derecha con $43.06 \mathrm{Kg} / \mathrm{F}$ con una desviación de 7.61 Kg/F, en donde la fuerza registrada es directamente proporcional a la talla y aumenta con respecto a la edad hasta los 39 años y en adelante disminuye [2]. Sin embargo, Andrés Felipe Gamboa de la Facultad de Salud de la Universidad del Valle, en su tesis de grado registra datos de la

III Encuentro Nacional de Semilleros de Investigación de Ingeniería Industrial

Universidad Santo Tomás. Facultad de Ingeniería Industrial. 1 de noviembre de 2019 
fuerza de agarre relacionada con las variables de edad y género, de los cuales concluye que la mayor fuerza de agarre se presenta en la mano izquierda con $51.25 \mathrm{Kg} / \mathrm{F}$ [3].

En 2016, el Congreso Brasileño de Ingeniería Biomédica registró un artículo científico acerca de la dinamometría escapular, su relación con la variables de edad, género y fuerza de agarre, con 2793 participantes entre los 18-63 años de edad. El estudio arrojó que las variables de edad y género se relacionan directamente con la edad, permitiendo identificar factores que contribuyen a la adopción de conductas preventivas [4]. Un estudio presentado en la revista SCIELO de Ciudad de México, con una muestra de 676 personas concluye que la mano derecha tiene mayor fuerza de agarre y no está relacionada con la mano dominante del participante [5]. Ecuador cuenta con estudios en donde se encuentra la relación de la fuerza de agarre con el género, edad y mano dominante, Milton Proaño asegura en su tesis para licenciatura que en la población afro ecuatoriana en género masculino y femenino se encontró que la fuerza de género masculino predomina sobre la fuerza del género femenino tanto en mano dominante como no dominante. Del mismo modo se evidenció la relación de la fuerza de agarre con longitud máxima es inversamente proporcional, disminuyendo la fuerza con 4 $\mathrm{Kg} / \mathrm{F}[6]$.

\section{Objetivos de investigación}

\section{Objetivo general}

Determinar la influencia de la edad y el género en la fuerza máxima de agarre de un grupo de trabajadores del sector industrial de la ciudad de Bogotá.

\section{Objetivos específicos}

- Documentar las dimensiones antropométricas de las manos de un grupo de trabajadores del sector industrial de la ciudad de Bogotá.

- Determinar la máxima fuerza de agarre en un grupo de trabajadores del sector industrial de la ciudad de Bogotá.

- Identificar la variación de la fuerza de agarre en función de la edad y género de un grupo de trabajadores del sector industrial de la ciudad de Bogotá.

\section{Metodología}

III Encuentro Nacional de Semilleros de Investigación de Ingeniería Industrial

Universidad Santo Tomás. Facultad de Ingeniería Industrial. 1 de noviembre de 2019 
Para el reclutamiento de población para el estudio se realizaron invitaciones abiertas y de participación voluntaria en empresas públicas, mixtas y privadas con vinculación de personal de hombres y mujeres en edad laboralmente activa, en edades entre los 18 y 68 años, que no presentaran antecedentes de DME, sin diagnósticos médicos en sus miembros superiores, que no entrenaran físicamente sus miembros superiores y que desempeñarán actividades en áreas industriales o afines en la ciudad de Bogotá, Colombia.

Como resultado, participaron en el estudio 7 empresas de diferentes actividades económicas: construcción, madera, textiles, metalmecánica, espumas y transportes. La población de estudio estuvo representada por un total de noventa y cuatro (94) trabajadores, sin embargo, sólo ochenta y nueve (89) trabajadores cumplieron los criterios de inclusión.

El protocolo de medición y recolección de la información se muestra detalladamente a través de los pasos de socialización y presentación del proyecto para cada colaborador, aprobación de participación y firma de consentimiento Informado del colaborador, diligenciamiento del formulario- Protocolo de medición, realización de la prueba fuerza máxima de agarre. Para el caso de instrumentos de medición y recolección de la información fueron utilizados el metro, pesa, calibrador, flexo metro, cono antropométrico y dinamómetro hidráulico Jamar. El tratamiento de los datos se realizó con estadística descriptiva por medio de la herramienta

Excel, en donde se analizaron las variables edad y género en función de la fuerza de agarre, teniendo en cuenta los promedios de la fuerza de agarre, la desviación estándar y varianza entre ellos.

\section{Análisis de resultados}

Para el desarrollo de este proyecto de investigación se tuvieron en cuenta noventa y cuatro (94) trabajadores, sin embargo, sólo ochenta y nueve (89) participaron ya que cumplían con todos los criterios de inclusión y bajo su consentimiento permitieron realizar la prueba y el registro de datos. El estudio contó con la participación de 29 mujeres y 60 hombres, correspondiente a $32.58 \%$ y $67.41 \%$ de la muestra, respectivamente. Asimismo, la población participante se encuentra en un rango de edad entre 18 y 68 años, en donde, el $44.9 \%$ presenta una edad entre los 18 y 32 años, el $24.71 \%$ entre los 33 y 47 años y el $30.33 \%$ entre los 48 y 68 años.

III Encuentro Nacional de Semilleros de Investigación de Ingeniería Industrial

Universidad Santo Tomás. Facultad de Ingeniería Industrial. 1 de noviembre de 2019 
En la Tabla I, se registran los promedios de la fuerza de agarre y su desviación estándar en relación con las variables edad y género.

Tabla 1. Valoración de la fuerza de agarre

\begin{tabular}{|c|c|c|c|c|c|c|c|c|c|c|}
\hline \multicolumn{3}{|c|}{ FUERZA DE AGARRE } & \multicolumn{4}{|c|}{ Mano derecha } & \multicolumn{4}{|c|}{ Mano izquierda } \\
\hline & /F) & $\begin{array}{c}\text { No. } \\
\text { Participante } \\
\text { s }\end{array}$ & Min & $\begin{array}{c}\text { Pro } \\
\text { m }\end{array}$ & $\operatorname{Max}$ & $\begin{array}{c}\text { Desv. } \\
\text { estánda } \\
\mathbf{r}\end{array}$ & Min & $\begin{array}{c}\text { Pro } \\
\text { m }\end{array}$ & Max & $\begin{array}{c}\text { Desv. } \\
\text { estánda } \\
\mathbf{r}\end{array}$ \\
\hline \multicolumn{2}{|c|}{ Población total } & 89 & $\begin{array}{c}21,0 \\
0\end{array}$ & 45,46 & $\begin{array}{c}84,0 \\
0\end{array}$ & 14,16 & $\begin{array}{c}18,6 \\
7\end{array}$ & 44,34 & $\begin{array}{c}82,0 \\
0\end{array}$ & 14,62 \\
\hline \multirow[t]{3}{*}{ Edad } & $\begin{array}{l}\text { Entre } 18 \text { a } \\
32 \text { años }\end{array}$ & 40 & $\begin{array}{c}25,6 \\
7\end{array}$ & 51,04 & $\begin{array}{c}84,0 \\
0\end{array}$ & 12,84 & $\begin{array}{c}24,0 \\
0\end{array}$ & 49,25 & $\begin{array}{c}78,3 \\
3\end{array}$ & 13,94 \\
\hline & $\begin{array}{c}\text { Entre } 33 \text { a } \\
47 \text { años }\end{array}$ & 22 & $\begin{array}{c}21,0 \\
0\end{array}$ & 44,87 & $\begin{array}{c}76,0 \\
0\end{array}$ & 15,05 & $\begin{array}{c}21,6 \\
7\end{array}$ & 44,36 & $\begin{array}{c}82,0 \\
0\end{array}$ & 15,72 \\
\hline & $\begin{array}{l}\text { Más de } 47 \\
\text { años }\end{array}$ & 27 & $\begin{array}{c}21,3 \\
3\end{array}$ & 38,14 & $\begin{array}{c}68,6 \\
7\end{array}$ & 12,02 & $\begin{array}{c}18,6 \\
7\end{array}$ & 37,48 & $\begin{array}{c}68,6 \\
7\end{array}$ & 12,16 \\
\hline \multirow[t]{2}{*}{ Género } & Masculino & 29 & $\begin{array}{c}31,3 \\
3\end{array}$ & 52,94 & $\begin{array}{c}84,0 \\
0\end{array}$ & 10,46 & $\begin{array}{c}35,6 \\
7\end{array}$ & 52,27 & $\begin{array}{c}82,0 \\
0\end{array}$ & 10,46 \\
\hline & Femenino & 62 & $\begin{array}{c}21,0 \\
0\end{array}$ & 29,96 & $\begin{array}{c}42,3 \\
3\end{array}$ & 5,57 & $\begin{array}{c}18,6 \\
7\end{array}$ & 27,92 & $\begin{array}{c}40,3 \\
3\end{array}$ & 5,21 \\
\hline \multirow{2}{*}{$\begin{array}{l}\text { Entre } \\
18 \text { a } 32 \\
\text { años }\end{array}$} & Masculino & 30 & $\begin{array}{c}39,0 \\
0\end{array}$ & 56,14 & $\begin{array}{c}84,0 \\
0\end{array}$ & 9,56 & $\begin{array}{c}35,6 \\
7\end{array}$ & 54,85 & $\begin{array}{c}78,3 \\
3\end{array}$ & 10,37 \\
\hline & Femenino & 9 & $\begin{array}{c}25,6 \\
7\end{array}$ & 34,02 & $\begin{array}{c}42,3 \\
3\end{array}$ & 5,35 & $\begin{array}{c}24,0 \\
0\end{array}$ & 30,60 & $\begin{array}{c}40,3 \\
3\end{array}$ & 4,88 \\
\hline \multirow{2}{*}{$\begin{array}{l}\text { Entre } \\
33 \text { a } 47 \\
\text { años }\end{array}$} & Masculino & 15 & $\begin{array}{c}33,3 \\
3\end{array}$ & 52,52 & $\begin{array}{c}76,0 \\
0\end{array}$ & 11,52 & $\begin{array}{c}37,0 \\
0\end{array}$ & 52,34 & $\begin{array}{c}82,0 \\
0\end{array}$ & 11,94 \\
\hline & Femenino & 7 & $\begin{array}{c}21,0 \\
0\end{array}$ & 28,50 & $\begin{array}{c}35,8 \\
3\end{array}$ & 4,94 & $\begin{array}{c}21,6 \\
7\end{array}$ & 27,25 & $\begin{array}{c}36,7 \\
3\end{array}$ & 5,60 \\
\hline \multirow{2}{*}{$\begin{array}{l}\text { Más de } \\
47 \text { años }\end{array}$} & Masculino & 15 & $\begin{array}{c}31,3 \\
3\end{array}$ & 46,98 & $\begin{array}{c}68,6 \\
7\end{array}$ & 8,86 & $\begin{array}{c}38,6 \\
7\end{array}$ & 47,07 & $\begin{array}{c}68,6 \\
7\end{array}$ & 7,27 \\
\hline & Femenino & 13 & $\begin{array}{c}21,3 \\
3\end{array}$ & 27,94 & $\begin{array}{c}38,0 \\
0\end{array}$ & 4,80 & $\begin{array}{c}18,6 \\
7\end{array}$ & 26,42 & $\begin{array}{c}35,8 \\
3\end{array}$ & 4,86 \\
\hline
\end{tabular}

De acuerdo a los resultados obtenidos en la recolección de información, se evidenció que la población total presenta mayor fuerza de agarre en la mano derecha, con un registro de fuerza promedio de 45.46 $\mathrm{Kg} / \mathrm{F}$, registrando una desviación de $14.16 \mathrm{Kg} / \mathrm{F}$. La mayor fuerza promedio en mano derecha la registran aquellos participantes pertenecientes al rango de edad entre los 18 y 32 años con una fuerza promedio de $51.04 \mathrm{Kg} / \mathrm{F}$ y una desviación de $12.84 \mathrm{Kg} / \mathrm{F}$. De acuerdo a la variable de género de los participantes, se evidenció que la fuerza de agarre promedio entre hombres y mujeres cuenta con una desviación de 16.24 $\mathrm{Kg} / \mathrm{F}$, de igual manera se registra mayor fuerza de agarre en los hombres con un dato promedio de 52.94

III Encuentro Nacional de Semilleros de Investigación de Ingeniería Industrial

Universidad Santo Tomás. Facultad de Ingeniería Industrial. 1 de noviembre de 2019 
$\mathrm{Kg} / \mathrm{F}$ y desviación de $10.46 \mathrm{Kg} / \mathrm{F}$. Los hombres que se encuentran en el rango de edad de 18 a 32 años, registran la mayor fuerza entre ellos, con una fuerza de agarre promedio en mano derecha de $56.14 \mathrm{Kg} / \mathrm{F}$ y una desviación de $9.46 \mathrm{Kg} / \mathrm{F}$.

\section{Conclusiones}

En el grupo de trabajadores de la población industrial de Bogotá incluidos en el estudio, se evidencia que los hombres entre los 18 y 32 años de edad registran una mayor fuerza de agarre en la mano derecha $(56.14 \mathrm{Kg} / \mathrm{F})$ y esta disminuye de acuerdo a la edad con una desviación de $4.61 \mathrm{Kg} / \mathrm{F}$. La mano derecha presenta mayor fuerza de agarre que la izquierda con una desviación de $0.79 \mathrm{Kg} / \mathrm{F}$, es decir, la fuerza de agarre es mayor en la mano derecha a pesar de la relación que se tenga con las variables edad y género.

\section{Referencias Bibliográficas}

[1] La Nota Económica. (2018). [Online]. Available:

http://lanotaeconomica.com.co/economica/como-avanza-la-seguridad-industrial-encolombia.html

[2] I. Bowen und D. Mendoza, "Valoración de la fuerza de la mano en adultos sanos.", 2001.

[3] A. Gamboa, "Manifestaciones clínicas y diagnóstico electromiográfico de síndrome de túnel carpiano en trabajadores expuestos a vibración del segmento mano-brazo en una empresa de construcción de la ciudad de Cali.”, Colombia, 2014.

[4] J. De Trotta, L. Beraldo und L. Ulbricht, "O.Apresentação de um protocolo de referência para análise dinamométrica da força escapular em funcionários do setor industrial eletromecânico.”, Brasil, 2016.

[5] J. Rojas, L. Vázquez, G. Sánchez, S. Banik und J. Argáez, "Dinamometría de manos en estudiantes de merida, méxico.”, México, 2012.

[6] M. Proaño, "Tesis previa a la obtención del título de licenciatura en, \& Terapia física médica", Ecuador, 2016.

III Encuentro Nacional de Semilleros de Investigación de Ingeniería Industrial

Universidad Santo Tomás. Facultad de Ingeniería Industrial. 1 de noviembre de 2019 


\title{
Antropometría y biomecánica aplicada al rediseño del puesto de trabajo soldadura de compresor
}

\author{
William Fernando Agudelo González ${ }^{28}$ \\ Santiago Giraldo Gámez ${ }^{2}$ \\ Mateo Gómez Duque 3 \\ Elizabeth Pérez Mergarejo 29
}

\section{Resumen}

Los diseños inadecuados de los puestos de trabajo contribuyen con la aparición de enfermedades en los trabajadores. En esta investigación se evalúan las condiciones físicas del puesto de trabajo soldadura de compresor desde el punto de vista antropométrico y biomecánico. Se usaron las directrices de la ISO 14743 y las dimensiones antropométricas de la población colombiana presentes en el estudio ACOPLA 95. De acuerdo con las características del puesto, la población objetivo fueron hombres que inicialmente se encontraban en posición sedente, y se rediseña para que la labor se haga de pie. El rediseño físico del puesto fue orientado hacia su adecuación para la mayoría de la población, la mitigación de esfuerzos y lesiones en los soldadores.

\section{Palabras Claves}

Dimensiones antropométricas, ergonomía, rediseño ergonómico, principios biomecánicos.

\section{Problema de Investigación}

\footnotetext{
${ }^{28}$ Universidad Pontificia Bolivariana, Sede Medellín. Semillero de Investigación en Productividad (SIPROC). Contacto: william.agudelog@upb.edu.co

${ }^{29}$ Universidad Pontificia Bolivariana, Sede Medellín. Docente asociado de Ergonomía y Seguridad y Salud en el Trabajo. Contacto: elizabeth.perezme@upb.edu.co
}

III Encuentro Nacional de Semilleros de Investigación de Ingeniería Industrial

Universidad Santo Tomás. Facultad de Ingeniería Industrial. 1 de noviembre de 2019 
Un correcto diseño del puesto de trabajo permite aprovechar los espacios dispuestos para realizar actividades productivas, con el fin de encontrar una armonía entre la operación a realizar y las dimensiones del cuerpo humano. En la práctica estos principios no siempre se cumplen. En muchas empresas se sigue cometiendo el error de diseñar los espacios físicos con muebles, equipos, herramientas diseñadas para poblaciones con características antropométricas y biomecánicas diferentes. Como consecuencia los trabajadores comienzan a presentar molestias y enfermedades musculoesqueléticas, que en la mayoría de los casos se buscan solucionar por vías erróneas.

Pregunta de investigación: ¿El adecuado diseño físico de un puesto de trabajo puede contribuir con el aumento de la productividad y la salud del trabajador?

Se interviene el puesto de trabajo soldadura de compresor, en una empresa manufacturera y de distribución de electrodomésticos. El trabajador permanece en posición sedente durante las 8 horas de la jornada laboral. El puesto requiere de alta presión visual y de la manipulación herramientas y de materiales inflamables.

\section{Antecedentes teóricos}

Una parte importante de los principios a considerar para el diseño físico adecuado de los sistemas de trabajo son derivados de la biomecánica y la antropometría [1]. La biomecánica implica el entendimiento del funcionamiento mecánico del cuerpo humano. Por lo cual, muchas leyes de la física mecánica son estudiadas para entender cómo el cuerpo, a través de los músculos y las articulaciones es capaz de adoptar posturas, de realizar movimientos y esfuerzos físicos [1].

Por su parte, la antropometría se centra en la determinación de las dimensiones y proporciones de cuerpo humano [1]. Esta información antropométrica resulta muy valiosa en el diseño físico de los sistemas de trabajo. El lineamiento principal es diseñar el lugar de trabajo para proporcionar espacio a más individuos respecto al tamaño y estructura del cuerpo humano [2]. En este mismo sentido la norma ISO 14743 expone los requisitos antropométricos para el diseño de los puestos de trabajo de máquinas [3, p. 14]. Estas directrices son una valiosa guía en diseño de puestos de trabajo.

Los conceptos anteriores son aplicados entonces en ergonomía para analizar y modificar las condiciones físicas de trabajo en los sistemas de trabajo. La aplicación de los principios de biomecánica y de antropometría en la concepción y diseño de los sistemas de trabajo, garantizan ambientes de trabajos saludables y productivos teniendo en cuenta las limitaciones y capacidades físicas de los trabajadores.

III Encuentro Nacional de Semilleros de Investigación de Ingeniería Industrial

Universidad Santo Tomás. Facultad de Ingeniería Industrial. 1 de noviembre de 2019 


\section{Objetivos de investigación}

\section{Objetivo general:}

Evaluar las condiciones físicas del puesto de trabajo soldadura de compresor considerando los principios antropométricos y biomecánicos.

\section{Objetivos específicos:}

Identificar los problemas físicos en el puesto de trabajo soldadura de compresor que dificultan la realización de la tarea, empleando los directrices de la norma ISO 14738 y los principios básicos de biomecánica.

$>$ Elaborar una propuesta de rediseño para el puesto de trabajo soldadura de compresor que cumpla con los principios biomecánicos y antropométricos requeridos para ejecutar la tarea.

\section{Metodología}

Se analizó un el puesto de trabajo soldadura de compresor, en el cual se requiere alta precisión visual para realizar la tarea y el trabajo se realiza sentado. Por esta causa el trabajador permanece con la espalda y el cuello en flexión durante toda la jornada laboral. La herramienta que utiliza en trabajador funciona con gas y emite grandes cantidades de luz y calor. La población objetivo para diseño fueron hombres, con edad laboral entre 20 y 59 años. La fuente de datos antropométricos para el diseño se tomó del estudio de las dimensiones antropométricas de la población colombiana ACOPLA 95 [4].

En la propuesta fueron considerados los principios de diseño para individuos extremos y el diseño ajustable. Fueron usados los percentiles 5 y 95 para el diseño (ecuaciones 1 y 2).

$$
\begin{array}{ccc}
X_{p 5}=\bar{X}-\beta S & \begin{array}{c}
\text { ecuación } 1 \\
\mathrm{Xp} \text { : percentil }
\end{array} & \text { Donde: } \\
X_{p 95}=\bar{X}+\beta S & \begin{array}{c}
- \\
\text { ecuación } 2
\end{array} & X: \text { media } \\
& \beta: 1,645 \text { para } \mathrm{X}_{\mathrm{p} 5} \mathrm{y} \mathrm{X}_{\mathrm{p} 95} \\
& S: \text { desviación estándar }
\end{array}
$$

III Encuentro Nacional de Semilleros de Investigación de Ingeniería Industrial 
El rediseño implicó la transformación de la tarea de postura sedente a postura de pie. Donde según las directrices de norma ISO 14738 se transformó la altura del plano de trabajo para trabajos con altura no ajustable (ecuación 3). La altura quedó ajustada para presión visual media, para aliviar las molestias ocasionadas por la herramienta de trabajo. Se diseñó una plataforma con altura ajustable (ecuación 4) para que el trabajador permaneciera de pie sobre esta y garantizar la ajustabilidad del puesto de trabajo.

$$
\begin{array}{lll}
A_{\text {máx }}=1,3 * h_{4}(P 95) & \text { ecuanción } 3 & \text { Donde: } \\
G_{\text {máx }}=h_{4}(P 95)-h_{4}(P 5) & \text { ecuación } 4 & h_{4}(P 95): \text { altura de codos }
\end{array}
$$

\section{Análisis de resultados}

En la tabla 1 y la Fig. 1 se muestran los resultados del rediseño físico en el puesto de trabajo soldadura de compresor. En el nuevo puesto de trabajo el operario permanecerá en una postura de pie, la cual es la óptima para este tipo de trabajo. Además, la plataforma se ajusta de manera hidráulica para qué la mayor parte de la población pueda realizar este trabajo. Las herramientas más necesarias estarán a una correcta distancia y con facilidad de ajuste en el caso del equipo de soldadura, las barras de soldadura y el espejo para la inspección. Se adiciona una silla donde puede descansar durante la jornada y una antifatiga.

Tabla 1. Medidas tenidas en cuenta para el rediseño.

\begin{tabular}{|l|c|}
\hline \multicolumn{2}{|c|}{ Altura posición de trabajo precision } \\
Alta $(\mathrm{cm})$
\end{tabular}

\begin{tabular}{|l|c|}
\hline \multicolumn{2}{|c|}{$\begin{array}{c}\text { Mltura posicion de trabajo precision } \\
\text { Media (cm) }\end{array}$} \\
\hline h4(P95) & 118,48 \\
\hline $\mathrm{k}$ & N.A \\
\hline Bmax & 118,48 \\
\hline
\end{tabular}

\begin{tabular}{|c|c|l|c|}
\hline \multicolumn{2}{|c|}{$\begin{array}{r}\text { Altura puesto de trabajo } \\
\text { Soldador(cm) }\end{array}$} & \multicolumn{2}{c|}{ Altura plataforma ajustable } \\
\hline \multirow{2}{*}{ Promedio } & 136,25 & h4(P95) & 118,48 \\
\cline { 3 - 5 } & & h4(P5) & 98,15 \\
\cline { 3 - 4 } & Gmax & 20,32 \\
\hline Altura de codos (Altura barandas \\
plataforma) (cm)
\end{tabular}

III Encuentro Nacional de Semilleros de Investigación de Ingeniería Industrial

Universidad Santo Tomás. Facultad de Ingeniería Industrial. 1 de noviembre de 2019 

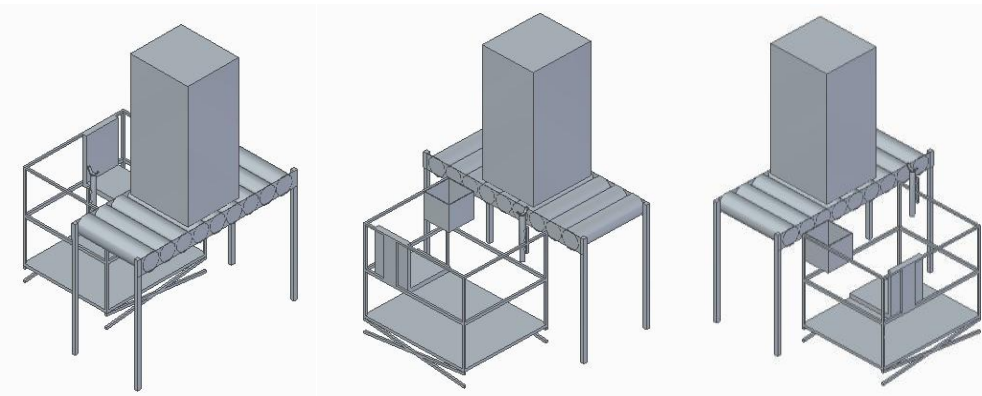

Figura 1. Vistas del rediseño puesto de trabajo. Fuente: propia

El costo total estimado del rediseño del puesto de trabajo es de 5.340.000 COP (cinco millones trescientos cuarenta mil pesos colombianos).

\section{Conclusiones}

$\mathrm{Al}$ evaluar el puesto de trabajo actual, se encontraron problemas de diseño que afectaban la salud de la mayoría de los soldadores, algunas de estas dolencias están ubicadas en la columna, mango rotador y túnel carpiano. Con el rediseño propuesto se eliminan afectaciones físicas y motrices, teniendo en cuenta los principios antropométricos y biomecánicos, pero aun así deben vigilarse los problemas que pueden generarse por las posturas de pie.

\section{Referencias Bibliográficas}

[1] J. Dul and B. Weerdmeester, Ergonomics for beginners: A quick reference guide Third Edition. London: Taylor \& Francis, 2008.

[2] A. Freivalds and B. W. Niebel, "Lugar de trabajo, equipo y diseño de herramientas," in Ingeniería Industrial de Niebel. Métodos, estándares y diseño del trabajo, 13th ed., McGraw-Hill, 2014, pp. 133-170.

[3] ISO 14738, "ISO 14738:2002 Safety of machinery - Anthropometric requirements for the design of workstations at machinery." ISO/TC 159/SC 3 Anthropometry and biomechanics, 2002.

[4] J. Estrada, J. Camacho, M. Restrepo, and C. Parra, "Parámetros antropométricos de la población laboral colombiana-Acopla-95.” Universidad de Antioquia. Instituto de Seguros Sociales, 1995.

III Encuentro Nacional de Semilleros de Investigación de Ingeniería Industrial

Universidad Santo Tomás. Facultad de Ingeniería Industrial. 1 de noviembre de 2019 


\section{Conclusiones}

La principal tendencia en las contribuciones de los estudiantes de todo el país fue este año hacia problemáticas ambientales de diversos aspectos; residuos, contaminación, emisiones, transporte, impacto ambiental y recuperación. Por otro lado, fue destacable a participación hacia el diseño de procesos productivos en especial los relacionados con transformación e industria química, alimenticia y de materiales. En tercer lugar, hubo una importante prevalencia hacia la salud y la seguridad en el trabajo principalmente desde la ergonomía. La figura 1 muestra una analítica de las principales palabras de los títulos de las propuestas.

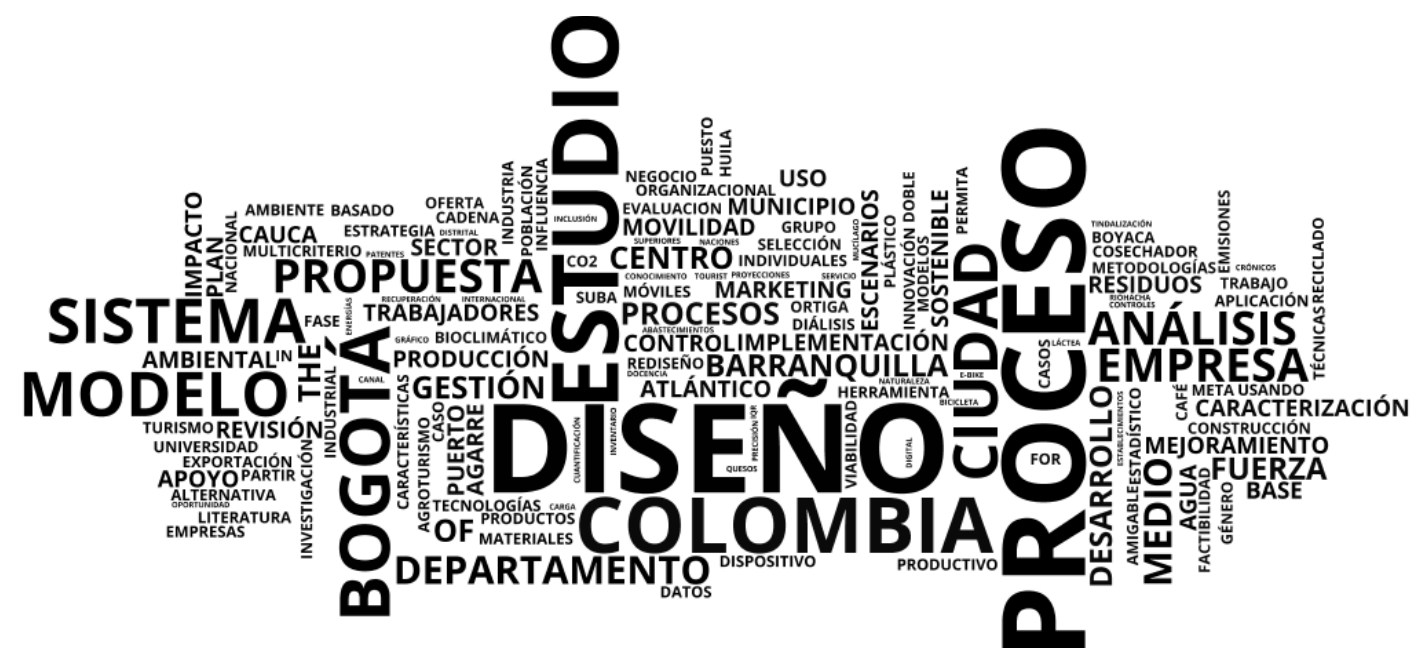

Figura 1. Analítica de los títulos de las contribuciones. Fuente: Compiladores con Wordle ${ }^{\circledR}$

Las contribuciones presentan en su mayoría resultados de investigaciones sobre tecnologías de materiales y procesos, así como buenas prácticas aplicables en diversos sectores. Es de señalar la prevalencia de resultados experimentales y prototipos lo que da solidez a las investigaciones y evidencia la fortaleza en ciencias básicas de la Ingeniería Industrial y su papel diferenciado de las ciencias administrativas y de gestión. Puede resumirse que el III ENSIII 2019 se concentró en la tecnología de los procesos y materiales con una visión sostenible y social basado en el control de emisiones e impactos ambientales y el estudio del ser humano como sujeto de la producción y su impacto en la salud.

III Encuentro Nacional de Semilleros de Investigación de Ingeniería Industrial

Universidad Santo Tomás. Facultad de Ingeniería Industrial. 1 de noviembre de 2019 